\title{
ENDOW: Efficient development of offshore windfarms
}

Barthelmie, R.J.; Larsen, Gunner Chr.; Bergström, H.; Magnusson, M.; Schlez, W.; Rados, K.; Lange, B.; Vølund, P.; Neckelmann, S.; Christensen, L.

Total number of authors:

13

Published in:

Proceedings of the ENDOW Workshop Offshore Wakes: measurements and Modelling

Publication date:

2002

Document Version

Publisher's PDF, also known as Version of record

Link back to DTU Orbit

Citation $(A P A)$ :

Barthelmie, R. J., Larsen, G. C., Bergström, H., Magnusson, M., Schlez, W., Rados, K., Lange, B., Vølund, P., Neckelmann, S., Christensen, L., Schepers, G., Hegberg, T., \& Folkerts, L. (2002). ENDOW: Efficient development of offshore windfarms. In R. J. Barthelmie (Ed.), Proceedings of the ENDOW Workshop Offshore Wakes: measurements and Modelling (pp. 4-8). Denmark. Forskningscenter Risoe. Risoe-R No. 1326(EN)

\section{General rights}

Copyright and moral rights for the publications made accessible in the public portal are retained by the authors and/or other copyright owners and it is a condition of accessing publications that users recognise and abide by the legal requirements associated with these rights.

- Users may download and print one copy of any publication from the public portal for the purpose of private study or research.

- You may not further distribute the material or use it for any profit-making activity or commercial gain

- You may freely distribute the URL identifying the publication in the public portal 


\title{
Proceedings of the ENDOW Workshop 'Offshore Wakes: measurements and Modelling'
}

\author{
R.J. Barthelmie (editor)
}
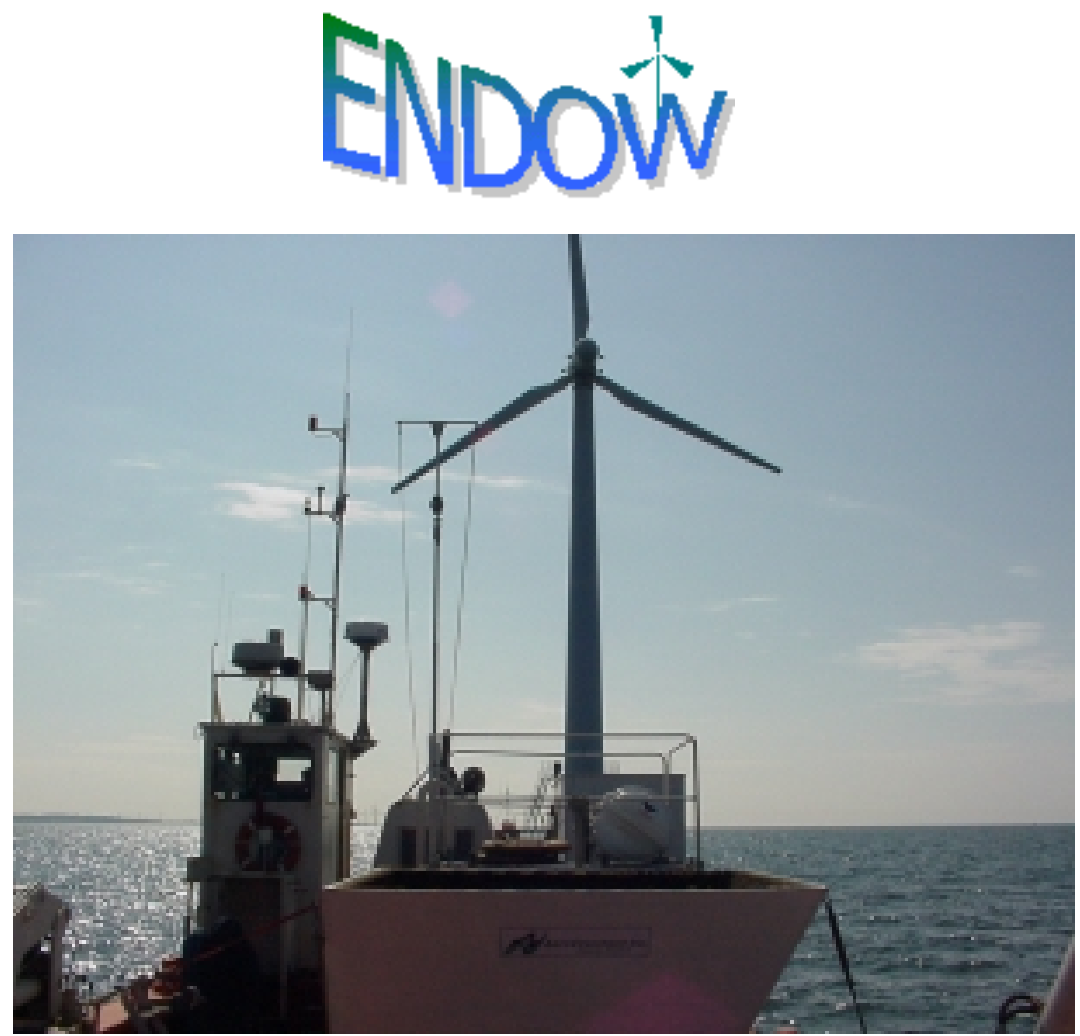

Risø National Laboratory, Roskilde

March 2002 


\begin{abstract}
The papers presented in these Proceedings are the result of a workshop held at Risø National Laboratory on March 7 and 82002 entitled 'Offshore Wakes: Measurements and Modelling'. The Workshop was arranged to showcase results of the European Community supported project 'Efficient Development of Offshore Windfarms (ENDOW)' and featured a series of eight presentations discussing modelling of wakes and boundary layers, existing and new measurements from offshore wind farms and how these will be linked in a new design tool and applied at planned offshore wind farms.

In addition seven invited presentations covered a range of relevant topics from analytical approaches to fatigue and extreme loads in wind turbine clusters, current wake modelling in WAsP, optimising power production at Arklow Bank, Particle Image Velocimetry study of a wind turbine wake in a yaw, offshore wind measurements in Massachusetts, accuracy of SODAR measurements for wind energy and tidal influence of offshore wind speeds and turbulence.
\end{abstract}

ISBN 87-550-3018-1(Internet)

ISSN 0106-2840

Information Service Department, Risø, 2002 


\section{Contents}

ENDOW: EFFICIENT DEVELOPMENT OF OFFSHORE WINDFARMS

Barthelmie et al.

COMPARISON OF WAKE MODELS WITH DATA

Rados et al.

IMPROVEMENT OF THE WIND FARM MODEL FLAP FOR OFFSHORE APPLICATIONS

Lange et al.

ENDOW: IMPROVEMENT OF WAKE MODELS

Schlez et al.

BOUNDARY-LAYER MODELLING FOR WIND CLIMATE ESTIMATES

Bergström

SODAR MEASUREMENTS OF OFFSHORE WAKES

Folkerts

LARGE OFF-SHORE WINDFARMS: LINKING WAKE MODELS WITH ATMOSPHERIC BOUNDARY LAYER MODELS

Schepers et al.

STATUS OF THE HORNS REV OFFSHORE PROJECT

Bonefeld and Neckelmann

TIDAL INFLUENCE ON OFFSHORE WIND FIELDS AND RESOURCE PREDICTIONS

Khan and Infield 


\title{
ENDOW: EFFICIENT DEVELOPMENT OF OFFSHORE WINDFARMS
}

\author{
Rebecca Barthelmie and Gunner Larsen, *Wind Energy Department, Risø National Laboratory, 4000 \\ Roskilde, DENMARK, R.Barthelmie@risoe.dk \\ Hans Bergström and Mikael Magnusson, Dept. of Earth Sciences, Meteorology, Uppsala University, \\ 75236 Uppsala, SWEDEN \\ Wolfgang Schlez, Garrad Hassan and Partners Ltd, Bristol BS2 0QD, UK \\ Kostas Rados, The Robert Gordon University, School of Mechanical and Offshore Engineering, \\ Aberdeen AB10 1FR, SCOTLAND \\ Bernhard Lange, Dept. of Energy and Semiconductor Research EHF, University of Oldenburg, \\ D-26111 Oldenburg, GERMANY \\ Per Vølund, SEAS Distribution Amba, 4690 Haslev, DENMARK \\ Søren Neckelmann, Techwise A/S, 7000 Fredericia, DENMARK \\ Lars Christensen, NEG MICON Project Development A/S, \\ 8900 Randers, DENMARK \\ Gerard Schepers and Terry Hegberg, Energy Research Centre of the Netherlands, Wind Energy, \\ 1755 ZG Petten, THE NETHERLANDS \\ Luuk Folkerts, Ecofys, NL-3503 RK Utrecht, THE NETHERLANDS
}

\begin{abstract}
The objective of the ENDOW project is to evaluate, enhance and interface wake and boundary-layer models for utilisation offshore. The model hierarchy will form the basis of design tools for use by wind energy developers and turbine manufacturers to optimise power output from offshore wind farms through minimised wake effects and optimal grid connections. The initial focus of the project is to use databases from existing offshore wind farms (Vindeby and Bockstigen) to undertake the first comprehensive evaluation of offshore wake model performances. The six wake models vary in complexity from empirical solutions to the most advanced models based on solutions of the Navier-Stokes equations using eddy viscosity or kepsilon turbulence closure. One of the wake models is also being coupled with a full aeroelastic model for the calculation of loads. Parallel research includes comparison of a local-scale stability/roughness model with a mesoscale model focusing on boundary-layer development within and over a large offshore wind farm, and particularly the influence of large scale thermal flows. A new experiment was conducted using SODAR offshore to examine vertical wind speed profiles to hub-height and beyond in near-wake conditions and wake dispersion to assist in model development and evaluation.
\end{abstract}

Keywords: Off-Shore, Wakes, Meteorology

\section{$1 \quad$ Project Objectives}

Europe has large offshore wind energy potential that is poised for exploitation to make a significant contribution to the objective of providing a clean, renewable and secure energy supply. While experience gained through the offshore wind farms currently operating is valuable, a major uncertainty in estimating power production lies in the prediction of the dynamic links between the atmosphere and wind turbines. Due to lower turbulence offshore, wake effects (velocity decrease, turbulence increase downstream of a wind turbine rotor) may be propagated over larger distances downstream than is the case over land. The potential result that in order to optimise power output offshore wind farms will require larger distances between rows than is common in design of onshore wind farms. This has a major economic disadvantage because undersea grid connections and connections between turbines are proportionally more expensive than their cost and installation at land sites. An additional uncertainty is introduced because coastal boundary-layers are not well characterised by current atmospheric models. Since most offshore areas are not routinely monitored, boundary-layer models are used to predict wind and turbulence regimes for prospective offshore wind farm sites. Large wind farms will cover distances of several to 
tens of kilometres over which changes in boundary-layer growth and feed-backs to/from the sea surface and to/from flow around and through individual turbines in the array are significant. Configuring offshore wind farms for optimal power output and minimum cabling costs is a large and complex operation. This project aims to reduce uncertainties in estimating power production introduced due to wake effects in large offshore wind farms particularly those operating in areas affected by the coastal discontinuity where the atmosphere is not at equilibrium with the surface. The major objectives are to evaluate wake models in offshore environments and to develop and enhance existing wake and boundary-layer models accounting for complex stability variations to produce a design tool to assist planners and developers in optimising offshore wind farms.

\section{$2 \quad$ Existing offshore wake databases}

Databases have been compiled comprising meteorological and turbine measurements from two offshore wind farms - Vindeby in Denmark and Bockstigen in Sweden (Figure 1). Data from Horns Rev in Denmark will be used in the evaluation stage of the project. These data are described in more detail in Neckelmann et al. (these proceedings).

Both wind farms are located close to the coast but Vindeby is a relatively sheltered location in shallow water $(2-5 \mathrm{~m})$ while Bockstigen is in deeper water. The monitoring systems are also very different. Vindeby has three masts one on the coast and two offshore providing a free stream wind speed for all wind directions (Figure 2) (Barthelmie et al., 1996) whereas the offshore mast at Bockstigen is in the centre of the wind farm. In addition to providing case studies for the offshore wake modelling, a new database of one-minute data has been provided for Vindeby (data from 1994-95). More than 400,000 simultaneous observations from the three masts have been analysed to examine wind and turbulence characteristics in different wake and meteorological conditions.

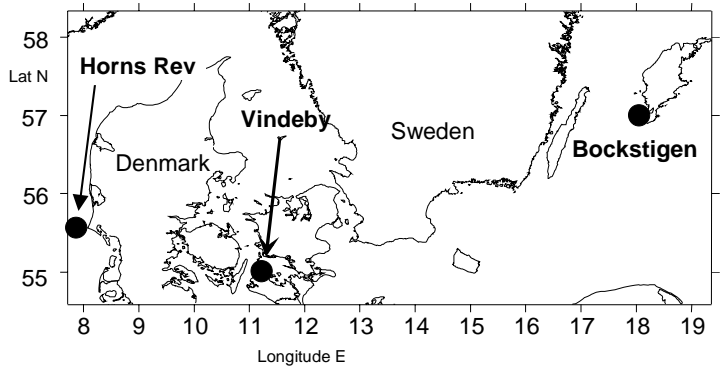

Figure 1. Locations of the offshore wind farms at Vindeby and Bockstigen and the planned wind farm at Horns Rev.

Using all available observations the average velocity deficit at hub-height $(38 \mathrm{~m})$ has been calculated for one, two and five wakes at Vindeby. The results shown in Figure 3 illustrate the relationship between the average velocity deficit and the number of wakes at a distance of 8.6/9.6 rotor diameters. Note that this relationship also depends on the wind turbine and the average meteorological conditions at each site.



Figure 2. Layout of the wind farm at Vindeby ( $\bullet$ shows each wind turbine and $\boldsymbol{\Delta}$ the two sea masts). The land mast is $1.4 \mathrm{~km}$ south.



Figure 3. Relationship between velocity deficit, wind speed and the number of wakes at Vindeby. 


\section{Comparison of wake models}

The partners performing wake modelling within the project and a brief description of the models are given in Table 1 . To evaluate wake model performances, the first approach used was to identify case studies at both sites but this was not sufficiently comprehensive.

Table 1. Description of the wake models being used for the offshore evaluation

\begin{tabular}{|c|c|}
\hline Partner & $\begin{array}{l}\text { Brief description of wake } \\
\text { model }\end{array}$ \\
\hline \multirow[t]{2}{*}{$\begin{array}{l}\text { Risoe National } \\
\text { Laboratory }\end{array}$} & $\begin{array}{l}\text { 1) Axisymmetric engineering } \\
\text { model }\end{array}$ \\
\hline & $\begin{array}{l}\text { 2) CFD using k- } \varepsilon \text { turbulence } \\
\text { closure coupled to an } \\
\text { aeroelastic model }\end{array}$ \\
\hline Uppsala University & $\begin{array}{l}\text { Velocity deficit model using } \\
\text { the transport time for the wake } \\
\text { development }\end{array}$ \\
\hline Garrad Hassan & $\begin{array}{l}\text { Axisymmetric numeric Navier } \\
\text { Stokes, eddy-viscosity closure } \\
\text { (Windfarmer) }\end{array}$ \\
\hline Robert Gordon & Fully elliptic 3D turbulent \\
\hline University & $\begin{array}{l}\text { Navier Stokes with k- } \begin{array}{l}\text { S } \\
\text { turbulence model }\end{array}\end{array}$ \\
\hline Oldenburg & Axisymmetric numeric Navier \\
\hline University & Stokes, eddy-viscosity closure \\
\hline Netherlands & Parabolized 3D Navier Stokes, \\
\hline Energy Research & $\mathrm{k}-\varepsilon$ turbulence model \\
\hline Foundation & \\
\hline
\end{tabular}

Hence a systematic range of 48 scenarios was identified to cover the expected range of conditions at Vindeby (Table 2). The simulations were conducted for 1,2 and 5 wakes at Vindeby (turbine rotor diameter 35 $\mathrm{m}$, hub height 38 ) and single wake case studies at Bockstigen. Considerable variability in the predictions of the various models is found. The largest discrepancy is in the near wake region ( 3 and 5 rotor diameters). Compared to the Vindeby experimental results, almost all models overestimate the wake effects at 8.6/9.6D in terms of the velocity deficit and the turbulence intensity levels. The wake model performance and comparison with data is given in (Rados et al., 2001) and Rados et al. and Schlez et al (these proceedings).

Following evaluation of the wake model performances, a number of modifications were made focusing on improved treatment of stability and turbulence particularly for the near-wake. Enhancements to the wake models undertaken as part of the ENDOW project is given by Schlez et al. and for the FlaP model by Lange et al. (these proceedings)
Table 2. Wake model scenarios (48 in total)

\begin{tabular}{lllcc}
\hline Parameter & \multicolumn{5}{c}{ Scenarios } \\
\hline $\begin{array}{l}\text { Wind speed } \\
(\mathrm{m} / \mathrm{s})\end{array}$ & 5 & 7.5 & 10 & 15 \\
$\begin{array}{l}\text { Turbulence } \\
\text { Intensity (\%) }\end{array}$ & 6 & 8 & 10 & 15 \\
$\begin{array}{l}\text { Monin- } \\
\begin{array}{l}\text { Obukhov } \\
\text { length }(\mathrm{m})\end{array}\end{array}$ & $\begin{array}{l}\text { Neutral } \\
\pm 1000 \mathrm{~m}\end{array}$ & $\begin{array}{l}\text { Stable } \\
>0,<200\end{array}$ & $\begin{array}{l}\text { Unstable } \\
<0,>-200\end{array}$ \\
\hline
\end{tabular}

\section{$4 \quad$ Boundary-layer modelling}

The objectives of the boundary-layer modelling are:

1) to model wake/boundary-layer interactions

2) to provide improved boundary-layer input to wake models which can account for the spatial variation of wind speed over large offshore wind farms and.

$3)$ to assess the impacts of large-scale thermally driven flows which cannot currently be incorporated into a design tool.

Further development and evaluation of a linearised model (the Coastal Discontinuity Model 2 - CDM2) is being undertaken to predict local scale flows based on either measured or modelled stability and roughness variations over the area of an offshore wind farm. It is being developed as an interface between either a time series of coastal measurements or output from a mesoscale model and the wake models. Since it cannot account for the effects of large-scale thermally drive flow such as sea breezes and low-level jets (which are often observed in the Baltic (Smedman et al., 1996)) a number of studies are being undertaken with the higher-order closure mesoscale MIUU-model to quantify the impact of these effects on wind energy resources. Wind speed profiles predicted by Risø's WAsP model are also being compared with those from the mesoscale model (Figure 4). This work is described in more detail in Bergström et al. (these proceedings). 


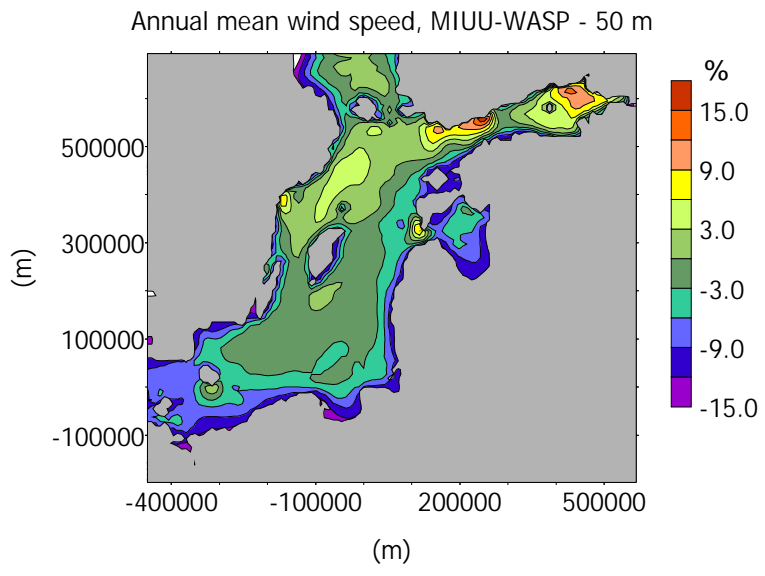

Figure 4. Difference in $50 \mathrm{~m}$ annual mean wind speed from MIUU and WAsP models.

\section{SODAR experiment}

In April 2001 an experiment was conducted at the Vindeby wind farm (Figures 1 and 2). The objectives of the experiment were to evaluate the performance of a SODAR operated from a ship, to ascertain whether SODAR could measure wind speed profiles in the wake of a wind turbine and to provide a wake decay constant for use offshore.

The SODAR was mounted on a stable ship used typically for diving. Once the ship was positioned at a given distance behind the wind turbine in the direct wake, wind speed profiles were measured for about 30 minutes. To provide a free-stream wind profile, the turbines were selectively turned off and the wind speed profiles measured again. Below 4 $\mathrm{m} / \mathrm{s}$ wind speed the turbines stopped generating. At other times the measurements were stopped by rain when the SODAR does not give reliable signals. Despite this, during one week of measurements, 36 wind speed profiles were measured during wake and nonwake conditions. Figure 5 shows one example of the relatively velocity deficit calculated using the calibrated SODAR data. More results are given in (Barthelmie et al., 2002) and Folkerts et al. (these proceedings).

\section{Design tool development}

The main focus of the project is to incorporate improvements in wake and boundary layer models within design tools for use in offshore environments. At this time three main components are envisaged:

1) Coupling between WAsP to provide a regional climatology and the CDM2 model with stability, wind-wave-roughness and internal boundary-layer sub modules.



Figure 5. SODAR measured offshore wind speed profiles (normalised with mast measured wind speed at $50 \mathrm{~m}$ ) and the relative velocity deficit for an experiment at 3.5D. Error bars shown are one standard deviation on each side of the mean.

2) Production of an enhanced wake model. This task is mainly directed towards selection of suitable codes according to performance, input requirements and computational feasibility.

3) Since grid connections are a major expenditure in offshore projects, minimisation of these costs will be a significant factor in the overall design optimisation of offshore wind farms.

Linking these components is a complex task which is described in more detail in Schepers et al. (these proceedings).

\section{Summary/Future Work}

The ENDOW project focuses on the evaluation and development of wake models for use in an offshore environment. Boundarylayer measurements from existing offshore wind farms are being used for the evaluation. Results from an experiment with a boat mounted SODAR are also providing nearwake wind speed profiles. Additionally boundary-layer models are being improved for use with wake models to improve prediction in 
the coastal zone and over the area of large offshore wind farms. The final product will be design tools developed for offshore wind farms. The utility and efficiency of the design tools will be evaluated at a number of planned offshore wind farms.

\section{ACKNOWLEDGEMENTS}

Financial support for this research was given in part by the European Commission's Fifth Framework Programme under the Energy, Environment and Sustainable Development Programme. Project Reference: ERK6-199900001 ENDOW (Efficient Development of Offshore Windfarms). Additional funding was supplied by NOVEM for Ecofys and ECN.

\section{References}

Barthelmie, R.J., Courtney, M.S., Højstrup, J. and Larsen, S.E., 1996: Meteorological aspects of offshore wind energy observations from the Vindeby wind farm. Journal of Wind Engineering and Industrial Aerodynamics, 62(2-3), 191211.

Barthelmie, R.J., Folkerts, L., Ormel, F., Sanderhoff, P., Eecen, P., Stobbe, O. and Nielsen, N.M., 2002: Offshore wind turbine wakes measured by SODAR. Journal of Atmospheric and Oceanic Technology, in review.

Rados, K., Larsen, G., Barthelmie, R., Schelz, W., Hassan, U., Lange, B., Waldl, H.P., Schepers, G., Hegberg, T. and Magnusson, M., 2001: A comparison of wake model performance in an offshore environment, European Wind Energy Conference and Exhibition, Copenhagen.

Smedman, A.S., Hogstrom, U. and Bergstrom, H., 1996: Low level jets - a decisive factor for off-shore wind energy siting in the Baltic Sea. Wind Engineering, 20(3), 137-147. 


\title{
COMPARISON OF WAKE MODELS WITH DATA
}

\author{
Konstantinos Rados, School of Engineering, Robert Gordon University, \\ Aberdeen AB10 1FR, SCOTLAND \\ Gunner Larsen and Rebecca Barthelmie, Wind Energy Department, Risø National Laboratory, \\ 4000 Roskilde, DENMARK \\ Wolfgang Schlez, Garrad Hassan and Partners Ltd, Bristol BS2 0QD, UK \\ Bernhard Lange, Dept. of Energy and Semiconductor Research EHF, University of Oldenburg, \\ D-26111 Oldenburg, GERMANY \\ Gerard Schepers and Terry Hegberg, Netherlands Energy Research Foundation ECN, Solar and \\ Wind Energy, \\ 1755 ZG Petten, THE NETHERLANDS \\ Mikael Magnusson, c/o Dept. of Earth Sciences, Meteorology, Uppsala University, 75236 Uppsala, \\ SWEDEN
}

\begin{abstract}
A major objective of the ENDOW project is to evaluate the performance of wake models in offshore environments in order to ascertain the improvements required to enhance the prediction of power output within large offshore wind farms [1]. The strategy for achieving this objective is to compare the performance of the models in a wide range of conditions which are expected to be encountered during turbine operation offshore. Six models of varying complexity have been evaluated initially against the Vindeby single wake data in [2] where it was found that almost all of them overestimate the wake effects and also significant inconsistencies between the model predictions appeared in the near wake and turbulence intensity results. Based on the conclusions of that study, the wake modelling groups have already implemented a number of modifications to their original models. In the present paper, new single wake results are presented against experimental data at Vindeby and Bockstigen wind farms. Clearly, some of the model discrepancies previously observed in Vindeby cases have been smoothed and overall the performance is improved.
\end{abstract}

\section{THE WAKE MODELS}

The present paper presents an evaluation of wake models in offshore environments against experimental data obtained from operating offshore wind farms. It is part of the work carried out for the WorkPackage 2 of the ENDOW project [2] with major objective to evaluate and improve existing wake models accounting for complex stability variations. The six modelling partners and their models are briefly presented in the sequel:

\footnotetext{
Partner 1: RISOE Risoe National Laboratory

Risø has developed two different wake models - an advanced model based on interfacing a CFD code to an aeroelastic code [3] and a semi-analytical engineering model [4]. The engineering model is based on an approximate solution of the boundary layer equations neglecting the pressure term, assuming a circular symmetric wake deficit and adopting a similarity assumption for the
}

shape of the wake deficit. The estimated wake deficit is thus subsequently superimposed on the undisturbed wind shear field to yield the resulting downstream mean wind profile. In the advanced model a CFD actuator disc model is interfaced to an aeroelastic code enabling a detailed modelling of turbine as well as flow field. The flow field emerging from the CFD calculation is used as input to the aeroelastic calculation, that is subsequently producing aerodynamic forces which are used to modify the CFD actuator disc model. The iteration is continued until equilibrium is achieved.

\section{Partner 2: MIUU Uppsala University}

MIUU has developed an analytical model based on the Taylor hypothesis using the transport time for the wake development [5].

Partner 3: GH Garrad Hassan

$\mathrm{GH}$ uses an axis-symmetric numeric Navier Stokes solver with eddy-viscosity closure (WindFarmer) [6]. The model is 
initiated at a distance of 2D behind the rotor with an empirical wake profile. The initial profile is of Gaussian shape and varies with thrust coefficient and ambient turbulence intensity. The eddy-viscosity is defined using the turbulence intensity in the wake [7].

Partner 4: $R G U$ Robert Gordon University

RGU has developed a fully elliptic turbulent 3D Navier-Stokes numerical solver (3D-NS) with k- $\varepsilon$ turbulence closure based on a previous axisymmetric model [5]. Initial data required to start the 3D-NS calculations are the velocity and turbulence intensity profiles in the atmospheric boundary layer upstream the rotor. The computational domain includes the rotor of the wind turbine(s), which is approximated by means of a semi-permeable disk to simulate the pressure drop across a real rotor disk (thrust).

\section{Partner 5: UO University of Oldenburg}

The wind farm model FLaP of UO uses an implementation of the wake model proposed by Ainslie, 1988 [6]. It is a two-dimensional (axis-symmetrical) model solving the momentum and continuity equations with an eddy-viscosity closure. The eddy-viscosity is modelled as a combination of contributions from the ambient turbulence of the free flow and the shear generated turbulence in the wake. The wake model starts at the end of the near wake with an empirical wake profile as boundary condition. The near wake length is calculated after Vermeulen (1980) [10] taking into account ambient, rotor generated and shear generated turbulence intensity. The mean turbulence intensity in the wake is calculated from modelled eddy-viscosity.

\section{Partner 6: ECN Netherlands Energy Research Foundation}

ECN uses the Wakefarm program [8]. This program is a slightly modified version of the UPMWAKE program, which has been developed by the Universidad Politecnica de Madrid. It is a parabolic method in which the turbulent processes in the far wake are modelled through a k- $\varepsilon$ model. The near wake is modelled with the standard momentum theory, to which empirical corrections are added.

\section{RESULTS - DISCUSSION}

\subsection{Vindeby Wind Farm}

The single wake case for the Vindeby wind turbine $6 \mathrm{E}$ (rotor diameter $35 \mathrm{~m}$, hub height 38) was investigated (Figure 1).

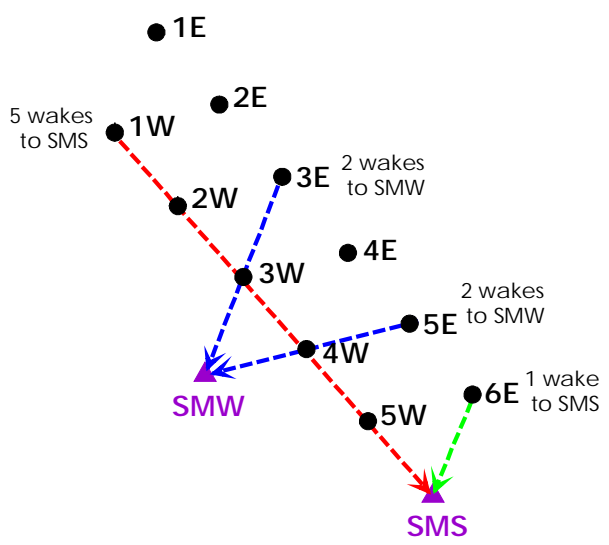

Figure 1. Layout of the wind farm at Vindeby ( $\bullet$ shows each wind turbine and $\boldsymbol{\Delta}$ the two sea masts).

The following parameters were considered to be the most important for the wake development:

- Free wind speed at hub height, Uo, which is related to the rotor thrust coefficient, $\mathrm{Ct}$

- Ambient Turbulence Intensity at the hub height, Io,

- Atmospheric stability (neutral, stable, unstable)

A systematic range of 48 case studies was identified to cover the expected range of conditions (Table I) at Vindeby.

Table I. Wake model scenaria (48 in total)

\begin{tabular}{lcccc}
\hline Parameter & \multicolumn{4}{c}{ Scenaria } \\
\hline Wind speed & 5 & 7.5 & 10 & 15 \\
{$[\mathrm{~m} / \mathrm{s}]$} & 0.92 & 0.76 & 0.58 & 0.35 \\
$\begin{array}{l}\text { Thrust } \\
\text { coefficient }\end{array}$ & & & & \\
\hline $\begin{array}{l}\text { Turbulence } \\
\text { Intensity [\%] }\end{array}$ & 6 & 8 & 10 & 15 \\
\hline $\begin{array}{l}\text { Atmospheric } \\
\text { stability }\end{array}$ & Neutral & Stable & Unstable \\
$\begin{array}{l}\text { Monin- } \\
\text { Obukhov [m] }\end{array}$ & \pm 10000 & 200 & -200 \\
\hline
\end{tabular}

Examples for some of the above scenaria for neutral atmospheric conditions are presented in Figures 2-4. Velocity profiles and turbulence intensity distributions are given on the vertical center plane and at six distances downstream the wind turbine rotor: $3,5,7$, 
9.6, 10 and 12 rotor diameters. The meteorological mast measuring the single wake of the turbine $6 \mathrm{E}$ for northerly winds $(23$ degrees) is located at $9.6 \mathrm{D}$ downstream of the $6 \mathrm{E}$. The experimental data corresponding to ambient conditions close to the modelling cases are presented with symbols. The dotted line represents the turbine hub height. The undisturbed free wind speed and turbulent intensity profiles shown in the figures (single solid line) were obtained by using MoninObukhov similarity theory applied to surface atmospheric boundary layer [9].

Considerable variability in the predictions of the various models is observed. The largest discrepancy appears in the near wake region (3 and 5 rotor diameters). These differences revealed the importance of the near wake parameterization for the overall wake model performance, a task currently in progress as part of WorkPackage 3 of the ENDOW project. ECN and UO have already made modifications in the near wake treatment. UO model has been improved drastically compared to previous results (see [2]). This is due to recent UO model extension, mainly taking into account the effect of turbulence and stability on the length of the near wake and an improvement of the eddy-viscosity model (presented by Lange, also in these proceedings).

Almost all models overestimate the wake effects at 9.6D in terms of the velocity deficit and the turbulence intensity levels (Figures 2 and 3). Large deviations appear in the low turbulence intensity case $(6 \%)$ where all models predict an expected slower wake recovery compared to the higher turbulence intensity $(8 \%)$ while the measurements show similar recovery rates (Figure 2). Further investigation of these cases is in progress using the whole range of 1 minute averaged measurements in Vindeby.

RISOE and MIUU velocity predictions are more sensitive to changes of the ambient turbulence intensity than the other models.

All models predict consistent turbulence intensity levels in the wake quite close to the observed values except MIUU which significantly overestimate the turbulence added by the rotor for wind speed $7.5 \mathrm{~m} / \mathrm{s}$ (Figure 3).

Some other general features:

- All models show higher rates of wake recovery as the ambient turbulence intensity increases (Figure 2) and thrust coefficient decreases (Figure 4). This behaviour is expected since higher levels of ambient turbulence result in higher rates of turbulent mixing in the wake whereas lower thrust coefficient values result in less velocity deficit and hence less mechanical generated turbulence (shear) added in the near wake.

- The 3 dimensional models (ECN and RGU) agree quite well in both the velocity and turbulence intensity profiles in the wake. The differences in the near wake (3 diameters) observed in [2] have been smoothed with recent improvements in the near wake modelling implemented by ECN. Also, there is clearly a better performance regarding turbulence predictions after the modifications introduced by ECN in the near wake region and by RGU in turbulence parameterization.

\subsection{Bockstigen Wind Farm}

The Bockstigen wind farm layout is presented in Figure 5. Two single wake scenaria were considered:

- Single wake of turbine 2 monitored by the meteorological mast at a downstream distance of 5.4D, for moderate wind speeds coming from the west (11 cases).

- Single wake of turbine three giving a wake flow on turbine four at a downstream distance of $10.3 \mathrm{D}$, for higher wind speeds coming from the south-west ( 8 cases).

Since there is only one meteorological mast in the wind farm, the undisturbed wind speed for the first scenario was estimated indirectly using a calculated power curve of turbine 2 . Also for the same case, an average value for the ambient turbulence intensity was used based on the mast experimental data of the second scenario.

Figures 6-8 display the results from the original wake models against measurements for all case studies simulated.

In general, the predictions are considered satisfactory especially for the power output (Figure 6) which is the kernel part for the ENDOW design tool development.

RISOE model significantly overestimates the wake effects in terms of velocity deficit (Figure 7a) but it predicts quite well the turbulence intensity levels (Figure 7b). Also, $\mathrm{GH}$ model predicts turbulence intensity levels very close to the observed values whereas ECN, RGU and UO overestimate them in 
almost all cases. This behavior has also been observed in the model comparisons with the Vindeby data [2] for ECN and RGU, and could be attributed to the expression used to translate the turbulent kinetic energy primarily predicted by ECN and RGU models into turbulence intensity. In both models, the above a posteriori calculation is based on the assumption that the anisotropy in the wake is the same as in the undisturbed wind field. The investigators are currently re-examining the above assumption for offshore conditions. In addition, the recent ECN improvements in the near wake modelling already provide reduced velocity gradients resuting in lower turbulence intensity levels in the wake.

MIUU model results compared with measurements are presented in Figure 8 where the normalized wake velocity deficit $(\Delta \mathrm{U} / \mathrm{U}-$ $\mathrm{Ct}$ ) is given as a function of the transport time, $\mathrm{t}$, which is the main parameter used in the MIUU model. The agreement between the measurements and the model results is rather good especially for the second scenario where the wind speed upstream as well as in the wake is taken from the turbine power curve (crosses). For the first scenario where the wake was measured by the mast, there is a systematic offset as the model overestimates the deficit. According to MIUU this is due to uncertainties in the calculated wind speed since the relation between the wind speed and the power production is based on an average value.

\section{FUTURE WORK}

The following steps are foreseen in the ENDOW project:

- Comparative investigation of the model performance against the double and multiple wake situations of the Vindeby experimental database (task is in progress). A first study is presented by Schlez et al. in these proceedings.

- Further improvements of the wake models for multiple wake situations.

- Comparison of wake model predictions against the SODAR measurements to evaluate the near wake parameterizations.

\section{ACKNOWLEDGEMENTS}

Financial support for this research was given in part by the European Commission's
Fifth Framework Programme under the Energy, Environment and Sustainable Development Programme. Project Reference: ERK6-1999-00001 ENDOW (Efficient Development of Offshore Windfarms).

\section{REFERENCES}

[1] Barthelmie, R.J., et al. (2001), "EfficieNt Development of Offshore Windfarms: a new project for investigating wake and boundary-layer interactions", EWEC 2001, Copenhagen

[2] K.G. Rados et al. (2001), “A comparison of wake model performances in an offshore environment", EWEC 2001, Copenhagen.

[3] Larsen G.C. (ed.), Carlén, I. and Schepers, G.J. European Wind Turbine Standards 2. Project results, Rep. ECNC-99-073 (1999).

[4] Madsen, H.AA., Proceedings of IEA Joint Action, Aerodynamics of Wind Turbines $13^{\text {th }}$ Symposium, Stokholm (1999).

[5] Magnusson, M., Rados, K.G., and Voutsinas, S.G., Wind Engineering 20 (1996) 389.

[6] Ainslie, J., J. Wind Eng. Ind. Aerod. 27 (1988) 213.

[7] Hassan, U., A wind tunnel investigation of the wake structure within small wind turbine farms, Rep. ETSU WN 5113, (1993).

[8] Schepers, J.G., Wakefarm, Nabij zog model en ongestoord windsnelheisveld (in Dutch), Rep. ECN-C--98-016 (1998).

[9] Stull, R., An Introduction to Boundary Layer Meteorology, Kluwer Academic Publishers (1999).

[10] Vermeulen, P. E. J., An experimental analysis of wind turbine wakes, Proc. International Symposium on Wind Energy Systems, Lyngby, Denmark, (1980). 


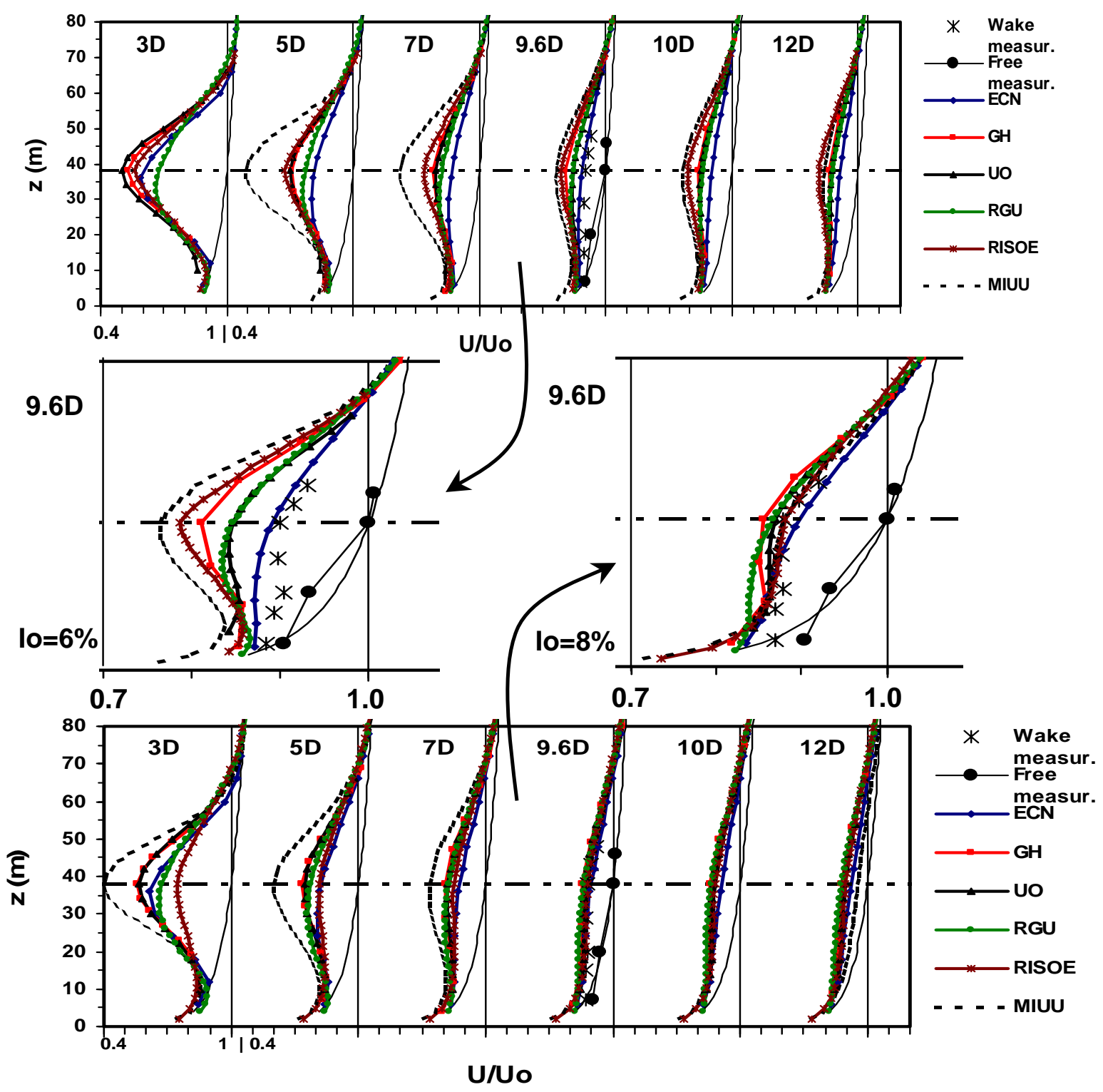

Figure 2.Velocity profiles normalized with the undisturbed wind speed at hub height on the vertical centre plane downstream of the $6 \mathrm{E}$ wind turbine for ambient turbulence intensities $6 \%$ and $8 \%$. Free wind speed at hub height, $\mathrm{Uo}_{0}=7.5 \mathrm{~m} / \mathrm{s}$, thrust coefficient, $\mathrm{Ct}=0.76$, Monin-Obukhov length, $\mathrm{L}=-10000 \mathrm{~m}$. 



Figure 3. Turbulence Intensity profiles on the vertical centre plane downstream of the $6 \mathrm{E}$ wind turbine for ambient turbulence intensity $6 \%$ and $8 \%$. Free wind speed at hub height, Uo=7.5 m/s, thrust coefficient, $\mathrm{Ct}=0.76$, Monin-Obukhov length, $\mathrm{L}=-10000 \mathrm{~m}$.

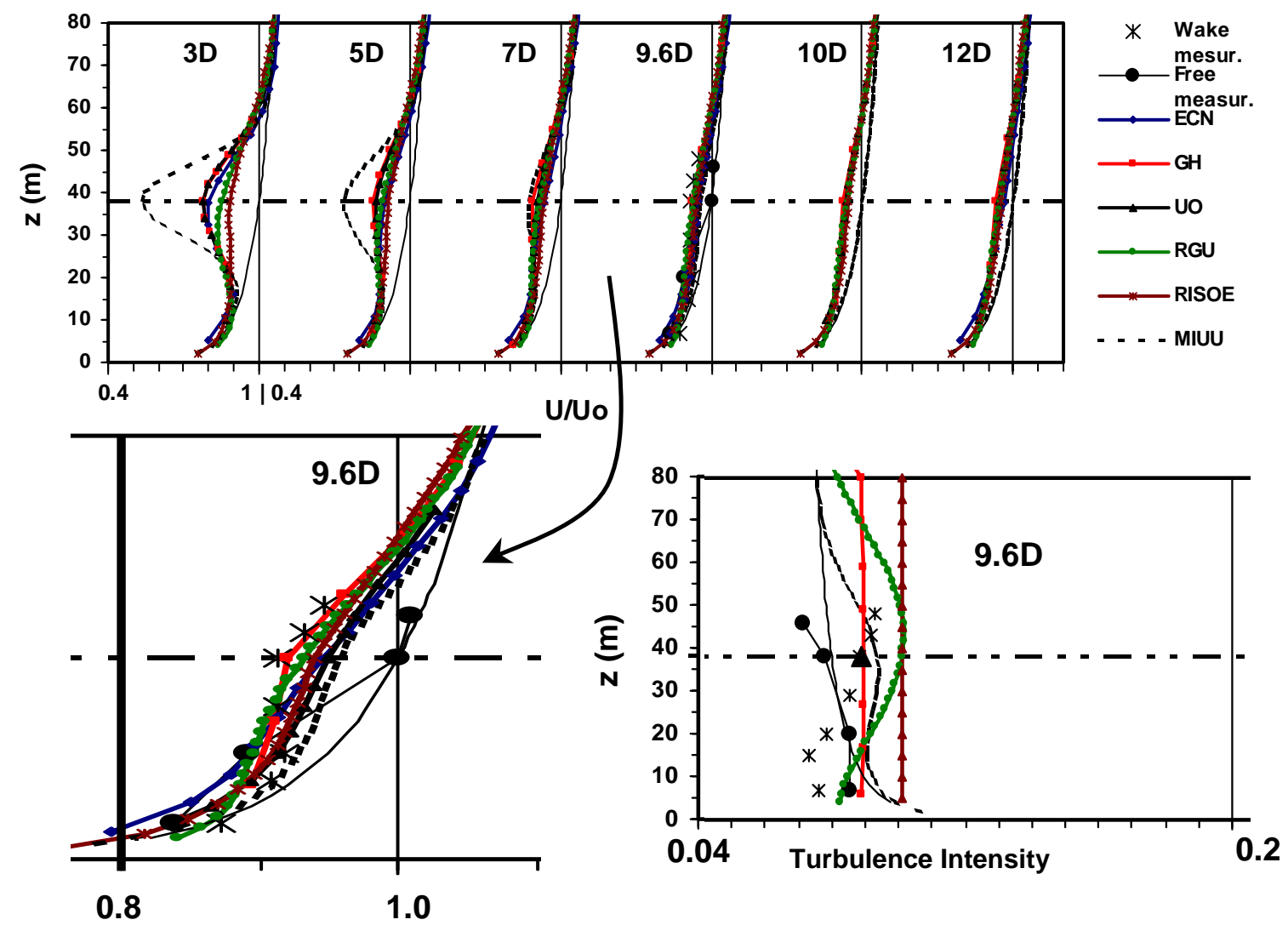

Figure 4.Velocity and turbulence intensity profiles on the vertical centre plane downstream of the $6 \mathrm{E}$ wind turbine. Ambient turbulence intensity $8 \%$, free wind speed at hub height, $U o=15 \mathrm{~m} / \mathrm{s}$, thrust coefficient, $\mathrm{Ct}=0.35$, Monin-Obukhov lenth, $\mathrm{L}=-10000 \mathrm{~m}$. 


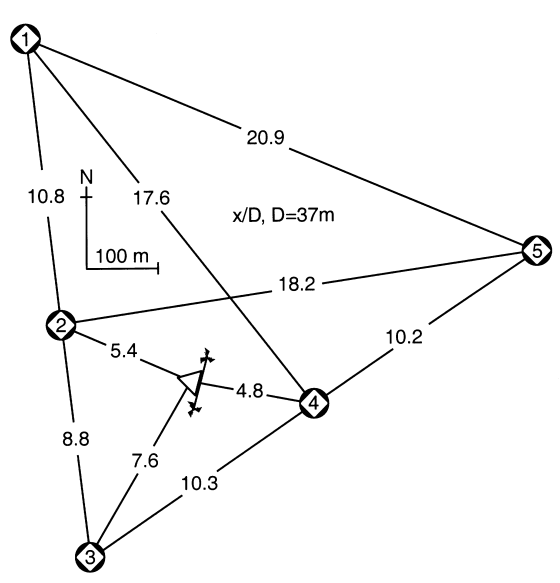

Figure 5. Layout of the Bockstigen wind farm

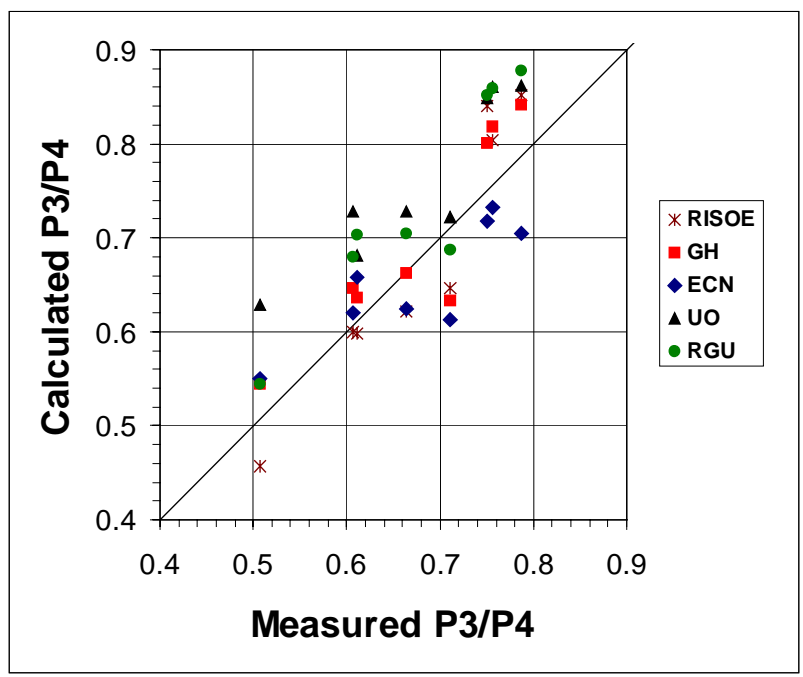

Figure 6.Calculated vs measured power ratio of Turbine 3 to Turbine 4 in Bockstigen cases

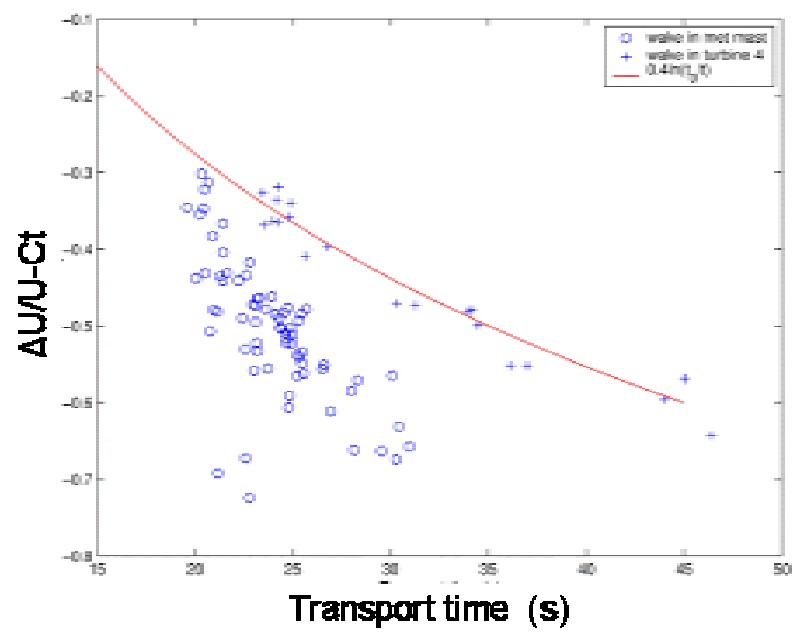

Figure 8.Comparisons of MIUU model wake velocity deficit against measurements for the Bockstigen cases
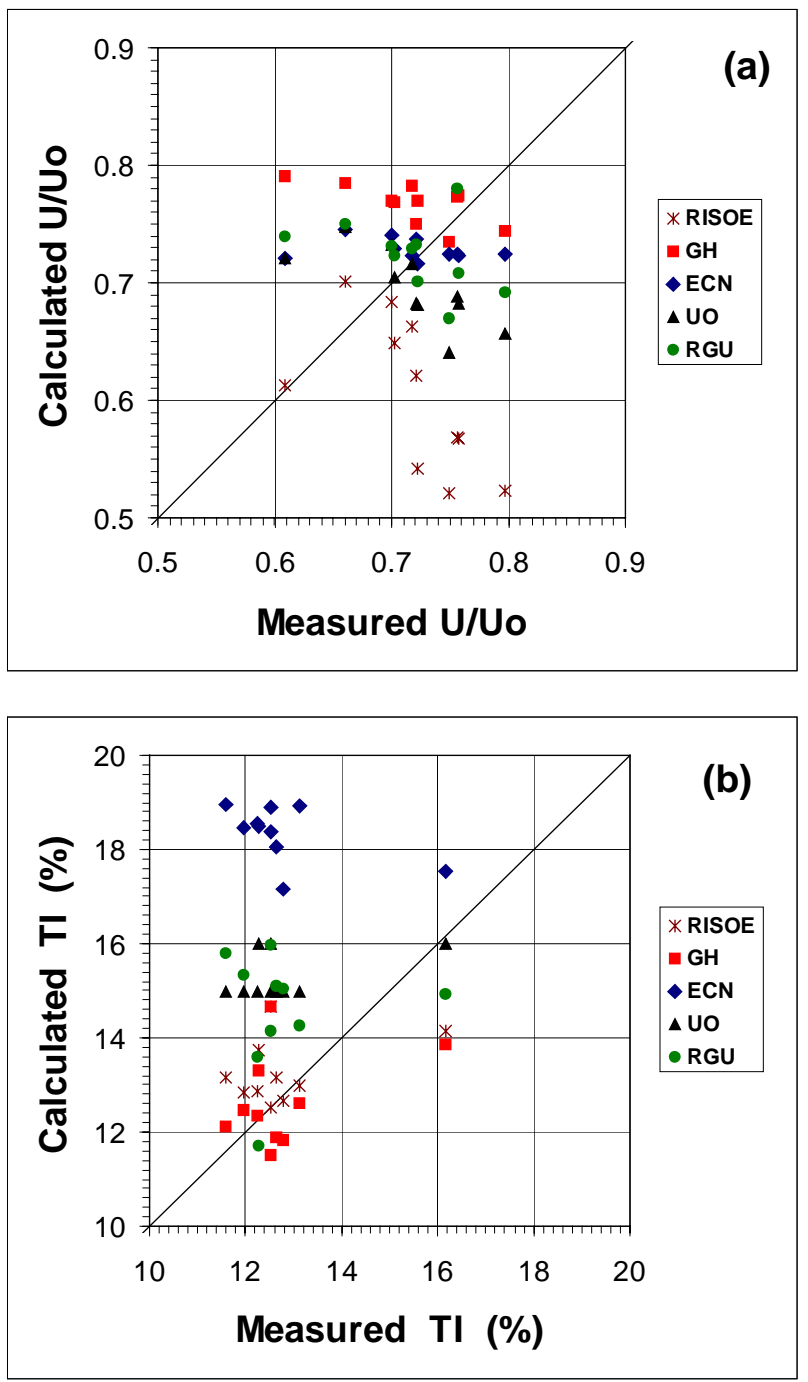

Figure 7.Calculated vs. measured wind speed ratio (a) and turbulence intensity (b) at the meteorological mast in Bockstigen wind farm 


\title{
IMPROVEMENT OF THE WIND FARM MODEL FLAP FOR OFFSHORE APPLICATIONS
}

\author{
Bernhard Lange(1), Hans-Peter Waldl(1)(2), Rebecca Barthelmie(3), Algert Gil Guerrero(1)(4), \\ Detlev Heinemann(1)
}

(1) Dept. of Energy and Semiconductor Research, Faculty of Physics, University of Oldenburg, D26111 Oldenburg, Germany, phone: +49-441-7983927, fax: +49-441-7983326, e-mail:

Bernhard.Lange@uni-oldenburg.de

(2) now at: Overspeed GmbH und Co KG, Oldenburg, Germany

(3) Wind Energy Department, Risø National Laboratory, P.O. Box 49, DK-4000 Roskilde, Denmark

(4) now at: : Lahmeyer International GmbH, Bad Vilbel, Germany

\begin{abstract}
The wind farm program FLaP (Farm Layout Program) has been developed at the University of Oldenburg since 1993. It combines an axis-symmetric wake model, describing the wake of one rotor, and a wind farm model, which takes care of the interaction of all wakes in a wind farm. Noise calculations and automatic layout optimisation are additional features. Different wake models are implemented. Here an approach based on (Ainslie, 1988) has been chosen, which solves the simplified Reynolds equation with an eddy-viscosity closure.

The wake model has been extended to improve the description of wake development in offshore conditions, especially the low ambient turbulence and the effect of atmospheric stability. Model results have been compared with measurements from the Danish offshore wind farm Vindeby. Vertical wake profiles and mean turbulence intensities in the wake were compared for 32 scenarios of single, double and quintuple wake cases with different mean wind speed, turbulence intensity and atmospheric stability.

It was found that within the measurement uncertainties the results of the wake model compares well with the measurements for the most important ambient conditions. The effect of the low turbulence intensity offshore on the wake development was modelled well. Deviations have been found when atmospheric stability deviates from near-neutral conditions. Especially for stable atmospheric conditions both the free vertical wind speed profile and the wake profile are not modelled satisfactorily.
\end{abstract}

\section{INTRODUCTION}

For the planning of large offshore wind farms, modelling of wake losses is an important part of the production estimation. Additionally, an estimation of turbulence intensity in the wind farm is essential for the load assumptions used in the design of the turbines. Some knowledge and considerable experience has been gained in the estimation of these wake effects from wind farms on land, which is available in wind farm models like PARK (Risø National Laboratory, Denmark), Windfarmer (Garrad, Hassan and Partners, United Kingdom) and FLaP (University of Oldenburg, Germany).

Some differences exist between the atmospheric flow on land and offshore and the models used for wake predictions on land might have to be extended for the use in offshore conditions. Two characteristics of the offshore conditions are of paramount importance for the wake development: Sea surface roughness and atmospheric stability. The roughness of water surfaces is different from land surfaces in that it is much smaller and dependent on the wave field, which in turn depends mainly on wind speed, but also on fetch, water depth, etc. (see e.g. Lange et al. (2001)). This needs to be taken into account in the description of the ambient vertical wind speed profile, but most importantly it leads to a low and wind speed dependent turbulence intensity. Since the wake development largely depends on the turbulence intensity of the surrounding flow, this has important consequences for the modelling of the wake. Atmospheric stability is important in offshore conditions, since atmospheric stratification departs from near neutral conditions also for higher wind speeds, which are important for 
wind power production, due to the land-sea temperature difference and the low roughness offshore. This has to be included in the modelling of the ambient flow, but also might have an influence on the wake development.

The wind farm modelling program FLaP has been extended with the aim to incorporate these effects in the wake modelling within the ENDOW project (Barthelmie et al., 2002). For the modelling of the ambient atmospheric flow standard Monin-Obukhov similarity theory (see e.g. Stull (1988)) has been used, employing the Charnock relation (Charnock, $1955)$ to estimate the sea surface roughness. A two-dimensional, axis-symmetric wake model with eddy-viscosity closure is used, based on the model described by Ainslie $(1985,1988)$. It has been extended to improve the modelling of the influence of turbulence intensity and atmospheric stability on the wake. Comparisons of model results with results of several other wake models and comparisons of results before and after the improvements are given in Rados et al. (2002) and Schlez et al. (2002).

Model results have been compared with measurements of the offshore wind farm Vindeby for a wide range of ambient conditions. Measurements were available for single, double and quintuple wakes for different ambient wind speed, turbulence intensity and stability. Vertical wind speed profiles in the wake and mean turbulence intensities are compared. The different parts of the wake model, namely the free flow model, the single wake model, the multiple wake model and the turbulence intensity model, have been considered separately where possible.

The plan of the paper is as follows: In the next chapter the improved FLaP model is briefly described. Section 3 contains a brief description of the measurements of Vindeby wind farm used for comparisons with the wake model. The results of the comparison are summarised in section 4. Conclusions are drawn in the final chapter.

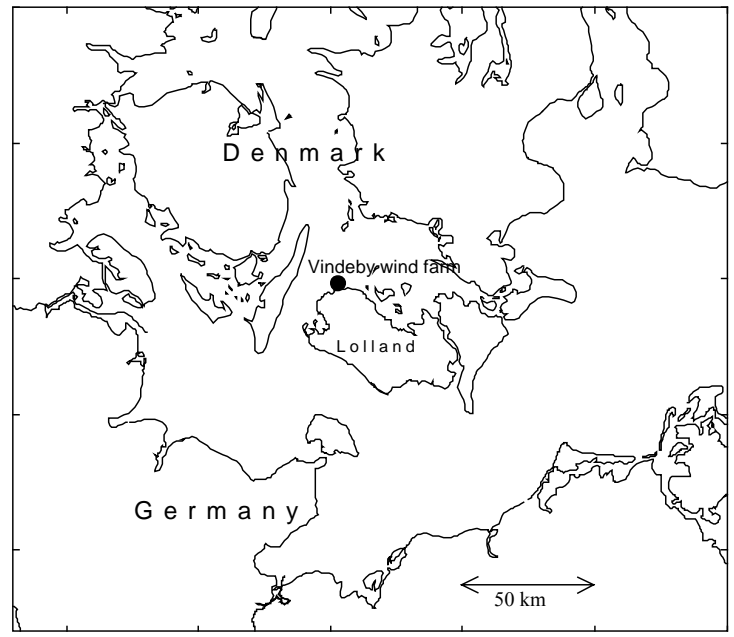

Figure 1: Locations of Vindeby wind farm in the Baltic Sea in the southern part of Denmark

\section{THE FLAP WIND FARM MODEL}

The wind farm program FLaP (Farm Layout Program) has been developed at the University of Oldenburg since 1993. It combines an axissymmetric wake model, describing the wake of one rotor, a free flow model for the undisturbed vertical wind speed profile and a wind farm model, which takes care of the interaction of all wakes in a wind farm. The program estimates wind speeds and turbulence intensities in wakes and their effect on the power output of the turbines in a wind farm. Noise calculations and automatic layout optimisation are additional features.

Different wake models are implemented. Here an approach based on (Ainslie, 1988) has been chosen. It is a two-dimensional (axissymmetrical) model solving the simplified momentum and continuity equations with an eddy-viscosity closure. The eddy-viscosity is modelled as a combination of contributions from the ambient turbulence of the free flow and the shear generated turbulence in the wake. The model does not include the near wake directly behind the rotor. Instead, it first starts at the end of the near wake with an empirical wake profile as boundary condition. The Ainslie wake model has been extended for the use in offshore conditions in three ways:

- Ainslie (1988) proposed a fixed near wake length of 2 rotor diameters (D). For offshore conditions the ambient turbulence intensity can be much lower than on land. This leads to a slower wake recovery and therefore to a longer near wake length. 
The model has therefore been extended by an estimation of the near wake length using a model by Vermeulen (1980).

- Because of the lower ambient turbulence, the modelling of the turbulence in the wake becomes more important. The Ainslie model has been extended to estimate the wake turbulence intensity, calculated directly from the eddy-viscosity of the Ainslie model.

- For offshore conditions, atmospheric stability plays a more important role than on land, since non-neutral stratification occurs more frequently at higher wind speeds, which are important for wind energy utilisation. The influence of atmospheric stability on wake development has therefore been included in the model by assuming that ambient and wake generated eddy-viscosity are affected by atmospheric stability in the same way.

Three sub-models are used to model the wind speed at any point in the farm or the power output of a turbine.

- The single wake model is used to calculate an axis-symmetric wake profile for any distance behind the rotor.

- Multiple wake model: For multiple wakes the wind speed incident on a rotor, which is influenced by wakes of upwind turbines, is calculated from the modelled wake deficits of the incident wakes. This wind speed is than taken as the new 'ambient' wind speed for this rotor, which is also used to calculate the power output of the turbine.

- Free flow model: For wind speeds at height different from the hub height the

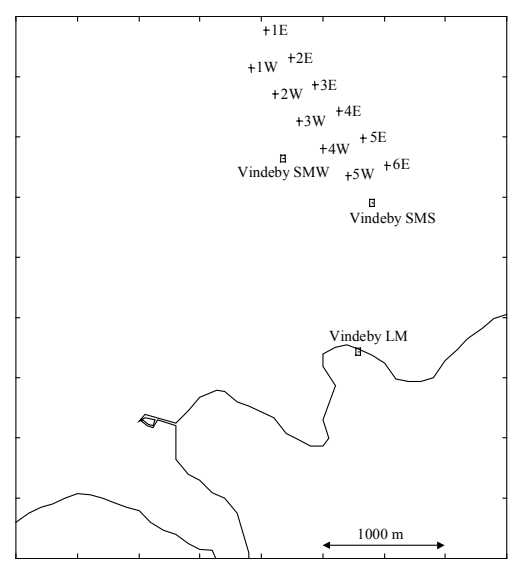

Figure 2: Layout of the Vindeby wind farm and the measurement masts Vindeby SMW, SMS and $L M$. vertical wind speed profile of the free flow is taken into account by convoluting the calculated wind speed in the wake with the incident ambient wind speed profile.

For a detailed description of the program and validation see Lange et al. (2002) and Waldl (1998).

\section{THE VINDEBY MEASUREMENTS}

\subsection{Vindeby wind farm}

Vindeby wind farm was built in 1991 in the Baltic Sea off the coast of Denmark, about 2 $\mathrm{km}$ off the north-west coast of the island of Lolland (see Figure 1). The distance of the turbines to the land is between $1.5 \mathrm{~km}$ and 2.7 $\mathrm{km}$.

The water depth is between 2.1 and $5.1 \mathrm{~m}$. The wind farm consists of 11 Bonus $450 \mathrm{~kW}$ wind turbines, arranged in two rows oriented along an axis of $325-145^{\circ}$ (see Figure 2). The distance of the turbines within the row as well as the distance between the rows is $300 \mathrm{~m}(8.6$ D). Since the turbine locations are shifted in the two rows with respect to each other, the minimum distance between turbines of two rows is $335 \mathrm{~m}(9.6 \mathrm{D})$.

The turbines are stall regulated Bonus $450 \mathrm{~kW}$ turbines with hub height $38 \mathrm{~m}$ and rotor diameter $35 \mathrm{~m}$. Their thrust coefficient and power output curves are shown in Figure 3. The thrust coefficient curve was provided by Bonus. The power curve stems from measurements at Vindeby. For a detailed description of the wind farm and measurements see (Barthelmie et al., 1994) and (Frandsen et al., 1996).

\subsection{Measurements and instrumentation}

Three meteorological masts have been erected close to the wind farm, one on land and two offshore. The land mast is located nearly $2 \mathrm{~km}$ south of the most southerly turbine in the array. The two offshore masts are placed at distances equal to the row and turbine spacing (335 and $300 \mathrm{~m}$ ), one to the west and one to the south of the first row. The locations of the masts with respect to the wind turbines are shown in Figure 2. The minimum distances from land to sea mast south (SMS) and sea mast west (SMW) are approximately $1.3 \mathrm{~km}$ and $1.6 \mathrm{~km}$, respectively. 
Wind speed measurements with cup anemometers are performed at 46, 38, 20 and $7 \mathrm{~m}$ height at the land mast (LM) and at 48, 43, 38, 29, 20, 15 and $7 \mathrm{~m}$ height at SMS and SMW. Cup anemometers of the type Risø P2546a have been used. Wind vanes of the type Risø Aa 3590 have been used for wind direction measurements at the two heights. The absolute accuracy of the wind direction is estimated to be $+/-2.5^{\circ}$.

The atmospheric stability is characterised by the Monin-Obukhov length $\mathrm{L}$, which is derived from temperature and wind speed difference measurements at the three masts.
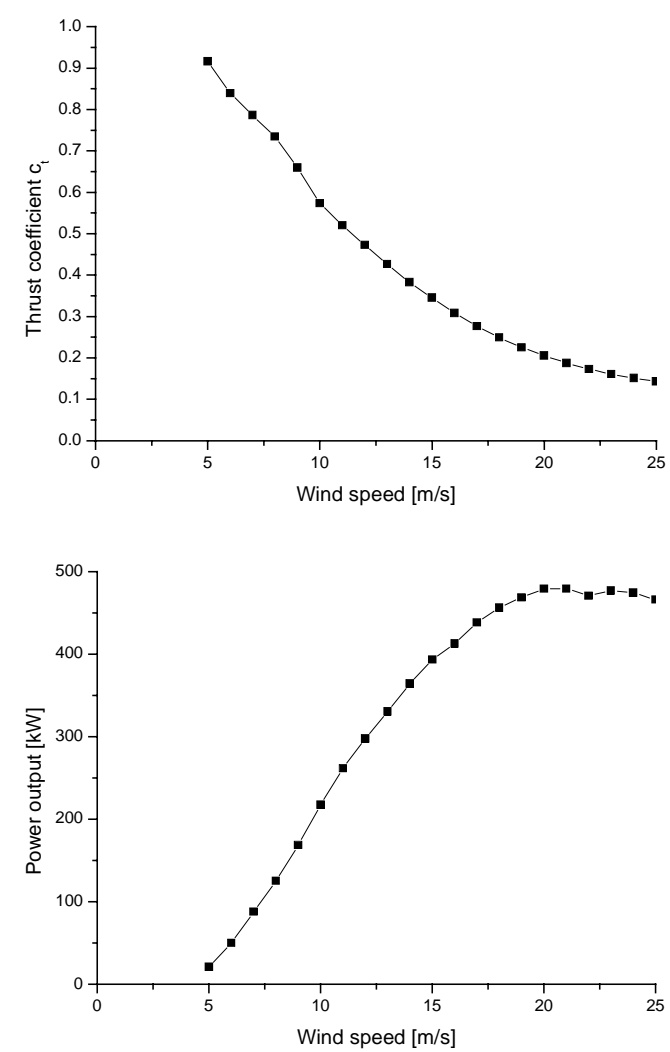

Figure 3: Thrust coefficient curve (upper) and power output curve (lower) for the Bonus 450 $k W$ turbine

\subsection{Data compilation}

Measurements from Vindeby wind farm from the years 1994 and 1995 have been used. One minute averages have been calculated for all data, resulting in a data base of 466116 observations.
Table 1: Measured wake cases at Vindeby wind farm

\begin{tabular}{|l|l|l|l|l|}
\hline $\begin{array}{l}\text { wind } \\
\text { direction } \\
\text { sector }\end{array}$ & $\begin{array}{l}\text { measured } \\
\text { wake }\end{array}$ & $\begin{array}{l}\text { free } \\
\text { mast }\end{array}$ & $\begin{array}{l}\text { wake } \\
\text { mast }\end{array}$ & $\begin{array}{l}\text { stability } \\
\text { deter- } \\
\text { mined } \\
\text { from }\end{array}$ \\
\hline $18^{\circ}-28^{\circ}$ & single & LM & SMS & LM \\
\hline $18^{\circ}-28^{\circ}$ & double & LM & SMW & LM \\
\hline $70^{\circ}-78^{\circ}$ & double & SMS & SMW & SMS \\
\hline $\begin{array}{l}314^{\circ}- \\
323^{\circ}\end{array}$ & quintuple & SMW & SMS & LM \\
\hline
\end{tabular}

Four cases of direct wake interference were selected where measurements of the wind speed in the wake as well as measurements of the free wind speed are available (see Table 1). For the selection of the data the wind direction at the wake mast was used. For each of the cases data have been classified according to the three criteria wind speed, turbulence intensity and atmospheric stability at the free mast. Wind speed bins of 4-6ms ${ }^{-1}, 6-9 \mathrm{~ms}^{-1}, 9$ $11 \mathrm{~ms}^{-1}$ and above $11 \mathrm{~ms}^{-1}$, turbulence intensity bins of $5-7 \%, 7-9 \%, 9-11 \%$ and above $11 \%$ and atmospheric stability bins of $|\mathrm{L}|>1000$, $0<\mathrm{L}<1000,0>\mathrm{L}>-1000$ have been used. The stability was determined at the free mast (LM at $23^{\circ}$ and SMS at $77^{\circ}$ ), except for the $320^{\circ}$ case, where the stability of the LM is used. For each case and each bin the data were averaged and normalised with the corresponding free stream wind velocity at $38 \mathrm{~m}$ height (hub height).

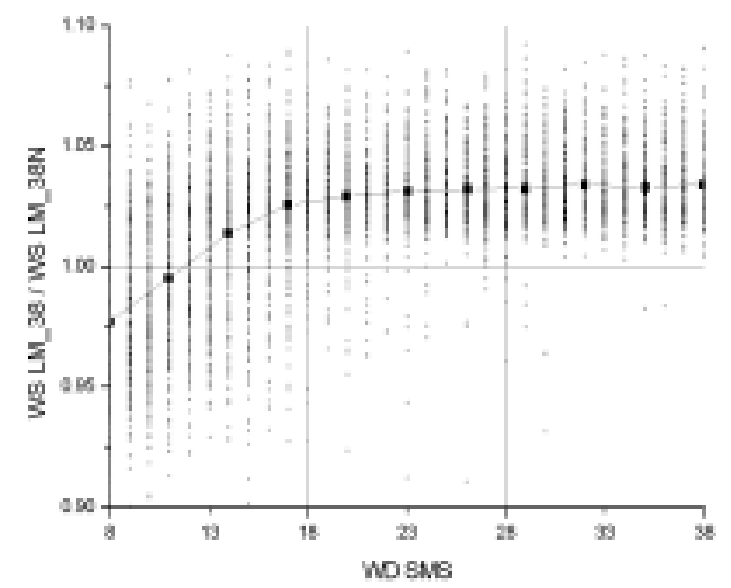

Figure 4: Ratio between the wind speeds measured by the north and south anemometer at $38 \mathrm{~m}$ height the LM versus wind direction measured at the SMS 


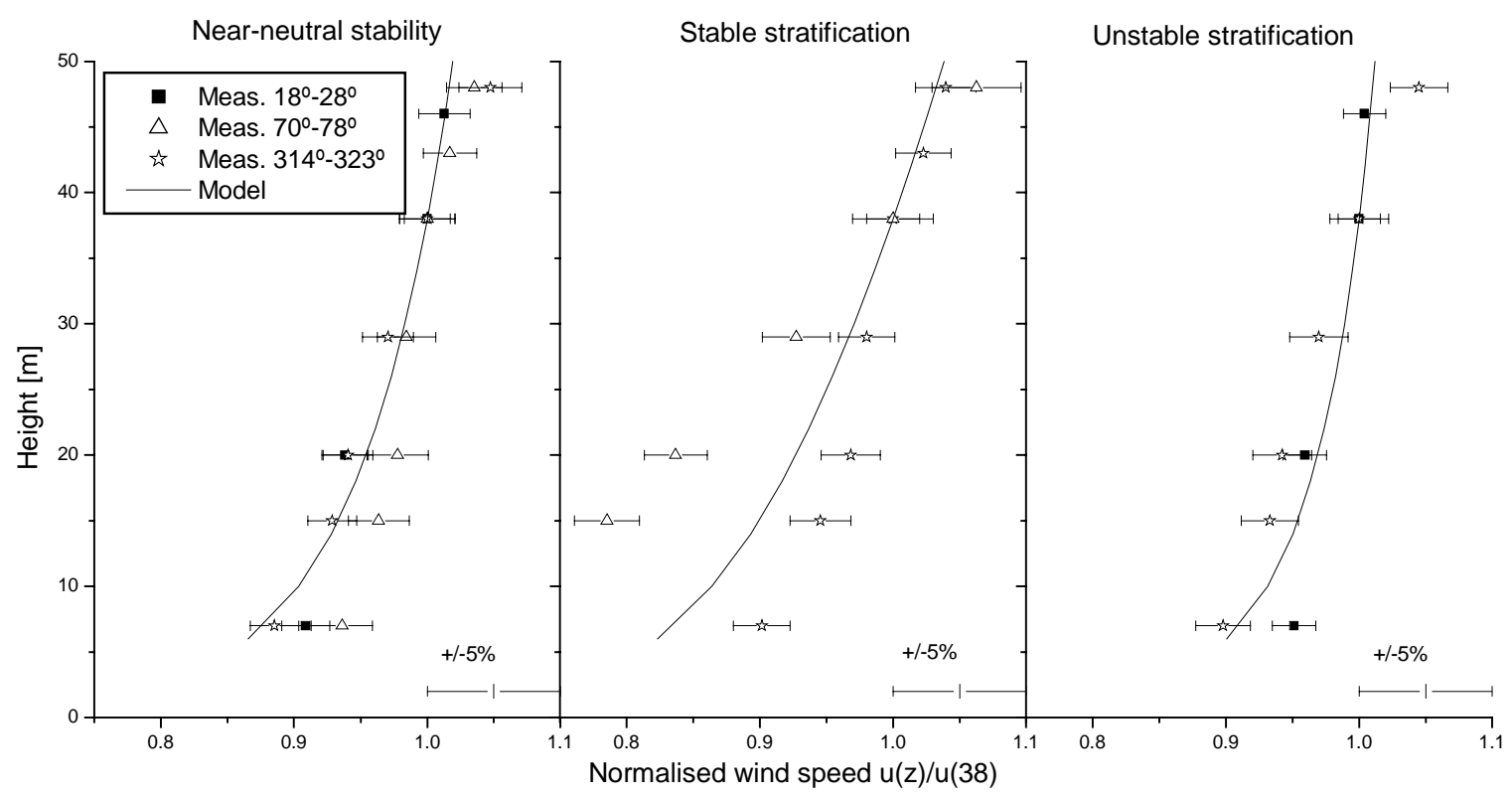

Figure 5: Measured and modelled free vertical wind speed profile for near neutral stratification $(|L|>1000)($ left), stable stratification $(0<L<1000)$ (middle) and unstable stratification $(0>L>-1000)$; turbulence intensity bin 8\% (7-9\%), wind speed bin $5 \mathrm{~ms}^{-1}$ (4-6ms $\left.{ }^{-1}\right)$, wind direction sectors as used for wake comparisons; error bars indicate the standard errors

\subsection{Measurement uncertainty}

The comparison of measured and modelled wakes is very sensitive for measurement uncertainties in the wind speed measurements. The reason is that the modelled wake deficit has to be compared with a measurement of a wind speed difference. For the comparison of measured and modelled wake deficits it is important to estimate the measurement uncertainty to avoid an over-interpretation of deviations and avoid adjusting of the models to systematic measurement errors.

Systematic errors are of main importance, as these are not included in the standard errors calculated in the data analysis. Four main sources have been identified:

- calibration uncertainty leading to offsets between the anemometers

- flow distortion around the mast and boom, leading to a wind speed enhancement for wind directions close to the sector of direct mast shade and a wind speed decrease for wind directions opposite to the mast shade direction

- direct mast shade, leading to a wind speed decrease

- biased distribution of measured values within a wind speed, turbulence intensity or stability bin, leading to a deviation of the bin average to its nominal value.
Systematic measurement uncertainties have been investigated by comparison of wind speed measurements of different anemometers at the same height. A comparison of the three south anemometers showed that the one at SMS measures wind speeds about $4 \%$ lower than the others for wind direction with undisturbed flow. No difference was found for the anemometers at SMW and LM at hub height.

At all heights the anemometers are mounted on booms on the south side of the mast. At hub height an additional anemometer is mounted on the opposite side. Comparisons of wind speeds measured at both sides of the masts showed that the influence of the direct mast shade on the anemometers for the wind directions used in the wake cases (see Table 1) is small. It is estimated to be below $2 \%$. The single wake case in wind direction $23^{\circ}$ is shown as an example. The free wind speed is in this case measured with the LM, which has a boom direction of $350^{\circ}$. Wind directions from $18^{\circ}$ to $28^{\circ}$ measured at SMS are used to determine the wake deficit. In Figure 4 the wind speed ratio between the south and north anemometer at LM is shown versus the wind direction at SMS. The beginning of the mast shade can clearly be seen for wind direction angles smaller than $15^{\circ}$, while the wake sector $18^{\circ}$ to $23^{\circ}$ is not affected be the direct mast shade. However, it can be seen that the ratio of 
the wind speeds in the wake sector is about 1.03 , i.e. the south anemometer measured a wind speed, which is about $3 \%$ higher than the north anemometer. This is partly an effect of the flow distortion around the mast and boom, as can be seen in (Højstrup, 1999), and partly a calibration offset between the two anemometers.

As a rough estimate of the total measurement uncertainty due to systematic errors can be assumed to be in the order of $5 \%$. This means that for a typical wake deficit of $15 \%$ the measurement uncertainty in wake deficit is about $30 \%$.

\section{RESULTS OF THE COMPARISON}

\subsection{Free flow profiles}

The measured wind speeds of the free mast, bin-averaged and normalised as described in section 3.3, are compared with the model of the free vertical wind speed profile. Data for the three different cases of wind direction sectors $\left(18^{\circ}-28^{\circ}, 70^{\circ}-78^{\circ}\right.$ and $\left.314^{\circ}-323^{\circ}\right)$ are used.

A subset of the results is shown in Figure 5. Measured and modelled free flow profiles are shown for turbulence intensity $8 \%$ (bin averaged for 7-9\%), wind speed $5 \mathrm{~ms}^{-1}$ (bin averaged for 4-6 ms ${ }^{-1}$ ). Results for the three stability classes are compared: near-neutral stability $(|\mathrm{L}|>1000)$, stable stratification $(0<\mathrm{L}<1000)$ and unstable stratification $(0>\mathrm{L}>$ $1000)$.

For near-neutral atmospheric conditions a good agreement can be found between the measured profiles and both models for almost all cases. For stable or unstable conditions the agreement is less good and in many cases insufficient for the use in a wake model. Here also the consistency among the measurements for different wake situations (wind direction sectors) is not sufficient in some cases. Stable situations gave clearly the largest deviations: Wherever there are different measurements available for stable conditions, they show large differences in profile steepness.

For both stable and unstable stratification the agreement with the model results is better for the $77^{\circ}$ case, where the wind speed profile and stability are measured at SMS, compared to the $320^{\circ}$ case, where the wind speed profile is measured at SMW and the stability at LM. Differences were found in the measured atmospheric stability between the sea masts and the land mast, which could be responsible for this. However, the reason for these differences is unclear, since both masts are subject to an undisturbed offshore flow for the $320^{\circ}$ case.

The measurement at the LM shows an unexpected behaviour of vertical profile with wind speed with large deviations from the logarithmic profile for the wind speed difference between the two lowest anemometers at $7 \mathrm{~m}$ and $20 \mathrm{~m}$. Terrain effects might have an influence here. Measurements of the LM are therefore difficult to interpret.

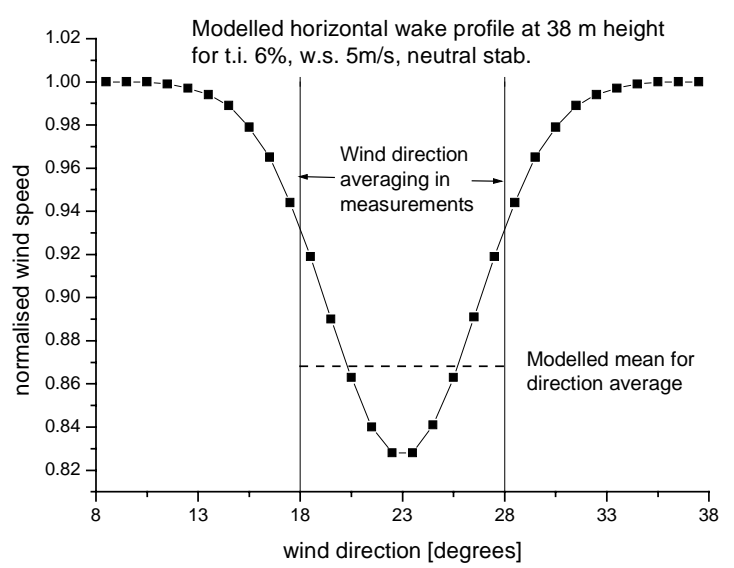

Figure 6: Wind direction dependent (horizontal) wake modelling at hub height for the case of $6 \%$ turbulence intensity, neutral atmospheric stability and a wind speed of 5 $\mathrm{ms}^{-1}$; the dashed line shows the average for the wind direction sector $18^{\circ}$ to $28^{\circ}$

\subsection{Wake profiles}

\section{Method of comparison}

Vertical profiles of single wakes, measured at SMS for wind direction $18^{\circ}-28^{\circ}$, are used for comparisons with model calculations. Double wakes, i.e. wakes of a turbine that itself is in a wake of a second upwind turbine, have been measured at SMW for wind direction $18^{\circ}-28^{\circ}$ and at SMS for wind direction $70^{\circ}-78^{\circ}$. Quintuple wakes (5 turbines in a row) occur at SMS for wind direction $314^{\circ}-323^{\circ}$ (see Table 11). Vertical profiles of bin-averaged measurement data are used for comparisons with model calculations (see section 3.3).

The nominal (mid-bin) values of turbulence intensity, wind speed and stability are used as input to the modelling. For multiple wakes the 
lowest wind speed class $\left(4-6 \mathrm{~ms}^{-1}\right)$ can not be used for comparisons since the downwind turbine(s) might not operate due to the reduction of wind speed in the wake.

For the wind direction a more detailed modelling of the variation of the wake wind velocity within the averaged range is necessary. The averaging of the measured values over all wind directions from $18^{\circ}$ to $28^{\circ}$ has been modelled by also averaging 10 model runs for wind directions from $18.5^{\circ}$ to $27.5^{\circ}$.

The effect of this is shown in Figure 6. It shows a modelled horizontal profile of a single wake at $38 \mathrm{~m}$ height (hub height) under a $6 \%$ turbulence regime, neutral atmospheric stability and a wind speed of $5 \mathrm{~ms}^{-1}$. The normalised wind speed is plotted versus the wind direction. The vertical lines indicate the averaged wind direction range and the horizontal line is the average of the modelled velocity deficit for the range used in the measurements. In this example the averaged normalised wake deficit is 0.132 , while the maximum wake deficit is 0.172 , which is a difference of about $30 \%$.

For multiple wakes the calculation is simplified by assuming that the effect of the increase in turbulence intensity in a wake is not relevant for the modelling of the wake profile. Instead, the ambient turbulence intensity has been used for all wakes.

\section{Comparison for near neutral stability}

From the Vindeby measurement 16 scenarios with near-neutral stability, wind speed bins 5 , 7.5 and $10 \mathrm{~ms}^{-1}$ and turbulence intensity bins 6 and $8 \%$ contained sufficient data for the bin averaging. Model results were within the estimated measurement uncertainty for all scenarios. Examples of the comparison for single, double and quintuple wake situations are given in Figure 7 for the most frequent turbulence intensity bin, $6 \%$, and the most frequent wind speed bins, $5 \mathrm{~ms}^{-1}$ and $7.5 \mathrm{~ms}^{-1}$. Some observations should be noted:

Comparing the form of the profiles of the modelled single wakes a tendency can be seen that the wake 'width', i.e. their vertical extension, is larger than measured. This is not visible for double and quintuple wakes.

Double wakes are measured in two different wind direction cases. Large differences can be seen between these two measured profiles. The measurements for the $70^{\circ}-78^{\circ}$ case show large velocity deficits at low heights, even down to $7 \mathrm{~m}$, while the measurements for the $18^{\circ}-28^{\circ}$ case show generally smaller wake deficits.

\section{Comparison for stable conditions}

In total 5 scenarios were available from the measurements for stable conditions, one each for single and quintuple wakes and 3 for double wakes. As for the comparison of the free flow models (see section 4.1), the comparison of model results with measurements for stable stratification is not as good as for near-neutral stratification and in some cases unsatisfying.

Figure 8 shows examples for the comparison of single, double and quintuple wake situations with measurements for $6 \%$ turbulence intensity and $5 / 7.5 \mathrm{~ms}^{-1}$ (single wake / double and quintuple wakes). Some observations:

In the single wake case the measured wind speed in the wake at $30 \mathrm{~m}$ height shows a value, which would almost be expected in the free flow. This unexpected behaviour can not be explained.

For the double wake case the measured wind shear is larger than modelled as already in the near-neutral cases for this direction. The form of the measured profiles is unexpected with large velocity deficits at low wind speeds. This is not reflected in the model results.

For quintuple wakes it can be seen that already the free flow wind shear is predicted too small. As the free flow is a part of the modelled wake the same is also present in the wake model result.

\section{Comparison for unstable conditions}

In total 11 scenarios were available from the measurements for unstable conditions.

As for stable conditions, the comparison of model results with measurements for unstable stratification is not as good as for near-neutral stratification and in some cases unsatisfying. Figure 8 shows examples for the comparison of single, double and quintuple wake situations with measurements for $6 \%$ turbulence intensity and $7.5 \mathrm{~ms}^{-1}$ mean wind speed. Some observations: 

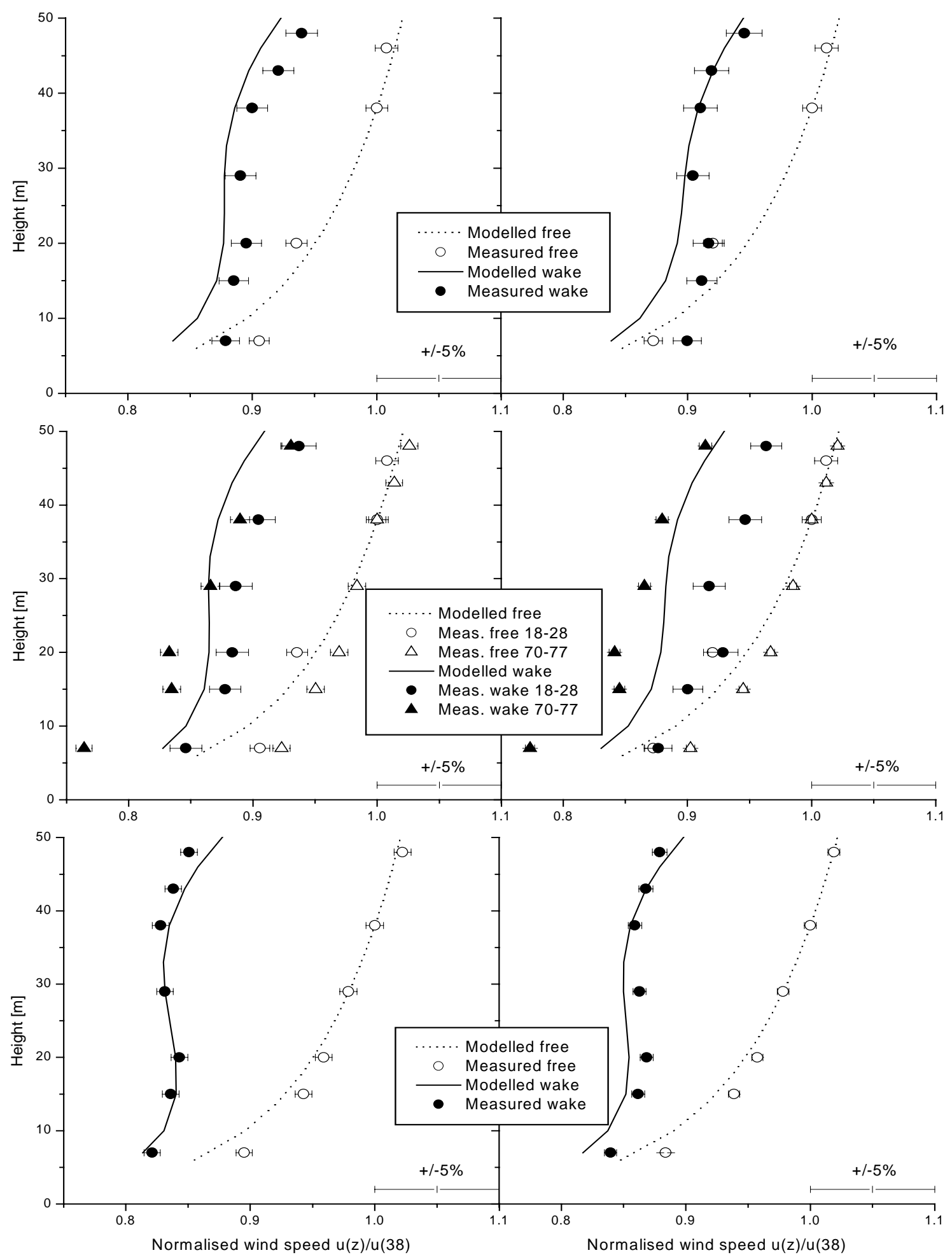

Figure 7: Vertical profiles of measured and modelled normalised wind speeds for the free and wake flow; Vindeby single (top), double (middle) and quintuple (bottom) wake with wind direction $314^{\circ}$ $323^{\circ}$, near-neutral stability, $6 \%$ turbulence intensity, $7.5 \mathrm{~m} / \mathrm{s}$ (left) and $10 \mathrm{~m} / \mathrm{s}$ (right) mean wind speed; error bars indicate the standard errors

The comparison is generally god for the single wake case, while for double and quintuple wakes larger deviations occur.

For the double wake case the model overpredicts the wake deficit. For the $70^{\circ}-78^{\circ}$ case also the wind shear deviates between model and measurement, as also was found for near-neutral and stable stratification for this wind direction case. 

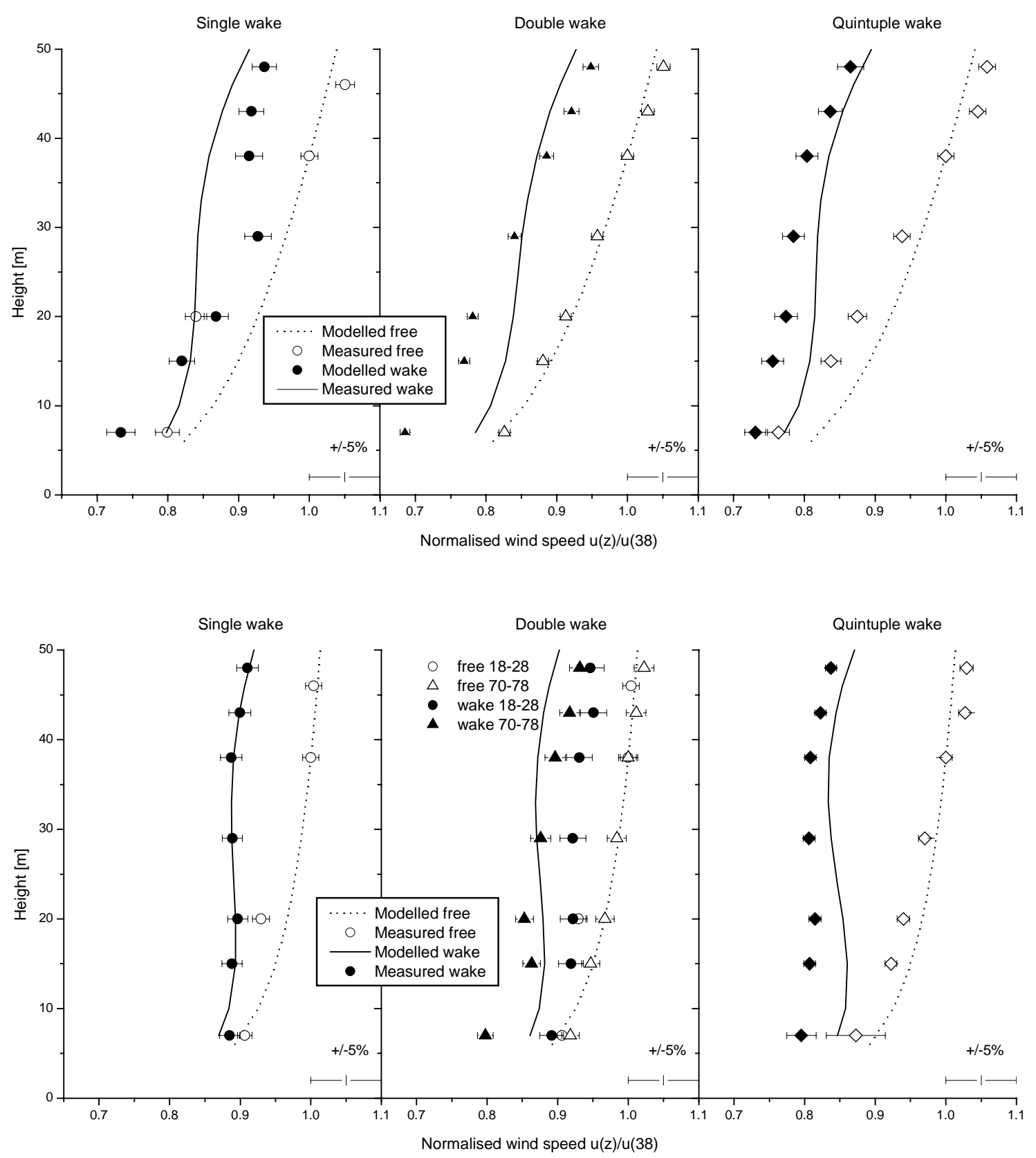

Figure 8: Vertical profiles of measured and modelled normalised wind speeds for the free and wake flow; Vindeby single, double and quintuple wakes, stable (top) and unstable (bottom) stratification, $6 \%$ turbulence intensity, $7.5 \mathrm{~m} / \mathrm{s}$ mean wind speed (except single wake stable: $5 \mathrm{~m} / \mathrm{s}$ ); error bars indicate the standard errors

For the quintuple wake case a slight underprediction of the wake deficit can be seen. Additionally, the measured free flow profile has a larger wind shear than modelled, which was also found for stable stratification.

\subsection{Turbulence intensity}

The turbulence intensity is calculated as the standard deviation of the wind speed divided by the mean ambient wind speed measured at the free mast for each bin. This is the definition of the turbulence intensity used in the model. It should be noted that the turbulence intensities are measured for a 1minute averaging period rather than the usual 10 minutes. The absolute values might therefore be slightly lower. However, the ambient turbulence intensity is measured in the same way and the influence of the absolute value on the relative increase is believed to be negligible. 
Table 2: Measured and modelled ( $m=$ measured, $w=$ wake model, $e=$ empirical formula) turbulence intensities in the single wake at Vindeby wind farm; $18^{\circ}-28^{\circ}$ case, 9.6D distance, $38 m$ height

\begin{tabular}{|c|c|c|c|c|c|c|c|c|c|c|c|c|c|}
\hline & & \multicolumn{3}{|c|}{$5 \mathrm{~ms}-1$} & \multicolumn{3}{|c|}{$7.5 \mathrm{~ms}-1$} & \multicolumn{3}{|c|}{$10 \mathrm{~ms}-1$} & \multicolumn{3}{|c|}{$15 \mathrm{~ms}-1$} \\
\hline & & $\mathrm{m}$ & $\mathrm{w}$ & $\mathrm{e}$ & $\mathrm{m}$ & $\mathrm{W}$ & $\mathrm{e}$ & $\mathrm{m}$ & $\mathrm{W}$ & $\mathrm{e}$ & $\mathrm{m}$ & $\mathrm{W}$ & $\mathrm{e}$ \\
\hline \multirow[t]{3}{*}{$6 \%$} & neutral & 9 & 8 & 7 & 8 & 8 & 7 & 8 & 8 & 7 & 9 & 7 & 6 \\
\hline & stable & 8 & 7 & 7 & & & & & & & & & \\
\hline & unstable & 7 & 9 & 8 & 8 & 9 & 7 & & & & & & \\
\hline \multirow[t]{3}{*}{$8 \%$} & neutral & 10 & 10 & 9 & 9 & 10 & 9 & & & & 9 & 9 & 8 \\
\hline & stable & & & & & & & & & & & & \\
\hline & unstable & 8 & 11 & 10 & 9 & 11 & 9 & & & & & & \\
\hline
\end{tabular}

The results have also been compared with the wake turbulence intensities calculated with the commonly used empirical formula by Quarton and Ainslie (1990).

The measured and modelled turbulence intensities in a single wake for the $18^{\circ}-28^{\circ}$ case of Vindeby wind farm at $38 \mathrm{~m}$ height are compared in Table 2. The two approaches (wake model and empirical formula) are shown.

The measured turbulence intensities show little dependence on either wind speed, atmospheric stability or ambient turbulence intensity. The differences can be seen as stochastic fluctuations, since the average standard deviation of the measurements within the bins is with $3 \%$ larger than these differences. The measured turbulence intensity can therefore be characterised by its mean value, which is $8.5 \%$. The predicted mean turbulence intensity of the wake model is $8.9 \%$ and that of the empirical formula is $7.8 \%$.

Both approaches predict an influence of ambient conditions on the wake turbulence intensity, especially of ambient turbulence intensity, but also of atmospheric stability and (less important) wind speed. These dependencies are the same for both models. The main difference is that the wake model generally predicts a slightly higher turbulence intensity in the wake. On average, this compares better with the measurements than the results of the empirical formula.

\section{CONCLUSION}

The wind farm layout program FLaP has been extended to improve the capability to model offshore wind farms. The characteristics of the offshore atmospheric flow most important for wind power utilisation have been addressed: Sea surface roughness and atmospheric stability.
Model performance has been compared with measurement results from the Vindeby offshore wind farm. In total 32 scenarios of single, double and quintuple wake cases with different mean wind speed, turbulence intensity and atmospheric stability have been selected. The measurement data have been bin-averaged and compared with the model results. The measurement uncertainty for the bin-averaged wind speed measurements in narrow wind direction sectors has been estimated to about 5\%. Since wake deficit measurements are measurements of wind speed differences this leads to large measurement uncertainties.

Given these measurement uncertainties the improved FLaP model agrees well with the measurements for the atmospheric conditions, which are most important for wind power utilisation. These are the conditions with important energy content and high frequency of occurrence, i.e. moderate wind speeds, typical turbulence intensities and near-neutral stability.

The model coped well with the low turbulence intensity offshore as no significant deviations were found for low turbulence situations. Modelling was less successful when atmospheric stability deviated from nearneutral conditions. This was the case both for stable and unstable stratification and both for the modelling of the free profile and the wake flow. This shows that the behaviour of free and wake flows in conditions with non-neutral atmospheric stratification is not understood sufficiently and needs further investigation.

The measurements of turbulence intensity in wakes showed little dependency on ambient conditions, especially on atmospheric stability. Since the model assumes such a dependency some deviations can be seen. However, the variation in the measurement is larger than the differences in question and further investigation is needed here. 
Comparison of single and multiple wakes shows that the measured wake width is smaller than modelled for single wakes while this is not the case for multiple wakes. This might be due to the increase in turbulence for multiple wakes, which develop within the wake of upstream turbines. This effect is presently not modelled, but is planned to be included as the next step.

\section{ACKNOWLEDGEMENT}

Financial support for this research was given in part by the European Commission's Fifth Framework Programme under the Energy, Environment and Sustainable Development Programme. Project Reference: ERK6-199900001 ENDOW (Efficient Development of Offshore Windfarms).

\section{REFERENCES}

Ainslie, J. F. (1985): Development of an Eddy Viscosity Model for Wind Turbine Wakes. 7th BWEA Wind Energy Conference, Oxford, U.K.

Ainslie, J. F. (1988): Calculating the flowfield in the wake of wind turbines. Journal of Wind Engineering and Industrial Aerodynamics vol. 27; 213-224.

Barthelmie, R.J., M.S. Courtney, J. Højstrup and P. Sanderhoff (1994): The Vindeby Project: A Description, Report RisøR-741(EN), Risø National Laboratory, Denmark

Barthelmie, R.J., G. Larsen, H. Jørgensen, K. Rados, H. Bergström, M. Magnusson, U. Hassan, W. Schlez, B. Lange, P. Vølund, S. Neckelmann, L. Christensen, J. Højstrup, G. Schepers, T. Hegberg, L. Folkerts, J. Coelingh (2002): ENDOW: Efficient development of offshore windfarms. Proceedings of the ENDOW Workshop on offshore wakes: Measurements and modelling. Risø National Laboratory, 7/8.3.2002, Roskilde, Denmark

Charnock, H. (1955): Wind stress over a water surface. Quart. J. Roy. Meteor. Soc, 81, 639-640

FLaP (1996): Farm Layout Program, University of Oldenburg, Germany

Frandsen, S., L. Chacón, A. Crespo, P. Enevoldsen, R. Gómez-Elvira, J. Hernández, J. Højstrup, F. Manuel, K. Thomsen and P. Sorensen (1996): Measurements on and Modelling of Offshore Wind Farms, Report
Risø-R-903(EN), Risø National Laboratory, Denmark

Højstrup, J. (1999): Vertical Extrapolation of Offshore Windprofiles. Wind energy for the next millennium. Proceedings. 1999 European wind energy conference (EWEC '99), Nice (FR). Petersen, E.L.; Hjuler Jensen, P.; Rave, K.; Helm, P.; Ehmann, H., Eds., 1220-1223

Lange, B. (2002): Evaluation and improvement of the FLaP wind farm program for modelling offshore wakes. ENDOW internal report. University of Oldenburg, Germany, 83 p.

Lange, B., J. Højstrup, S. E. Larsen and R. J. Barthelmie (2001): A fetch dependent model of sea surface roughness for offshore wind power utilisation. Proceeding of the European Wind Energy Conference 2001, Copenhagen, Denmark, 830-833

Quarton, D. C. and J. F. Ainslie (1990): Turbulence in wind turbine wakes. Wind Engineering vol. 14 (1); pp.15-23.

Rados, K. et al. (2002): Comparison of wake models with data.: Proceedings of the ENDOW Workshop on offshore wakes: Measurements and modelling. Risø National Laboratory, 7/8.3.2002, Roskilde, Denmark

Schlez, W. A., Umaña E. A., R. Barthelmie, G. Larsen, H. Jørgensen, K. Rados, H. Bergström, M. Magnusson, B. Lange, P. Vølund, S. Neckelmann, G. Schepers, T. Hegberg (2002): ENDOW: Improving wake models. Proceedings of the ENDOW Workshop on offshore wakes: Measurements and modelling. Risø National Laboratory, 7/8.3.2002, Roskilde, Denmark

Stull, R. B. (1988): An introduction to boundary layer meteorology. Dordrecht, Boston, London, Kluwer Academic Publishers.

Vermeulen, P. E. J. (1980): An experimental analysis of wind turbine wakes. in: Proceedings of the International Symposium on Wind Energy Systems, Lyngby, Denmark; pp. 431-450

Waldl, H.-P. (1998); Modellierung der Leistungsabgabe von Windparks und Optimierung der Aufstellungsgeometrie. Dissertation an der Universität Oldenburg; 175p. (in German) 


\title{
ENDOW: IMPROVEMENT OF WAKE MODELS
}

\author{
Wolfgang Schlez and Alejandro Umaña E., \\ Garrad Hassan and Partners Ltd, Bristol BS2 0QD, ENGLAND
}

Rebecca Barthelmie and Gunner Larsen, Wind Energy Department, Risø National Laboratory, 4000 Roskilde, DENMARK

Kostas Rados, The Robert Gordon University, School of Mechanical and Offshore Engineering, Aberdeen AB10 1FR, SCOTLAND

Bernhard Lange,

Dept. of Energy and Semiconductor Research EHF, University of Oldenburg, D-26111 Oldenburg, GERMANY

Gerard Schepers and Terry Hegberg, Energy Research Centre of the Netherlands, Wind Energy, 1755 ZG Petten, THE NETHERLANDS

ABSTRACT: The partners in the ENDOW project are validating, testing, designing and improving wind farm design tools for the efficient design of offshore wind farms. The different meteorological conditions offshore constitute a challenge for the current design tools and models because they have been developed and tested primarily for the design of land based wind farms. Measured, wake-affected wind speed profiles at Vindeby offshore wind farm have been compared with the model predictions for single, double and quintuple wake cases. The modelling groups have based on these results adjusted their wake models for offshore wind farm design. This paper presents the data, model comparisons and the improvements to the models.

Keywords: Offshore, Wake Models, Wind Farm Design

\section{INTRODUCTION}

Wake models predict the reduced wind speed within a wind farm. They allow the wind farm designer to quantify the reduction in energy yield of a turbine in a wind farm compared to a single turbine at the same location. The wake effect is a function of the turbine properties and wind farm layout. It further depends on the characteristic properties of the wind flow like the mean wind speed profile and the turbulence. These are different offshore than for an on-land situation. The Endow project contributes to the understanding and accurate prediction of the offshore wind climate that is then used as input to improved wind farm design tools.
The wake models in the Endow project are designed to make use of the improved description of the wind climate.

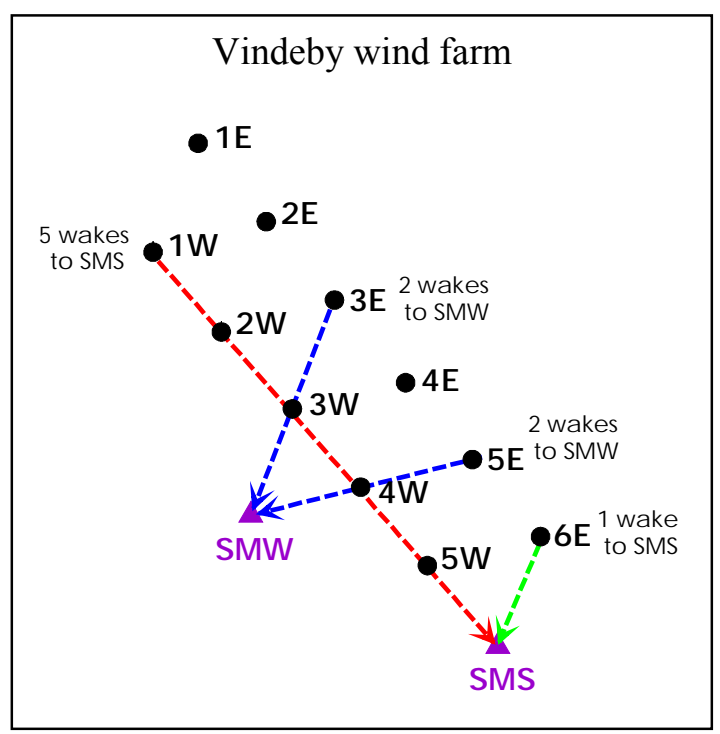

Figure 1: Measurement configurations 


\section{THE EXPERIMENT}

Experimental data from the Vindeby offshore wind farm [1], consisting of 11 Bonus $450 \mathrm{~kW}$ wind turbines, is compared in the ENDOW project with model predictions from 7 different wake models.

- ECN: WAKEFARM

- GH: WindFarmer

- MIUU wake model

- Risø: Engineering Model

- Risø: CFD Model

- RGU: 3D-NavierSokes solver

- UO: FlaP

An overview over the basic characteristics of the models and references for detailed information is given in [2].

The layout of the turbines and measurement masts in the Vindeby wind farm allows a comparison to be made for wind speed measurements of a single wake case, two double wake cases and one quintuple wake case with the model predictions as shown in Figure 1.

\section{WAKE PROFILES}

\section{Single wake case}

The single wake case with the wake of one turbine $6 \mathrm{E}$, measured at the mast SMS has already been discussed in detail in [3]. An example result for the single wake case and different ambient turbulence intensities is shown in Figure 2. The improved model results are presented in Figure 2 together with the experimental data. The data consists of bin-averaged records of one-minute mean wind speed values. The wind speed was measured at seven heights at masts SMS and SMW and four heights at mast LM. Only wind speed data from a mast designated LM are available as a measure of the free stream wind speed for the single wake case. This mast is located to the south of the wind farm on land. A detailed discussion of the set-up is found in [4]. This paper concentrates on the improvements made to the wake models and demonstrates these on example multiple wake cases. No multiple wake results are available for the MIUU model or the Risø CFD model so these models are not considered in this paper.

Single Wake, neutral, Uo=7.5 m/s, 9.6D downstream of turbine $6 \mathrm{E}$

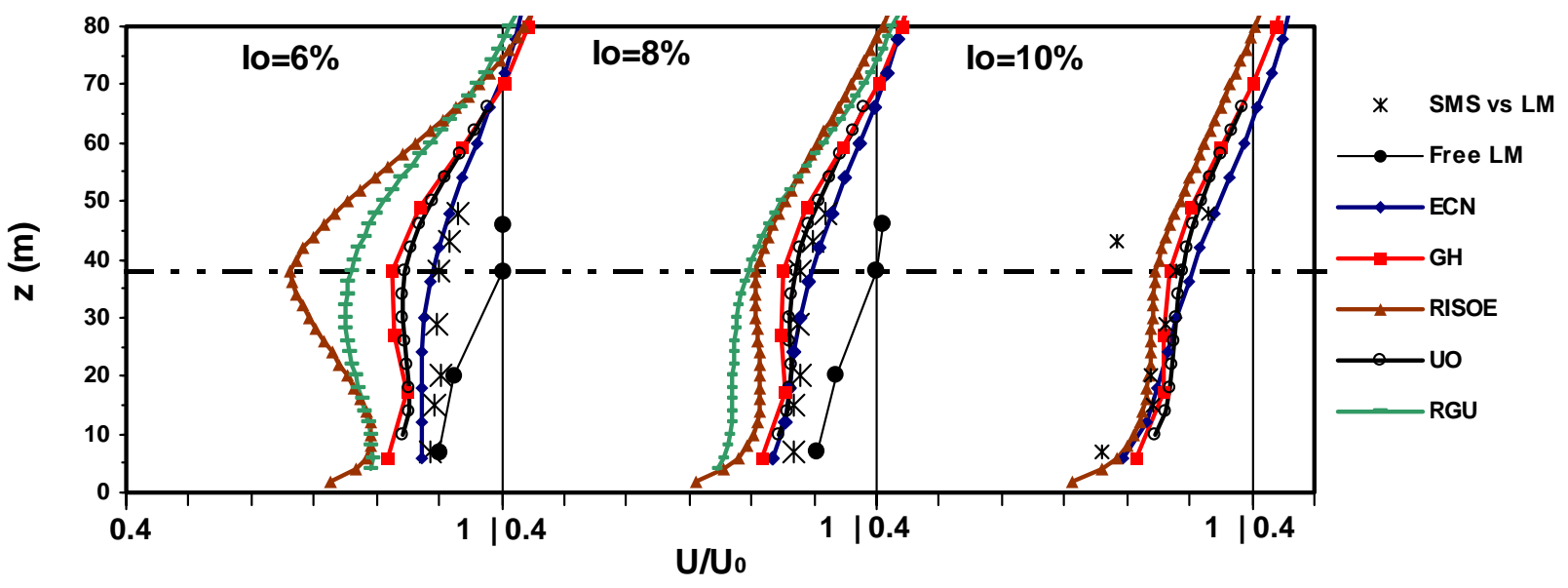

Figure 2: Experimental data and improved wake models for the single wake case 


\section{Double wake cases}

The combined wake of two turbines situated in a row, can be evaluated for two cases. The wake of turbines $5 \mathrm{E}$ and $4 \mathrm{~W}$ is measured at mast SMW. The free wind speed is simultaneously measured at mast SMS. The second double wake is caused by turbines $3 \mathrm{E}$ and $3 \mathrm{~W}$ and is again measured at mast SMW. Only wind speed data from a mast designated LM are available as a measure of the free stream wind speed. This mast is located to the south of the wind farm on land. The distances between the first and second turbine and between the second turbine and the SMW mast are 9.6 rotor diameters $(\mathrm{D})$.

The measured double wake wind speed profiles at mast SMW, normalised with the free wind speed, are presented in Figure 3 together with the predictions of the wake models.
The upper set of graphs in Figure 3 represents the original model predictions at the outset of the project. The lower graph shows the improved wake models. The free wind speed measured at LM is used as an input parameter in Figure 3 and varies between 5 and $10 \mathrm{~m} / \mathrm{s}$. The difference between the measurements for the two double wake cases indicate that the choice of the wind speed measured at LM is problematic. The ambient turbulence intensity is used as an input parameter Figure 4 and varies between 6 and $10 \%$.

Many of the models predict significantly higher wake effects for the double wake case than is supported by the measurement. The improved models show better agreement. However the predictions are still not satisfactory for all of the models. The model that shows the largest improvement is the UOFlaP model. Details of this model are presented in [4].

Double Wake, neutral, lo=6\%, 9.6D downstream
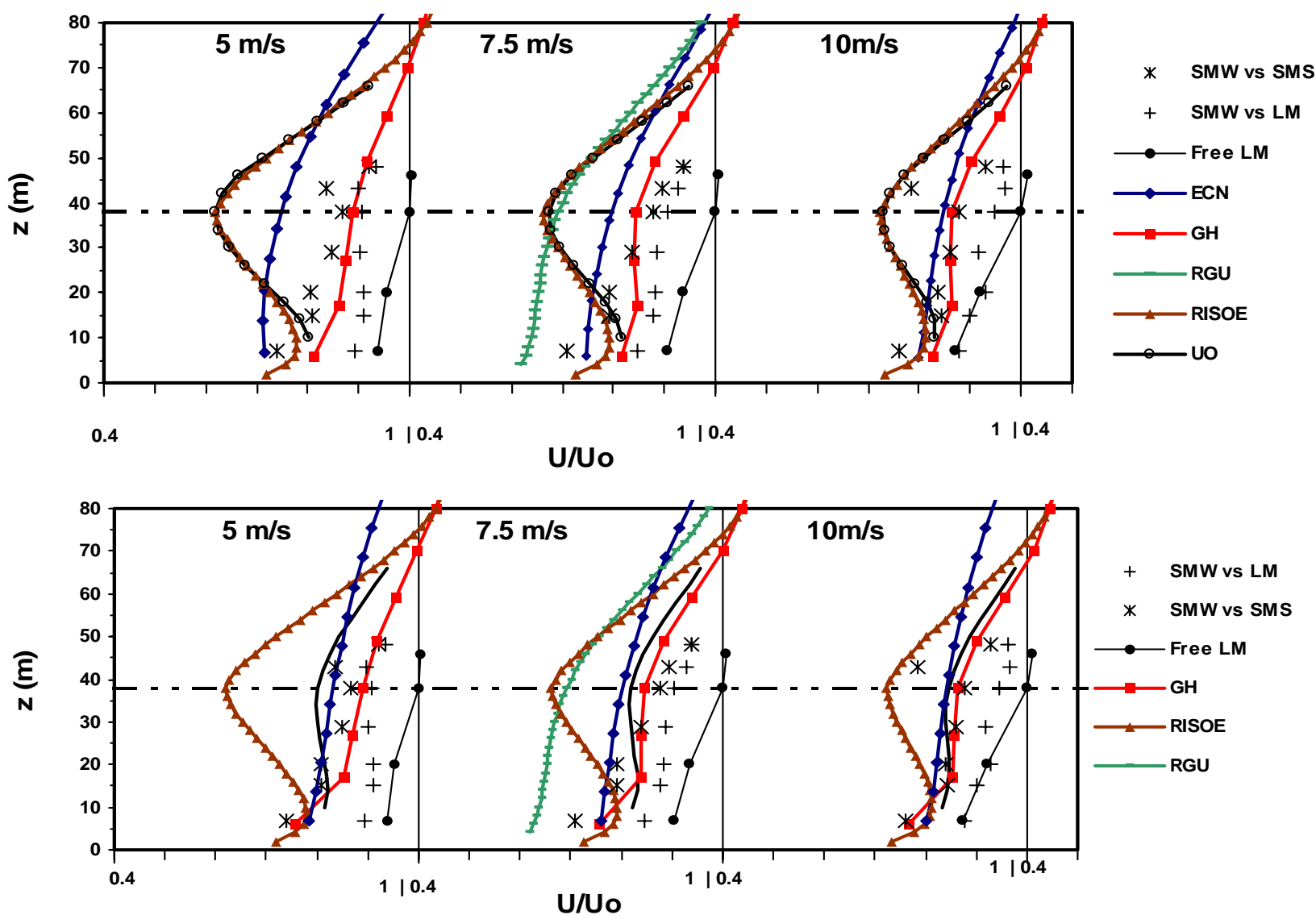

Figure 3: Experimental data, original (upper) and improved (lower) wake models. 


\section{Wake model improvements}

The fundamental set of equations of motion that is used to calculate the wake expansion is the same for all the advanced numerical wake models in this comparison. The main differences between the models are idealisations, the initialisation, the turbulence closure scheme and the parameters used for the turbulence closure.

The initialisation of the ECN-WAKEFARM model has been changed from an assumed box type profile to a Gaussian profile at $2.25 \mathrm{D}$ distance. This and changes to the turbulence characterisation brings the prediction closer to the models of GH and UO that use a Gaussian profile at $2 \mathrm{D}$ distance for the initialisation of the model (see Figure 3, especially visible at $5 \mathrm{~m} / \mathrm{s})$.
The UOL-FlaP model has been extended, mainly by taking into account the effect of turbulence and stability on the length of the near wake and by an improvement of the eddy-viscosity model. This brings the model prediction close to the very similar wake model of GH-WindFarmer.

No changes that affect the wind speed predictions were made to the GH-WindFarmer model as the model already displayed a good performance. The small differences that can be seen between the old/improved graphs for the GH model and also some of the other models are due to a more accurate physical representation of the wind farm.

\section{Double Wake, neutral, Uo=7.5 m/s, 9.6D}

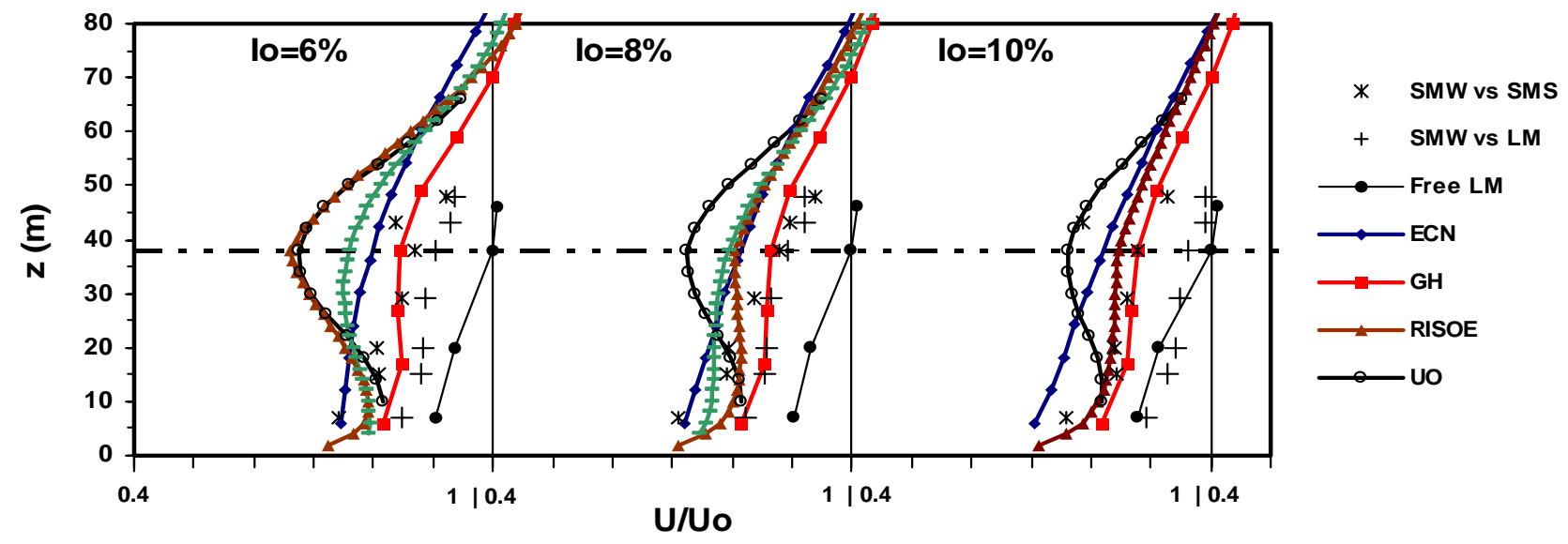

Double Wake, neutral, Uo=7.5 m/s, 9.6D

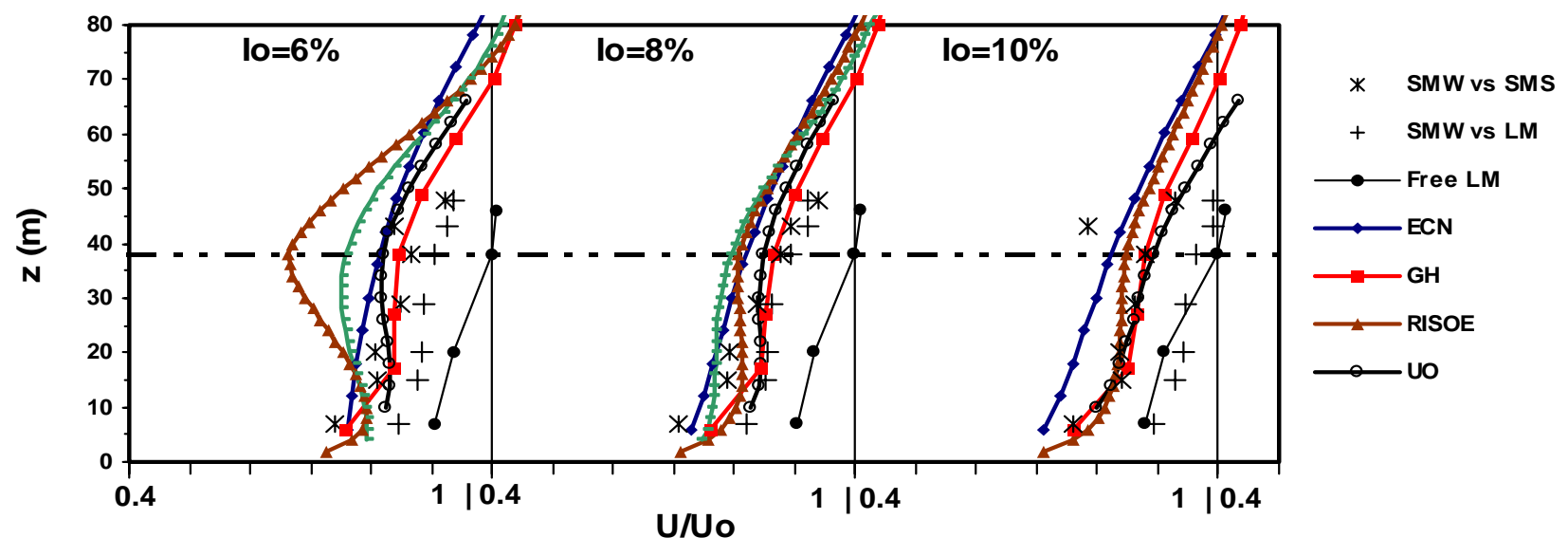

Figure 4: Experimental data, original (upper) and improved (lower) wake models 


\section{Quintuple wake case}

The combined wake of 5 turbines in a row $1 \mathrm{~W}, 2 \mathrm{~W}, 3 \mathrm{~W}, 4 \mathrm{~W}$, and $5 \mathrm{~W}$ is measured at mast SMS. The distance between the turbines is equidistant $8.6 \mathrm{D}$ and between the turbine $5 \mathrm{~W}$ and the mast SMS is also 8.6D. The wind speed measured at SMS is normalised by the free wind speed. The free wind speed measurement is taken from the land-based mast LM.

Original (lower graph) and improved model (upper graph) results are presented together with the experimental results for quintuple wakes in Figure 5. In the original results all models but the GH-WindFarmer model overestimate the wake effect. The GHWindFarmer model underestimates the wake slightly at a wind speed of $5 \mathrm{~m} / \mathrm{s}$.

\section{Improvements}

It is again the model of UOL-FlaP that shows the most significant performance improvement. The changes to the ECN near wake model do not seem to have any significant effect on the performance of the model when looking at the quintuple cases. No improved model calculations are available for the Risø-Engineering Model.

The differences between the majority of the models and the data tend to increase from single to double and then to quintuple wakes. This indicates that one consideration for the further improvements of the models should be the method for superposition of wakes.

Quintuple Wake, neutral, lo=8\%, 8.6D

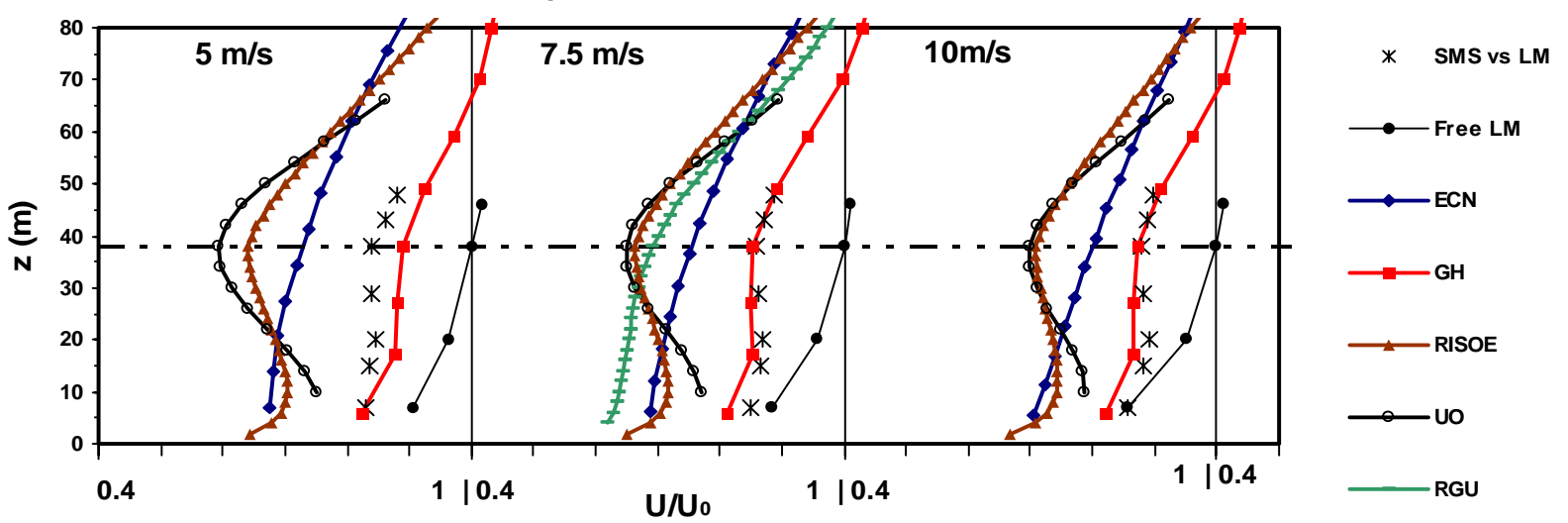

Quintuple Wake, neutral, lo=8\%, 8.6D

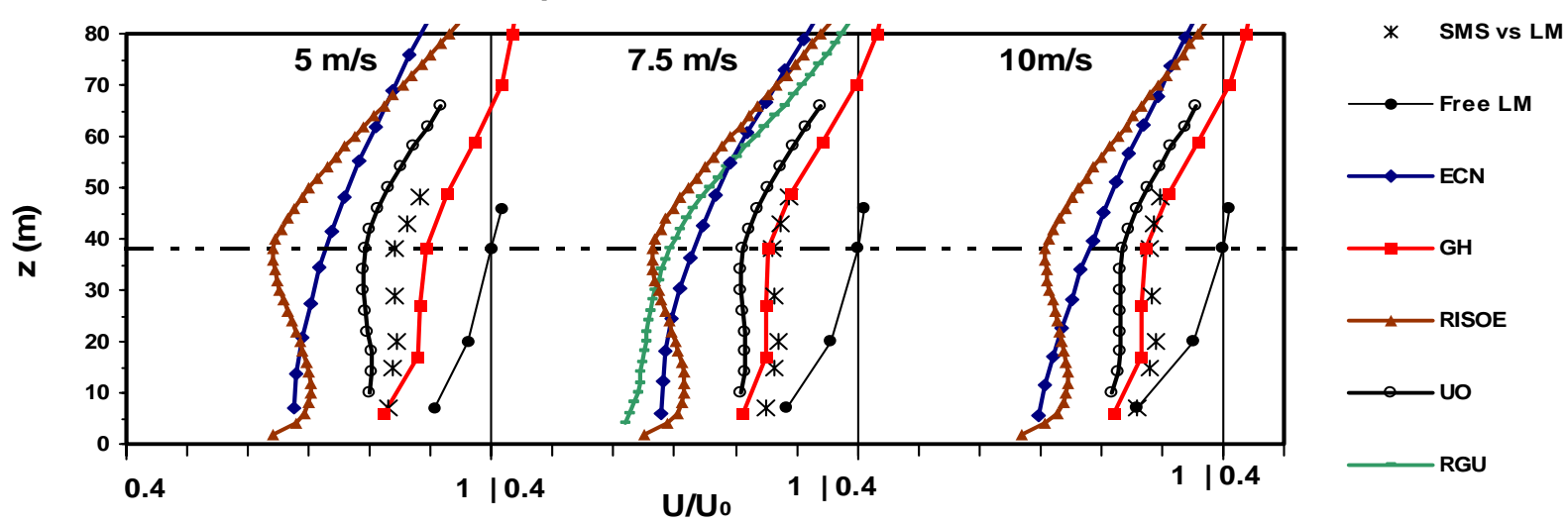

Figure 5: Experimental data, original (upper) and improved (lower) wake models 


\section{SUMMARY}

Wake profiles measured in the offshore wind farm Vindeby have been compared with a number of existing wake models.

The investigation gives new insights into the importance of parameters such as turbulence intensity for the design of offshore wind farms.

It is clear from this work that the inclusion of the ambient turbulence intensity is a vital part of a successful modelling approach.

The initialisation of the wake models in the near wake of the turbine is another area where improvements have been made.

Further work must concentrate on the validation and developments of models of the turbulence in single and multiple wake situations.

\section{ACKNOWLEDGEMENT}

Financial support for this research was given in part by the European Commission's Fifth Framework Programme under the Energy Environment and Sustainable Development Programme. Project Reference ERK6-199900001 ENDOW (Efficient Development of Offshore Wind farms).

\section{REFERENCES}

[1] S. Frandsen (ed.), et al. 'Measurements on and Modelling of Offshore Wind Farms', Risø-R-903 (EN), 1996

[2] Gerard Schepers et al., 'Linking boundary layer and wake models: design tools development' ENDOW workshop 2002.

[3] K. Rados et al. 'Comparison of wake models with data' ENDOW workshop 2002.

[4] B. Lange et al., 'Improvement and evaluation of the wind farm program FlaP for offshore conditions', ENDOW workshop 2002. 


\title{
BOUNDARY-LAYER MODELLING FOR WIND CLIMATE ESTIMATES
}

\author{
Hans Bergström \\ Department of Earth Sciences - Meteorology, \\ Villavägen 16, Uppsala University, SE-752 36 Uppsala, Sweden \\ Tel: +46 1847171 81, fax: +46 185511 24, http://www.met.uu.se \\ Email: hans.bergstrom@met.uu.se
}

\begin{abstract}
The offshore wind climate over the Baltic Sea area has been investigated using the threedimensional higher-order closure MIUU-model from Uppsala University. A technique to model the wind climate with this type of model is presented. The results are verified against measurements. Following the good agreement between model estimates and observations, it is judged that the model output may be used to analyse different aspects of the offshore winds in a detail not possible with existing observations. Thus the influence from land/sea temperature differences on the wind climate and the effects of the related thermally driven flows was investigated. An attempt was made to quantify their effects on the offshore wind potential over the Baltic Sea.
\end{abstract}

\section{Introduction}

When mapping the wind climate for wind energy purposes, it is important to take into account both land and sea areas, and the interaction between the two. The horizontal gradient of air pressure, the geostrophic wind, is the primary driving force for wind, but over land it is well known that also topography, roughness and variations in thermal stratification, are factors affecting the wind climate. In coastal areas also other factors, related to the land-sea transition, are of importance and contribute to a rather complex offshore wind field, which may affect the wind also at large distances from the coast.

Spatial variations of wind speed over large offshore areas, like the Baltic Sea, are difficult to measure directly. Instead models may be used. Often these models include just a simplified description of the physics determining the boundary layer wind profiles and the wind field. This means that the simplified models will e.g. not be able to account for the effects of large-scale thermally drive flows since the physics needed for this has been excluded from the models.

During many experiments in the Baltic Sea area it has been shown that the atmospheric boundary layer far from seldom departs from simplified relations, where it is assumed that to a good approximation the wind when crossing a shoreline will adapt to offshore conditions with smaller roughness and a different thermal stability, finally reaching equilibrium. Even during the thermally most stable conditions, when the adapting process is very slow, the wind in the layer of interest for wind energy should, according to the simplified models, be in equilibrium with the new underlying surface at least at distances from the coast of the order $20 \mathrm{~km}$. Several factors, however, act to make this assumption about equilibrium conditions at large distances from the coast invalid, c.f. Källstrand et al. (2000). One is the low-level jets often observed in the Baltic Sea area, whose origins may be an inertial oscillation initiated with air flowing from land out over the sea (Källstrand, 1998). Sea breeze circulations and thermal winds are other phenomena, which may give rise to lowlevel jets.

Non-homogeneous offshore conditions may also be due to the internal boundary layer growth differing from the expected, and more generally to thermally driven flows. Offshore internal boundary layers may develop much more slowly than predicted by simplified models, and observations show that with stable conditions over the sea the wind speed may even, in contrary to what is normally assumed, decrease with distance offshore up to at least $100 \mathrm{~km}$ from the coast (Källstrand et al., 2000). Among the thermally driven flows giving inhomogeneous offshore wind conditions, we have the sea breeze circulations, common during spring and summer. Due to complex interaction between land and sea, the offshore wind is often not only a function of distance from the coast but may also be affected by the actual curvature of the shoreline, and an influence from land may also be found upstream the coast (Källstrand 
and Smedman, 1997). Although the thermally driven flows may not always give rise to a sea breeze, the temperature differences between land and sea often affect the wind field far out at sea, changing both speed and direction of the wind from what would otherwise be the case.

Low-level jets and other features, which do not always follow simplified 'normal' behaviour, may however be modelled quite well using higher-order closure boundary layer models like the MIUU-model from Uppsala University (e.g. Källstrand et al, 2000). The MIUU-model has proved to give accurate results comparing with observations in many different types of terrain and during a large variety of atmospheric conditions. Specifically the MIUU-model generates the observed and for the wind climate important low-level jets over the Baltic Sea (Mohr, 1997).

The higher-order closure MIUU-model will be described and a method to model the Baltic Sea wind climate will be outlined. Results from large a number of runs with MIUUmodel will be used in an attempt to climatologically quantify the impacts upon the wind resource of thermally driven flow modifications, which are not normally accounted for in simplified models.

\section{The MIUU-model}

The MIUU-model, a three-dimensional hydrostatic mesoscale model, has been developed at the Department of Meteorology, Uppsala University, Sweden, (Enger, 1990). The model has prognostic equations for wind, temperature, humidity and turbulent kinetic energy. Turbulence is parameterised with a level 2.5 scheme following Mellor and Yamada (1974). The closure is described in detail in Andrén (1990). The MIUU model has a terrain-influenced coordinate system (Pielke, 1984), roughly following the terrain close to the surface and gradually transforming to horizontal at the model top. To reduce influences from the boundaries, the model area is chosen to be much larger than the area of interest. This also makes it possible to account for effects of e.g. mountains and water areas which are outside the investigated area, but which may anyhow be of importance to the wind field. To limit the number of grid points in the horizontal, a telescopic grid is then used, with the highest resolution only in the area of interest. In the vertical, the lower levels are log spaced while the higher levels are linearly spaced. The lowest grid point is at height $\mathrm{z}_{0}$, where $z_{0}$ is the roughness length, and the model top is typically at $10000 \mathrm{~m}$. Typically 8 levels are used in the model up to $100 \mathrm{~m}$ height.

At the lower boundary, roughness length and altitude have to be specified at each grid point. Topography and land use are taken from digitised maps, with a resolution of $1 \mathrm{~km}$ (the U.S. Geological Survey, the University of Nebraska-Lincoln, and the European Commission's Joint Research Centre 1-km resolution global land cover characteristics data base, 1999). The roughness over land has been divided into classes according to land use. For water $\mathrm{z}_{0}$ is either assumed constant, equal to $0.00025 \mathrm{~m}$, or estimated from the Charnock relation. During winter, the roughness length is set to $0.001 \mathrm{~m}$ over open terrain to represent snow-covered land areas. Also temperature has to be given or estimated at the lower boundary for each grid point. The land surface temperature and its daily and monthly variation are estimated with a surface energy balance routine using as input solar radiation and land use. Over sea the observed monthly average sea-surface temperatures have been used.

The MIUU model has been used earlier in many case studies in different types of landscapes, with satisfactory results. Wind climate investigations have been made for a mountain area in northern Sweden (Bergström and Källstrand, 2000 and 2001), and the model has been used in a study over lake Torneträsk, also in northern Sweden, (Smedman et al., 1996a). Simulations with the MIUU model in mountainous terrain have also been performed around Lake Mohave in the Colorado River Valley, (Enger et al., 1993) and (Koracin and Enger, 1994). In Bergström, 1996, and Sandström, 1997, the MIUU-model has been used to simulate the climatological wind field over the Baltic Sea.

\section{A method to model the wind climate}

In an ideal climate study, all synoptic and boundary conditions should be covered. But this would require an unrealistically large number of simulations. Since the MIUUmodel is rather computer time consuming to run, some compromises have to be made. The most important flow forcing parameters have to be identified and varied in order to cover a reasonably wide range of atmospheric conditions. The parameters judged to be of 
most importance to the wind field are: geostrophic wind (strength and direction), thermal stratification (through the daily temperature variation), surface roughness, topography, and land-sea/lake temperature differences.

The pressure gradient, i.e. the geostrophic wind, is the primary driving force of the wind. Using only the mean geostrophic wind speed in the simulations would reduce the effect of thermal stratification, as the daily stability variations is much larger with a low geostrophic wind speed compared to a high one. This effect is sometimes very large, why it is important to include simulations with different geostrophic wind speeds (Sandström, 1997). Model runs have thus been made using three values of the geostrophic wind speed (5, 10 , and $15 \mathrm{~m} / \mathrm{s}$ ) for 8 wind directions.

The air temperature shows a clear annual as well as a daily variation, which also must be included in the simulations. To limit the number of model runs but still include the annual variations, 4 months (January, April, July and October) have been selected to represent the four seasons. It has been shown by Bergström (1996) that this approach is accurate enough. A monthly average soil temperature has been used as input to the surface energy balance routine estimating the surface temperatures. To include the spatial differences, data from a number of weather stations have been used and the data have been interpolated within the model domain. The mean temperature also varies according to wind directions. Thus the mean temperature for different directions was also estimated. The daily variation of sea surface temperature is rather small compared with the variations of the air temperature. Therefore, model runs were made with the seasonal mean sea surface temperature at each grid point, with no daily variation but including a spatial variation.

Summing up, for each season runs were made with three values of the geostrophic wind speed, and with 8 wind direction sectors. We thus end up with 96 model runs to cover the most important parameters determining the boundary layer wind climate. Each simulation was run for a 36-hour time period, of which only the last 24 hours were used, allowing for 12 hours initialization. The background flow for each model run is specified as a geostrophic wind constant in time. The initial potential temperature and humidity profiles were taken from climatologically averaged radiosonde data for the different seasons.

All simulations were finally weighted together using climatological data for the geostrophic wind. This gives the climatological averages for each month, grid point, and height. The annual mean wind speed may then be calculated by weighting the four individual months together. Thus, the result from a study of the climatological wind field may be presented as the mean wind speed (annual or seasonal), or wind energy potential, at different heights. The wind speed distribution may also be determined. It should be pointed out that the MIUU model uses no local wind measurements as input.

\section{Baltic Sea wind climate simulations}

The model domain used covers the whole Baltic Sea area with a horizontal resolution of $9 \mathrm{~km}$. The model output predicts annual averages at $50 \mathrm{~m}$ height around $5-6 \mathrm{~m} / \mathrm{s}$ over southern Sweden and 8.5-9 m/s over the Baltic Sea (c.f. Figure 1). A comparison with observations made at several sites in the area show good agreement both offshore and over land (Bergström, 2001). At two offshore lighthouses (Almagrundet and Ölands södra grund) the observations show the annual mean winds $8.2 \mathrm{~m} / \mathrm{s}$ at $32 \mathrm{~m}$ height, while the model gives 8.0 and $8.1 \mathrm{~m} / \mathrm{s}$. Over land in partly forested areas, the model estimates annual mean winds of about $5.0 \mathrm{~m} / \mathrm{s}$ at $50 \mathrm{~m}$ height and about $6.7 \mathrm{~m} / \mathrm{s}$ at $100 \mathrm{~m}$ height, also in agreement with observations at two locations in southern Sweden.

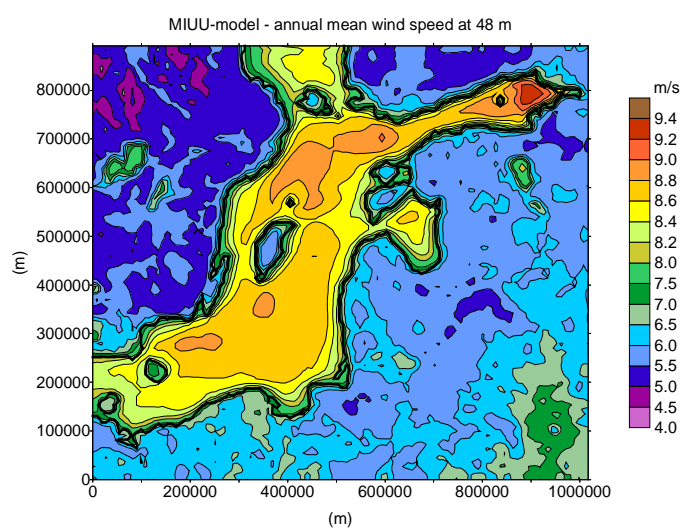

Figure 1: Annual mean wind speed at $48 \mathrm{~m}$ height estimated from the MIUU-model runs.

This agreement between modelled wind climate and observations, together with several earlier model verifications (e.g. Källstrand et al. 2000, Enger et al. 1993, Enger 1990), 
support the accuracy of the modelled wind fields. We may thus with some confidence use the MIUU-model simulations to study influences on the wind climate caused by phenomena which are not commonly included in model investigations of the wind climate. Primarily this includes flow modifications due to differences in temperature and stratification between land and sea. Also the diurnal cycle of air temperature over land has an influence on the offshore wind field.

\section{Thermally driven offshore wind modifications}

The Baltic Sea is surrounded by land surfaces, which means that land areas might influence the wind and turbulence structure over the sea regardless of wind direction. We may also expect temperature differences between land and sea to be of importance to the offshore wind. The location of the Baltic Sea at fairly high latitudes causes the land surface temperature to be higher than the sea surface temperature during a large part of the year, which often will give a stable internal boundary layer over the sea. Measurements have shown that the lowest $100 \mathrm{~m}$ of the marine boundary layer over the Baltic Sea is probably stably stratified during between $1 / 2$ and 2/3 of the time (Smedman et al. 1997), at least over parts of the Baltic Sea. The growth of the stable internal boundary layer may affect the wind speed for large distances from the coast, even giving decreasing wind speeds at lower levels (Källstrand et al., 2000). At the top of this internal boundary layer a low level jet may develop as a result of frictional decoupling at the coast (Smedman et al. 1996b, Källstrand 1998), when warm air (from the surrounding land areas) is advected out over the cooler sea. This produces an analogy in space to the well-known nocturnal jet (Blackadar 1957).

The growth of internal boundary layers and low-level jets, together with sea-breeze circulations, are examples showing the importance of taking thermal factors into consideration when the offshore wind field is studied, not only in coastal areas but also far out at sea. They may contribute to a spatial variability of the wind field also on a climatological basis.

An example of the wind field in the Baltic Sea area is shown in Figure 2. The MIUUmodel was run using temperature data representative for July and with a geostrophic wind of $10 \mathrm{~m} / \mathrm{s}$ from south. The pressure field (gesostrophic wind) is kept constant throughout the simulation period of 24 hours $(+12$ hours initialization in advance), and it is also constant in the whole modelled area. In spite of this, the offshore wind field is not constant, neither in space nor in time. The main reasons are the complex geography leading to a complex land/sea interaction, together with the temperature differences between land and sea and its diurnal cycle. The variation of the wind over the Baltic Sea area is also clearly visible in the daily average, as shown in Figure 2. The highest winds are found in the southern Baltic Sea area, along the Lithuanian and Latvian costs, in the Bay of Riga. In these areas the daily average wind speed amounts to as much as $7.5-8 \mathrm{~m} / \mathrm{s}$, while in other areas, as in the northeastern part of the Baltic Sea, the daily average may even be below $5.5 \mathrm{~m} / \mathrm{s}$.

Remembering that the model runs were made with a southerly geostrophic wind, constant in space, giving winds in the boundary layer approximately from southsoutheast, these differences are not expected using analytical descriptions of the wind commonly used in simplified wind models. Instead we would then expect a more or less homogeneous wind field at $12 \mathrm{~m}$ height after an offshore distance of some $10 \mathrm{~km}$ or so from the southern or eastern coasts of the Baltic Sea. Also we would not expect the upstream deceleration of the wind modelled in the offshore areas southeast of Sweden. Such flow modifications upstream this coast has, however, been observed in measurements by aircraft (Källstrand and Smedman, 1997).

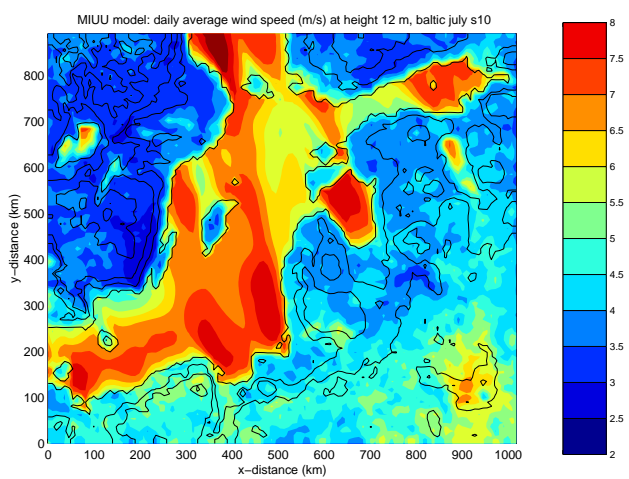

Figure 2: Daily average wind speed in the Baltic Sea area at $12 \mathrm{~m}$ height as modelled by the MIUU-model using July temperature conditions and the geostrophic wind $10 \mathrm{~m} / \mathrm{s}$ from south. 
It is thus clear that the model, even with a constant pressure gradient in the area, does not at all predict a homogeneous offshore wind field for individual flow situations, the main reason for this being thermally driven flow modifications. We will further investigate the influence from these thermally driven flows, both on a seasonal and an annual basis.

\section{Effects on the wind climate from thermally driven flows}

To test and get some quantitative estimates of the importance of thermally driven flows upon the offshore wind climate over the Baltic Sea, the MIUU-model was run with no temperature differences between land and sea, i.e. the sea was treated as a large plain with very low roughness $\left(\mathrm{z}_{0}=0.00025 \mathrm{~m}\right)$. These runs were otherwise done exactly as the full climate runs, in which the sea surface temperature was instead kept at the observed climatological monthly averages, which were allowed to vary with location at sea.

The results for each individual run show differences in the daily average wind speed of about $\pm 40 \%$, comparing the test runs with the full climate runs. An example is shown in Figure 3. It is obvious that the result to a high degree depend on wind direction. For winds from southeast, southwest, and northwest, positive percentages dominate, i.e. the runs with no land/sea temperature differences result in a higher wind. For winds from east, south, and west negative values are most common. The geographical variability is also large, so that the runs could over predict the wind with no land/sea temperature differences in one area, but at the same time the wind could be under predicted in another area. Where these different areas are located is highly dependent on wind direction. At the same time there are also differences between the seasons. We may thus conclude that the thermal differences between land and sea have a large influence on the offshore wind field, and also that this is not only the case for the coastal areas. The influence reaches far out at sea so that no part of the Baltic Sea is unaffected. But the fact that the magnitude and sign of the thermal influences varies highly between different areas and different wind directions, have the implication that the effects of the land/sea temperature differences on the monthly average wind speed will be smaller than for the individual runs representing specific weather situations.

The differences in wind speed, comparing runs without and with the land/sea temperature differences, varies within $\pm 14 \%$ looking at the monthly averages (Figure 4), as compared to $\pm 40 \%$ when looking at the individual runs for each wind direction. The differences also vary systematically with season. During January, the western parts of the Baltic Sea have differences of the order $-6 \%$ to $-2 \%$, while in the eastern parts $+2 \%$ to $+6 \%$ are more typical. During April the differences vary systematically from $+6 \%$ in the south to $-8 \%$ in the north. During July the differences are typically positive, i.e. the winds estimated from model runs with no land/sea temperature differences are higher, with the highest magnitudes in the south of up to $+14 \%$. In October the differences are typically smaller and vary between $-4 \%$ and $+6 \%$.

Due to the non-systematic differences between the four monthly model runs, the annual average difference in wind speed between the model runs with and without land/sea temperature differences will be even further reduced. The annual average differences are shown in Figure 5, and we can see that they vary between $-6 \%$ and $+4 \%$, with the largest positive values in the southern and eastern parts of the Baltic Sea, while the negative differences are found along the Swedish coast.

Thus according to the comparison between MIUU-model runs with and without such temperature differences, the errors in the annual mean wind speed are typically within $\pm 2 \%$ over large areas of the Baltic Sea and in the extreme between $-6 \%$ and $+4 \%$ (see Figure 5). But of course the errors in the potential energy production will be higher. As the energy is proportional to wind speed raised to the power of three, the errors in energy will be of the order $-20 \%$ to $+10 \%$.

The energy production is also dependent on the wind distribution, and not only on the mean wind speed, which will further increase the uncertainty excluding effects from thermally driven flows. 

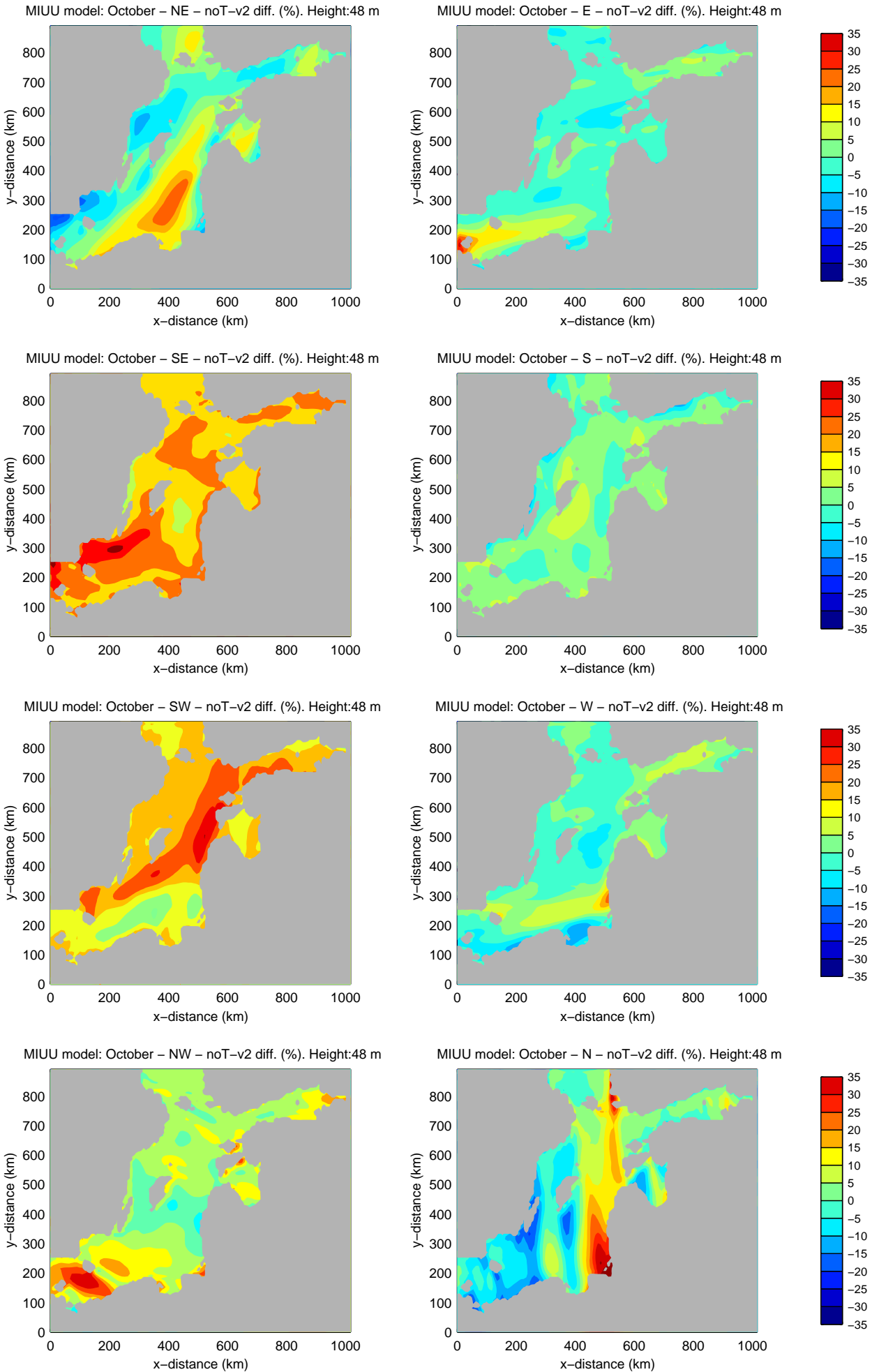

Figure 3: Average wind speed difference (\%) between a model run made without and with land/sea temperature differences. Temperatures representative for October with a northerly geostrophic wind. 


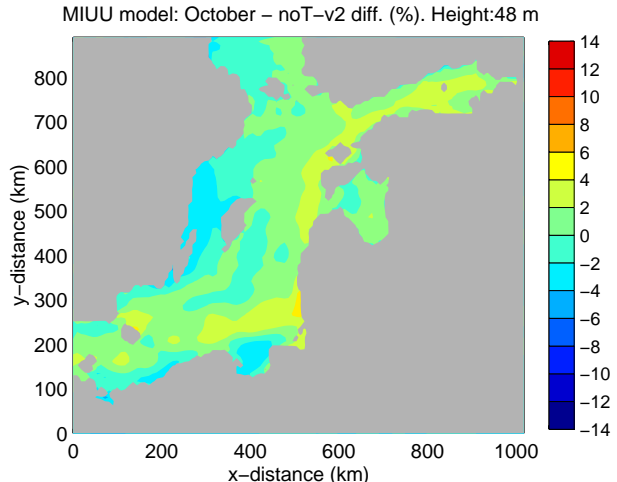

Figure 4: Average wind speed differences (\%) between the model runs made with no land/sea temperature differences, and the full climatological runs. Monthly averages for January, April, July, and October

As positive and negative errors tend to cancel each other when estimating the annual or monthly average wind speed errors, such average error numbers will, however, not be typical for the errors introduced by not taking into account the land/sea temperature differences and its effects on the offshore wind field. Instead the differences in wind speed (\%) for each of the 24 hours of all the model runs (month, speed and direction of geostrophic wind) were squared, and the rootmean-square (RMS) errors are presented in Table 1 as monthly averages and extremes at the heights 12, 48, and $103 \mathrm{~m}$ for all offshore grid points.

The average RMS errors vary between $6 \%$ and $11 \%$, with the highest values at the $12 \mathrm{~m}$ height in April and July, and the lowest values at the $48 \mathrm{~m}$ height in April and October. For all months somewhat smaller RMS values are found at the $48 \mathrm{~m}$ height compared to both 12 $\mathrm{m}$ and $103 \mathrm{~m}$ heights. From the extreme values we can see that the scatter is large as regards the errors in wind speed, from $-52 \%$ in January as a minimum to $+75 \%$ in October as a maximum. From the RMS error statistics we learn that although the average errors, which arise by excluding land/sea temperature differences, only are within a few percent over large offshore areas, this is partly just a consequence of the fact that the sign and the magnitude of the errors vary with the meteorological conditions, primarily season and wind direction.
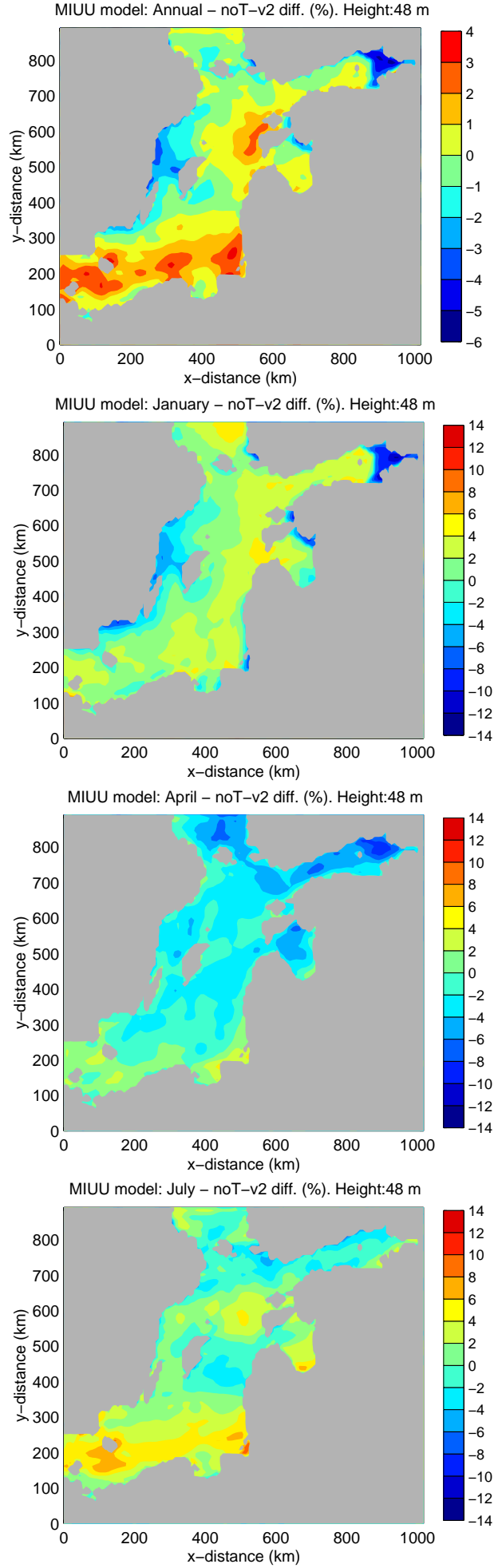

Figure 5: Annual average of difference (\%) in mean wind speed between the model runs made with no land/sea temperature differences, and the full climatological runs. 
An overestimation of the wind in an area for some meteorological conditions, which may be the consequence of not taking into account thermally driven flows, may very well to a large extent be compensated by an underestimated wind speed in the same area during other meteorological conditions. A more typical estimate of the error in wind speed introduced by ignoring temperature differences between land and sea is given by the RMS errors, which are of the order $8 \%$, as compared to the $\pm 2 \%$ errors in annual average wind speed error.

Table 1: Root-mean-square errors of mean wind speed differences (\%) between MIUUmodel runs without and with land/sea temperature differences. Data from offshore grid points over the Baltic Sea. Monthly mean and extreme values at the heights $12 \mathrm{~m}, 48 \mathrm{~m}$, and $103 \mathrm{~m}$.

\begin{tabular}{|l|c|c|c|c|}
\hline Month & Height & \multicolumn{3}{|c|}{ RMS } \\
\hline & & Mean & Max & Min \\
\hline \multirow{3}{*}{$\begin{array}{l}\text { Januar } \\
\text { y }\end{array}$} & 12 & 9.8 & -52.0 & 68.2 \\
\cline { 2 - 5 } & 48 & 7.3 & -41.0 & 48.9 \\
\cline { 2 - 5 } & 103 & 9.8 & -33.0 & 46.8 \\
\hline \multirow{4}{*}{ April } & 12 & 10.8 & -28.4 & 44.8 \\
\cline { 2 - 5 } & 48 & 6.3 & -21.4 & 31.4 \\
\cline { 2 - 5 } & 103 & 7.4 & -23.6 & 27.3 \\
\hline \multirow{3}{*}{$\begin{array}{l}\text { Octobe } \\
\text { r }\end{array}$} & 12 & 10.4 & -20.6 & 53.0 \\
\cline { 2 - 5 } & 48 & 8.0 & -21.0 & 47.1 \\
\cline { 2 - 5 } & 103 & 8.2 & -27.0 & 45.1 \\
\cline { 2 - 5 } & 12 & 8.4 & -26.9 & 75.3 \\
\cline { 2 - 5 } & 103 & 6.1 & -21.2 & 62.5 \\
\hline
\end{tabular}

\section{Summary and conclusions}

Observations of offshore winds over the Baltic Sea show complexity and inhomogeneity to a much larger extent than has earlier been expected. As not much data exist of true offshore winds, the need for models to map the wind potential is obvious. Results with the MIUU-model show that with this type of model the complex and inhomogeneous wind fields also turn up in the model results. At the same time it is obvious that more simple models, like the commonly used $\mathrm{WA}^{\mathrm{S}} \mathrm{P}$, do not include the physics needed to get the complex offshore winds.
A method to simulate the climatological wind field using a three-dimensional higher order closure mesoscale model (the MIUU model) is described. A number of simulations are performed, with different wind and temperature conditions, and a weighting based on climatological data for the geostrophic wind is made to estimate the wind climate. The method is applicable for mapping the wind resources with a resolution of 1-10 km. To use this method geostrophic wind (strength and direction), sea and land temperatures, topography, and roughness are needed. Comparisons between model results and measurements show good agreement.

The MIUU-model was further used to investigate the importance of land/sea temperature differences on the offshore wind climate. The effects on the monthly averages were found to be of the order $-14 \%$ to $+14 \%$. But the effects are much more pronounced looking at runs for individual meteorological conditions and for specific wind directions. Here the differences vary between $-40 \%$ and $+40 \%$. When averaging over all wind directions, the differences are reduced as a region might have too high winds, not taking account of thermally driven flows, for some conditions, while for other conditions wind estimates in the same region might be too low excluding the thermal forcing. A typical value of the offshore annual average wind speed error at $48 \mathrm{~m}$ height over the Baltic Sea thus turns to be as small as $\pm 2 \%$, and in the extreme being between $-6 \%$ and $+4 \%$.

The RMS-error of the wind speed differences between estimates not taking account of and including effects from thermally driven flows give an alternative and more relevant estimate of the errors. The RMS was estimated to be 6$11 \%$ as judged from errors determined on a monthly basis as the average over all offshore grid points within the Baltic Sea area in the model domain, that is about five times larger than the $\pm 2 \%$ errors arrived at by just looking at typical errors in the annual average wind speed. The most extreme RMS errors found offshore were $-52 \%$ and $+75 \%$.

\section{References}

Andrén, A., 1990: Evaluation of a turbulence closure scheme suitable for air pollution applications. J. Appl. Meteor., 29, 224-239.

Bergström, H., 2001: Estimating Offshore Wind Potential - a more complex task than 
expected? Proceedings EWEC'2001, Copenhagen $3^{\text {rd }}-7^{\text {th }}$ July 2001.

Bergström, H., 1996: A climatological study of boundary layer wind speed using a meso$\gamma$-scale higher-order closure model. J. Appl. Meteor., 35, 1291-1306.

Bergström, H. and Källstrand, B., 2001: Estimating Wind Potential in a Complex Terrain Arctic Mountain Valley. Proceedings EWEC'2001, Copenhagen $3^{\text {rd }}$ $-7^{\text {th }}$ July 2001.

Bergström H. and Källstrand K., 2000: Measuring and modelling the wind climate in a mountain valley in northern Sweden. Proceedings, Boreas V, 29 Nov.-1 Dec. 2000, Levi, Finland.

Blackadar, A. K., 1957: Boundary layer maxima and their significance for the growth of nocturnal inversions. Bull. Amer. Meteor. Soc., 38, 283-290.

Enger, L., Koracin, D. and Yang, X., 1993:'A Numerical Study of the Boundary-layer Dynamics in a Mount Valley. Part 1: Model Validation and Sensitivity Experiments', Boundary-Layer Meteorol., 66, 357-394.

Enger L., 1990: Simulation of dispersion in a moderately complex terrain. Part A. The fluid dynamic model. Atmos Environ., 24A, 2431-2446.

Koracin, D. and Enger, L., 1994: A Numerical Study of the Boundary-layer Dynamics in a Mount Valley. Part 2: Observed and Simulated Characteristics of Atmospheric Stability and Local Flows, Boundary-layer Meteorol., 69, 249-283.

Källstrand B., Bergström H., Højstrup J., and Smedman A.-S., 2000: Mesoscale wind field modifications over the Baltic Sea. Boundary-Layer Meteorol., 95, 161-188.

Källstrand B., 1998: Low Level Jets in a Marine Boundary Layer During Spring, 1998: Contribution to Atmospheric Physics, 71, 359-373.

Källstrand B. and Smedman A.-S., 1997: A case study of the near-neutral coastal internal boundary-layer growth: Aircraft measurements compared with different model estimates. Boundary-Layer Meteorol., 85, 1-33.

Mellor, G. L., and T. Yamada, 1974: A hierarchy of turbulence closure models for planetary boundary layers. J. Atmos. Sci., 31, 1791-1806.
Mohr M., 1997: Comparison of simulations with two mesoscale models, the MIUU model and the KAMM model, using two low-level jet cases over the Baltic Sea. Wind Energy Report WE97:2, Dep. of Meteorol., Uppsala University, 107 pp.

Pielke, R. A., 1984: Mesoscale Meteorological Modelling. Academic Press, 612 pp.

Smedman, A., H. Bergström, and B. Grisogono, 1997: Evolution of stable boundary layers over a cold sea. J. Geophys. Res., 102,1091-1099.

Smedman, A., H. Bergström, and U. Högström, 1996a: Measured and modelled local wind field over a frozen lake in mountainous area. Beitr. Phys. Atmosph., 69, 501-516.

Smedman, A., U. Högström, and H. Bergström, 1996b: Low level jets - a decisive factor for offshore wind energy siting in the Baltic Sea. Wind Engineering.20, 137-147.

Sandström, S., 1997: Simulations of the Climatological Wind Field in the Baltic Sea Area using a Mesoscale Higher-Order Closure Model, J. Appl. Meteor., 36, 1541 1552. 


\section{SODAR MEASUREMENTS OF OFFSHORE WAKES}

Luuk Folkerts, (Ecofys bv, P.O. Box 8408, NL-3503 RK Utrecht, the Netherlands, tel.+31302808300, L.Folkerts@ecofys.nl),

Rebecca Barthelmie and Peter Sanderhoff (Risø National Laboratory, Roskilde, DK), Frank Ormel and Peter Eecen (Energy Research Centre of the Netherlands (ECN), Petten, NL), Oliver Stobbe (Ecofys Energieberatung und Handelsgesellschaft mbH, Köln, DE).

ABSTRACT: In April 2001 the first offshore wake measurements with a SODAR were conducted at Vindeby. Wake effects were measured at distances from the turbine varying from 1.4 to 7.1 rotor diameters. The corresponding calculated relative velocity deficits cover a range from $12 \%$ up to $56 \%$. The recorded wake profiles provide excellent reference cases for the development and evaluation of offshore wake models.

1

\section{INTRODUCTION}

The ENDOW project (Barthelmie et al., 2001) aims to reduce uncertainties in estimating power production introduced due to wake effects in large offshore wind farms. The major objectives are to evaluate wake models in offshore environments and to develop and enhance existing wake and boundary-layer models accounting for complex stability variations to produce a design tool to assist planners and developers in optimising offshore wind farms.

To provide additional data on offshore wakes and to form part of the evaluation process for wake models within the ENDOW project a large-scale experiment was conducted at the $5 \mathrm{MW}$ offshore wind farm at Vindeby in Denmark. Especially in near-wake situations, very few data sets are available, even for land sites.

For the first time, a SODAR mounted on a boat was used to measure wind profiles in the turbine wake in an offshore wind farm. Selective operation of turbines in carefully monitored conditions reflecting wind speed, wind direction and atmospheric stability allow the direct impact of turbine operation on wake effects to be measured at varying distances from the turbine. Use of a SODAR provided vertical wind speed profiles to hub and rotor heights, which supplements ongoing measurements on three meteorological masts.

\section{EXPERIMENT}

The measurement campaign was conducted at the Vindeby wind farm in Denmark during the period 21-28 April 2001. The Vindeby farm consists of 11 BONUS $450 \mathrm{~kW}$ turbines in two rows oriented towards the southwest. The hub-height is $38 \mathrm{~m}$ and the rotor diameter is $35 \mathrm{~m}$. The distance between two adjacent turbines is $300 \mathrm{~m}$. This site was chosen because it is one of very few operating offshore wind farms and has three monitoring masts (two offshore and one at the coast) providing detailed meteorological measurements to $50 \mathrm{~m}$ height. The site has the advantage of relatively low water depth (2-5 $\mathrm{m})$ offering the possibility of relatively low wave heights and swell.

The SODAR used was an Aerovironment mini-SODAR model 3000 equipped with a model 4000 speaker array, operating at 4500 $\mathrm{Hz}$. The SODAR was mounted on a ship, $5.5 \mathrm{~m}$ wide and $18.6 \mathrm{~m}$ long ('Seaworker', Figure 1). 


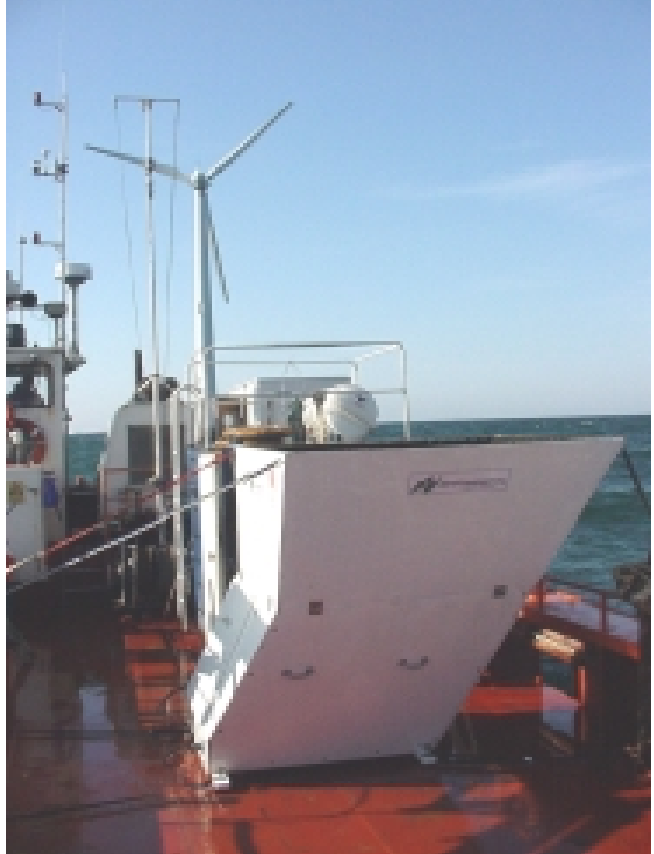

Figure 1. SODAR mounted on the ship 'Seaworker' at the Vindeby wind farm.

Accurate position and orientation of the SODAR were determined using GPS and compass. Positioning of the boat in the direct wake of a wind turbine, using 3 anchors, took approximately 40 minutes. Profile measurements were taken over period of approximately half an hour. Free stream reference measurements were conducted with the wind turbine in question switched off.

The movement of the SODAR was monitored with an inclinometer, recording both the longitudinal and transversal tilt angles (see figure 2). Considering the operation of the SODAR, only data taken with limited swing $(< \pm 2$ degree $)$ was accepted in the analysis.

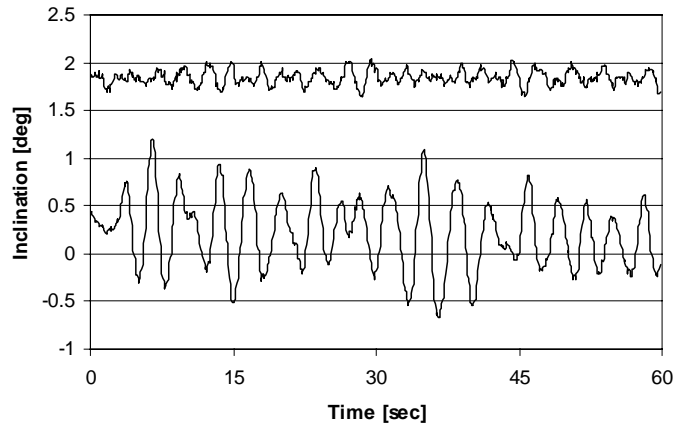

Figure 2. Recorded longitudinal (upper line) and transversal (lower line) tilt angles.

Variation in distance from the turbine was an important goal of the experiment. We succeeded in getting useful wake profiles at a minimum distance of 1.4 rotor diameters, and up to 7.1 rotor diameters. Especially at the larger distance, small variations in the wind direction mean that the SODAR moves in and out of the centre of the wake. Using the wind direction of the mast SMW, the off-center distance (or angle) can be calculated. Only data near the wake center was accepted in the analysis.

Figure 3 shows the layout of the wind farm at Vindeby and the positioning of the SODAR at 3.5 rotor diameters behind turbine $1 \mathrm{~W}$.
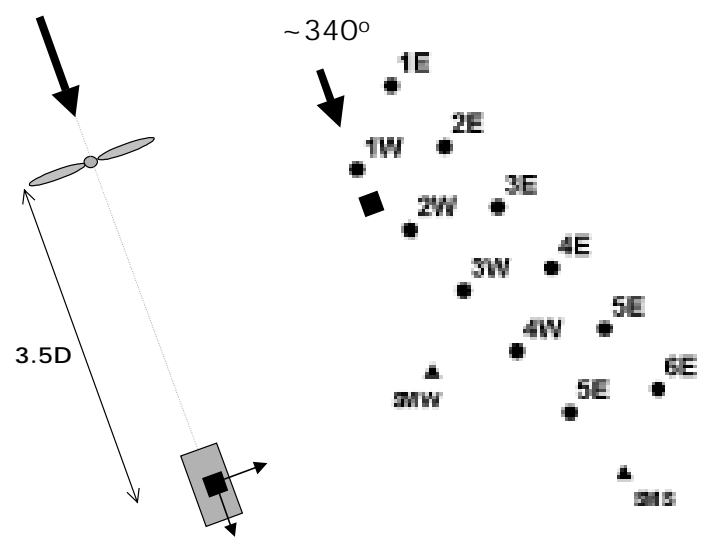

Figure 3. Layout of the wind farm at Vindeby ( $\bullet$ shows each wind turbine and $\boldsymbol{\Delta}$ the two sea masts) and the positioning of the SODAR ( $\mathbf{})$ in the wake of turbine $1 \mathrm{~W}$. On the left the positioning of the SODAR is shown in more detail. 


\section{RESULTS}

The first experiment was taken at approximately $3.5 \mathrm{D}$ (rotor diameter $\mathrm{D}=35 \mathrm{~m}$ ) in the direct wake of turbine $1 \mathrm{~W}$ and the wake measured for approximately 40 minutes. During this period the wind direction was $343 \pm 2^{\circ}$ and the stability at the land mast was near-neutral.

The average wind profiles for wake measurement and the corresponding free stream measurements are shown in figure 4. Resulting wind profiles were composed by averaging over the recorded one-minute profiles. The resulting standard deviation on the averaged wind speeds consists of both actual variations in the wind speed as well as deviations resulting from the measuring technique.

Average wind speeds measured at $50 \mathrm{~m}$ (at the land mast) decreased by $15 \%$ between the free stream and wake measurement. A correction is applied to increase the SODAR wake profile accordingly.

The figure also shows the calculated relative velocity deficit (defined as in (Hogstrom et al., 1988) as):

$$
\Delta \mathrm{U} / \mathrm{U}_{\text {freestream }}=1-\mathrm{U}_{\text {wake }} / \mathrm{U}_{\text {freestream }}
$$

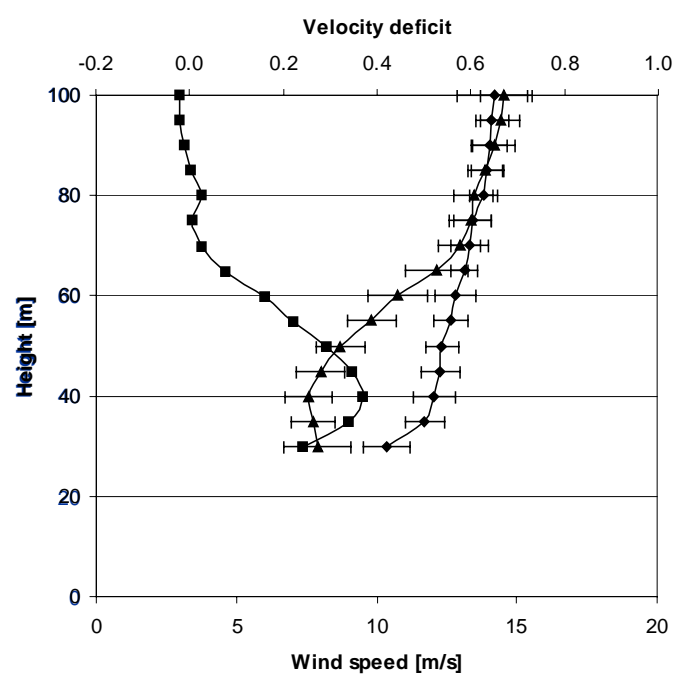

Figure 4. Profile of the free stream wind $(\bullet)$ and the wake profile $(\boldsymbol{\Delta}$, corrected for the change in free wind speed) measured at 3.5D behind turbine $1 \mathrm{~W}$. Also shown is the calculated relative velocity deficit ( $\mathbf{n}$, top axis).
As expected, the velocity deficit is approximately zero well above the tip height of the rotor. The maximum velocity deficit in this case is $37 \%$ around hub-height.

During the wake measurements (turbine on), variation in the wind direction meant that the SODAR profile was taken at various distances from the centre of the wake. This was especially critical at the larger distances. In the analysis of the wake profile taken at 7.1D a gate was set to only include profiles near the centre of the wake. The maximum displacement from the wake centre allowed is $0.5 \mathrm{D}$.

Figure 5 shows the measured wake profile at 7.1D behind turbine $1 \mathrm{E}$, the corresponding free stream profile and the calculated relative velocity deficit. The velocity deficit at hub height at this distance amounts to about $12 \%$.

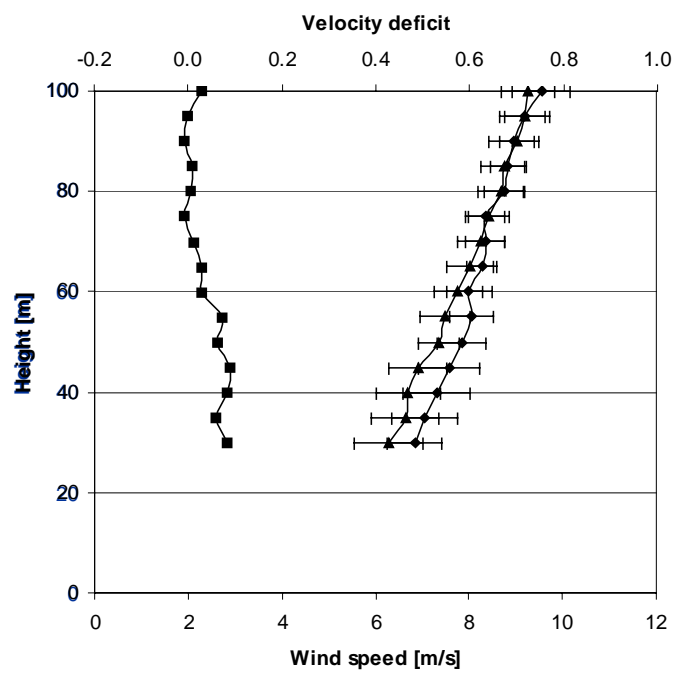

Figure 5. Profile of the free stream wind $(\bullet)$ and the wake profile $(\boldsymbol{\Lambda}$, corrected for the change in free wind speed) measured at 7.1D behind turbine 1E. Also shown is the calculated relative velocity deficit ( $\mathbf{\square}$, top axis).

Wake profiles were measured at 13 different positions. The corresponding calculated maximum relative velocity deficits are shown in figure 6 as a function of the distance. The line in figure 6 is a meant to 'guide the eye' to the obvious trend. 


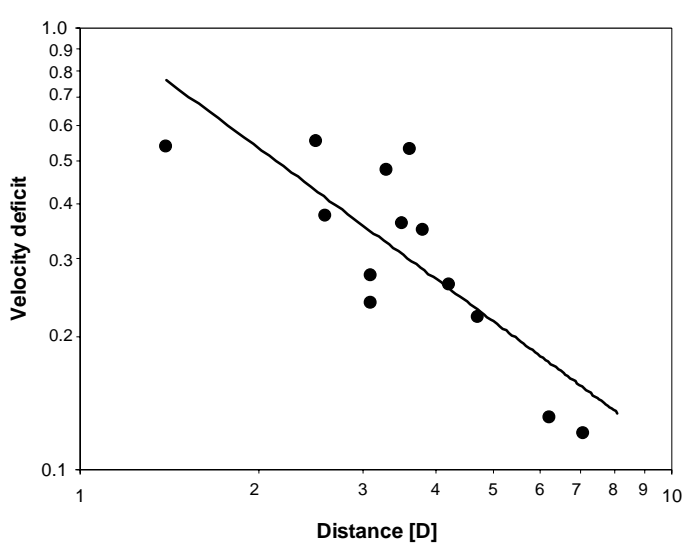

Figure 6. Relative velocity deficit by distance (shown here as number of rotor diameter). The trendline is a fit to the points 'to guide the eye'.

\section{FUTURE WORK}

The ENDOW project focuses on the evaluation and development of wake models for use in an offshore environment. The six partners performing wake modelling within the project and a brief description of the models are given in (Barthelmie et al., 2001). So far, comparison of the model output with experimental results was limited to the Vindeby mast measurement at $8.6 \mathrm{D}$. The results from the here described experiment provide near-wake wind speed profiles for further direct comparison with the various wake models in the ENDOW project.

\section{ACKNOWLEDGEMENTS}

Financial support for this research was given in part by the European Commission's Fifth Framework Programme under the Energy, Environment and Sustainable Development Programme. Project Reference: ERK6-1999-00001 ENDOW (Efficient Development of Offshore Windfarms). Additional funding was supplied by NOVEM for Ecofys and ECN.

\section{REFERENCES}

Barthelmie, R., et al., 2001: Efficient development of offshore windfarms: wake and boundary-layer interactions, EWEA Offshore Conference, December 2001, Brussels, (these proceedings).

Hogstrom, U., Asimakopoulos, D.N., Kambezidis, H., Helmis, C. and Smedman, A., 1988: A field study of the wake behind a 2 MW wind turbine. Atmospheric Environment, 22(4), 803820. 


\title{
LARGE OFF-SHORE WINDFARMS: LINKING WAKE MODELS WITH ATMOSPHERIC BOUNDARY LAYER MODELS
}

\author{
Gerard Schepers, Energy Research Centre of the Netherlands, Wind Energy, 1755 ZG Petten, THE \\ NETHERLANDS \\ Rebecca Barthelmie, Wind Energy Department, Risø National Laboratory, 4000 Roskilde, \\ DENMARK, \\ Kostas Rados, The Robert Gordon University, School of Mechanical and Offshore Engineering, \\ Aberdeen AB10 1FR, SCOTLAND \\ Bernhard Lange, Dept. of Energy and Semiconductor Research EHF, University of Oldenburg, \\ D-26111 Oldenburg, GERMANY \\ Wolfgang Schlez, Garrad Hassan and Partners Ltd, Bristol BS2 0QD, UK
}

\section{INTRODUCTION}

One of the main objectives of the EU-5th Framework project ENDOW (Efficient Development of Off-Shore Wind Farms) is to develop a design tool, which calculates the power production of a large off-shore wind farm. This design tool will consist of an atmospheric model coupled with a wake model. An atmospheric model is meant to calculate the free flow in off-shore conditions, taking into account terrain and meteorological effects, but usually no wind turbines and resulting wake effects are included. The wake model is then meant to fill this gap, i.e it calculates the disturbance from a wind turbine on the initial flow, where meteorological and terrain effects are usually not included in the principal wake calculations. Some wake models assume that the outer atmospheric flow remains constant over the farm and as a consequence the flow at infinity returns to the initial flow field again. Other wake models calculate a wake deficit under the assumption of a constant outer flow, and superimpose this wake deficit on a (possibly) varying outer flow.

Within the ENDOW project various candidate atmospheric and wake models are available to be incorporated into the design tool. In order to gain insight into the suitability of the various models and in the way how they can be linked, a questionnaire has been distributed between the various modelling partners. Using the response on the questionnaire an inventory of the different models has been made with emphasis on the items which determine the compatibility of the different models. Aspects, which are of importance for this compatibility are consistancy from a physical point of view, but also consistancy from an informatic point of view (i.e. input/output, platform, compiler etc.).

In the paper the first results from the questionnaire are summarized. Thereto Section 2 gives a brief description of the questionnaire. This is followed by section 3 and 4, in which the response on the wake and the atmospherice models is summarized. In section 5 some first ideas on the interfacing are proposed.

It must be noted that the present inventory is very preliminary: Many answers on the questionnaire are still lacking and the paper is mainly intended to serve as food for discussion within the project group.

\section{DESCRIPTION OF THE QUESTIONNAIRE}

In the questionnaire, questions are posed on the physics of the models, the input and output of the models, the grid, the platform, compiler, the computational effort, possible convergence problems, as well as many related items.

\section{QUESTIONNAIRE, THE WAKE MODELS}

\section{Available wake models}

Until February 2002, answers on the questionnare were only available from:

- The Energy Research Center of the Netherlands, ECN: (The WAKEFARM program)

- Robert Gordon University, RGU: (A 3DNS program)

- University of Oldenburg (UO): (The FlaP program)

- Garrad Hassan and Partners (GH): (WindFarmer) 


\section{Wake cases, Statistics, Analysis of wind farm lay-out}

In the response on the questionnaire some confusion became apparent because of the fact that participants apply the wake models differently. Basically, all participants run the wake models for separate cases, i.e. the wake is calculated for a particular (mean) ambient wind speed, turbulence intensity, wind direction, Monin-Obukhov length scale etc. However some additional processing is needed in order to determine the power production of a wind farm.

- A tool is required which determines the wake distances and the multiple wake situations from the lay-out of the wind farm. This information is used as additional input to the wake cases;

- The wake wind speeds should be processed to a rotor averaged wake wind speed from which the power of the turbine is derived using the power curve;

- Then a summation of the different wake cases should be performed, using the appropriate frequency distributions of the free stream conditions, in order to obtain the resultant annual energy production.

The summation, the calculation of power production and the analysis of the wind farm lay-out are essential parts of the design tool, but they are not considered to be part of the wake modelling itself. For the present purpose, the modelling of the separate wake cases will form the basis for the questionnaire. Note that all wake models in the ENDOW project are already integrated with a wind farm model, which determines the required wake cases and sums the wake cases over the appropriate distributions.

\section{Wake models: Physical description}

- ECN: ECN's program is a slightly modified version of the UPMWAKE program [1], which has been developed by the Universidad Politecnica de Madrid. It is a parabolic method in which the turbulent processes in the far wake are modelled through a k- $\varepsilon$ model. The wake is initialised at $2 \mathrm{D}$. The near wake is modelled with the standard momentum theory, to which empirical corrections are added.
- RGU has developed a fully elliptic turbulent 3D Navier-Stokes numerical solver (3D-NS) with $\mathrm{k}-\varepsilon$ turbulence closure based on a previous axisymmetric model [6]. Initial data required to start the 3D-NS calculations are the velocity and turbulence intensity profiles in the atmospheric boundary layer upstream the rotor (ambient atmospheric conditions). The computational domain includes the rotor of the wind turbine(s), which is approximated by means of a semipermeable disk to simulate the pressure drop across a real rotor disk (thrust).

- UO: The wind farm model FLaP of UO uses an implementation of the wake model proposed by Ainslie, 1988 [2]. It is a twodimensional (axi-symmetrical) model solving the momentum and continuity equations with an eddy-viscosity closure. The eddy-viscosity is modelled as a combination of contributions from the ambient turbulence of the free flow and the shear generated turbulence in the wake. The wake model starts at a distance of $2 \mathrm{D}$ behind the rotor with an empirical wake profile as boundary condition.

- GH: Similar to the UO model

\section{Wake models: Grid}

- ECN: Output is generated in an orhogonal grid:

- Size in flow direction: $0.25 \mathrm{D}$

- Size in lateral direction:

Approximately $\mathrm{D} / 7$

- Size in vertical direction:

Approximately D/7

Note that grid-sizes in lateral and vertical direction are thrust dependant, because they are related to the so-called expanded diameter.

- RGU: Output is generated in a nonuniform orthogonal grid:

- Flow direction: $\mathrm{D} / 10$ grid length at the turbine locations.

- Lateral direction: Approximately D/10 at the rotor tip (minimum).

- Vertical direction: Approximately $\mathrm{D} / 50$ minimum close to the ground/sea and $\mathrm{D} / 10$ at the rotor tip 
Note: The orthogonal grid is dense close to the turbines and the ground/sea plane

- UO

- Axi-symmetric 2-dimensional grid

- Typical grid distances: radial 0.033D, axial $0.5 \mathrm{D}$

- $\mathrm{GH}$

- Axi-symmetric 2-dimensional grid

- Typical grid distances: radial 0.1D, axial $0.2 \mathrm{D}$

Wake models, Input of atmospheric conditions

- ECN: Friction velocity, roughness height $\left(\mathrm{z}_{0}\right)$ and Monin-Obukhov length scale L (Or wind speed $\mathrm{U}(\mathrm{z})$, turbulence intensity $\mathrm{I}(\mathrm{z})$ and $\mathrm{L})$, wind direction. For the wind farm model [4], frequency distributions are needed as well.

- RGU: Wind speed, $U\left(\mathrm{z}_{\mathrm{ref}}\right)$, turbulence intensity $\mathrm{I}\left(\mathrm{z}_{\mathrm{ref}}\right)$ at a reference height and Richardson number or equivalently Monin-Obukhov length scale, wind direction

- OU:

- In time series mode (case studies): Wind speed $\mathrm{U}\left(\mathrm{z}_{\mathrm{ref}}\right)$, wind direction, turbulence intensity $\mathrm{I}\left(\mathrm{z}_{\mathrm{ref}}\right)$, MoninObukhov-length scale

- In climatology mode: wind direction dependent frequency distributions of wind speed, mean turbulence intensity and stability

- GH: Frequency distributions (P,A,k) of wind and ambient turbulence intensity

\section{Wake models, Input of wind farm lay-out}

Several formats are apparent, but basically the positions of the turbines are defined by means of the $\mathrm{x}, \mathrm{y}$ coordinates of the turbines.

\section{Wake models, Description of Turbine}

Basically all wake models describe the wind turbines by means of diameter, hub height and thrust curve of every turbine (and power curve if power of downwind turbines is to be calculated).
Wake models, Unequal spacing and different turbines:

The question was posed whether it is possible to model wind farms with unequal spacing between the turbines and with different turbine types. This is possible for all wake models. In ECN's, GH's and OU's wake model, the minimum distance between the turbines should be approximately 2D (due to the initialisation of the wake).

\section{Wake models, Output}

- ECN: For every x-position a file can be generated with data on the $\mathrm{y}_{\text {lat }}, \mathrm{z}_{\mathrm{vert}}$ grid points: $\mathrm{u}, \mathrm{v}, \mathrm{w}, \mathrm{k}, \varepsilon, \mathrm{T}$ (Turbulence intensity and turbulent length scales can be derived). Hence the output which is generated are statistical, averaged, data. In the windfarm model [4], a summation to power output is performed, using approprate frequency distributions of the different wake cases;

- RGU: For every cell of the computational domain a file can be generated with data on the $\mathrm{x}$-flowdirection, $\mathrm{y}_{\text {lat }}, \mathrm{z}_{\mathrm{vert}}$ grid points: $\quad \mathrm{u}, \mathrm{v}, \mathrm{w}, \mathrm{k}, \varepsilon$ (Turbulence intensity and turbulent length scales can be derived). Power is obtained indirectly from the rotor averaged wind speed and a power curve.

- UO:

- Gaussian wind profile and mean I at specified x-position or:

- (Wind farm model) Wind speed at specified points or;

- (Climatology mode) Annual mean wind speeds at specified points.

- Power

- GH: Wind speed, turbulence, energy production

\section{Wake models: Platform}

- ECN: Unix Workstation or PC;

- RGU: Unix Workstation or PC with Linux

- OU and GH: PC with MS-Windows-xx

\section{Wake models: Compiler}

- ECN and RGU: Fortran 77(90)

- OU: Borland Pascal and $\mathrm{C}++$

- $\mathrm{GH}: \mathrm{C}++$ 
Wake models: Calculational time

- ECN: Order of 1 minute for a quintuple 9.5D calculation on a Unix work station comparable to a $500 \mathrm{MHz}$ PC

- RGU: Order of 12 hours for a single wake calculation on a Unix work station comparable to a $500 \mathrm{MHz}$ PC

- OU and GH: Seconds

\section{Wake models: Convergence}

- ECN: In $99 \%$ of the cases. The program may crash at low wind speeds near the cutin wind speed in combination with low turbulence intensities.

- RGU, OU and GH: Always

\section{QUESTIONNAIRE, ATMOSPHERIC MODELS}

\section{Available atmospheric model}

Until February 2002, answers on the questionnaire were received from

- RISOE: Coastal Discontinuity Model (CDM)

- RISOE: Wind Atlas Analysis and Application Program (WAsP)

- RISOE: WAsP Engineering

\section{Atmospheric models: physical description}

- CDM: This is a very simple model based on stability and roughness changes to a wind speed profile moving offshore. An earlier version was described in [3] and more recently it is described in the report to the EC from the POWER project (forthcoming).

- WAsP: see http:// www.wasp.dk/Program_Features.htm. WAsP constitutes a complete analysis and application package. Wind data, whether in the form of a time series or a climatological table, can be transformed into regional wind atlases. Such data may be the users own measurements or general climatological data. The program can be applied directly for estimation of wind climate with wind atlas data from the Danish and the European Wind Atlases and corresponding data collections from other countries - all over the world. WAsP has a number of sub-models for correcting the wind flow behind obstacles, in complex terrain and for roughness changes. The wake model in Park uses momentum deficit theory where the wake is assumed to expand linearly behind the model.

- WAsP-engineering:

http://www.waspengineering.dk The mean flow model at the heart of WAsP Engineering has been used at Risoe for more than 15 years (LINCOM). It has been used in many different contexts and a modified version is the central algorithm in WAsP. In addition, WAsP Engineering incorporated various new algorithms: A model for the description of roughness over water (Charnock), a component to model the effect of roughness changes and orography on turbulence, and a procedure to estimate the 50-year storm over complex terrain. The base of this version of the code, giving the influence of the topography on the flow of a neutrally stratified atmosphere, has been extended by Astrup et al (1997) with a model for the influence of varying surface roughness. This extension was based on the assumption that close to the ground the flow is in equilibrium with the local surface roughness, and on a complicated model for the vertical extent of this equilibrium zone. Later the model has been extended to calculate spatial derivatives of the mean wind field, such as the vertical shear $\mathrm{dU} / \mathrm{dz}$, which is used in the turbulence modeling. LINCOM is based on an analytical solution in Fourier space to a set of linear equations derived from the normal non-linear mass- and momentum equations for incompressible fluid flows. The linear equations describe the perturbations in velocity and pressure, which the real terrain induces in an equilibrium flow corresponding to a flat terrain with uniform surface roughness. The perturbations caused by horizontal gradients in ground elevation and surface roughness are determined separately and added as a first order approximation to the combined perturbation. Another difference from WAsP is that LINCOM has a more realistic treatment of the inner layer, i.e. the layer close to the ground where perturbations in the turbulent momentum transport are important. 
Atmospheric models: Grid

- CDM: Of the order 100-500 m;

- WAsP: The program has a high-resolution, zooming, polar grid. In the centre of the region of interest the grid resolution is of the order $4 \mathrm{~m}$. WAsP can be applied to generate wind fields with varying grids. However, WAsP is a local to mesoscale model - the central assumption is that the regional wind climate is valid for the area of interest which gives its maximum domain of 50-100 km;

- WAsP-eng: The size of the domain should be approximately 100 times the height above the ground in which modelling required. Grid sizes of more than 200 by 200 points requires a very fast computer with vast memory resources and are not recommended. LINCOM calculates the wind vector by Fourier techniques in every mesh point of a rectangular grid. This is appropriate for WAsP Engineering for two reasons. Firstly, to model a wind speed (and fetch) dependent roughness at sea it is necessary to know the wind speed over the entire body of water. Secondly, the turbulence model uses the flow field upwind from the point of interest as input.

\section{Atmospheric models: Input of atmospheric conditions}

- CDM: Either a wind speed profile at the coast or a geostrophic wind speed together with a temperature profile or air-sea temperature difference.

- WAsP: Wind speed and direction

\section{Atmospheric models: Input of wind farm lay-out}

It is reminded that atmospheric models generally do not include the effect of wind turbines. The exception is in the WAsP model, which does include a wake model. The input for this program is basically given by $\mathrm{x}$ and $\mathrm{y}$ coordinates.

Atmospheric models: Description of turbine This question is again only relevant for the WAsP program. This program needs diameter, hub height, power curve and thrust curve (if wake effects are to be calculated).
Atmospheric models, Unequal spacing and different turbines:

The question was posed whether it is possible to model wind farms with unequal spacing between the turbines and with different turbine types. Again this question is only relevant for the wake model in the WAsP program. In the current version of WAsP, only one wind turbine type can be modelled, with a minimum distance between the turbines of approximately 4D.

\section{Atmospheric models, Output}

- CDM: Usually a wind speed profile, turbulence, Monin-Obukhov length scale and the wind direction.

- WAsP: Wind speed, wind direction distribution

- WAsP-eng: WAsP Engineering 1.0 has five different reports:

- Extreme wind report: 50 year winds for all sites and all heights.

- Site report: The mean wind speed for the selected site for all winds and heights.

- Detailed site report: Various mean flow parameters and turbulence intensities for a single wind at a single height.

- Turbulence for winds report: Horizontal wind, velocity tilt and horizontal turbulence intensity for all defined winds for a chosen height and site.

- Turbulence transect report: Wind speed, direction, velocity tilt and the two horizontal turbulence intensities.

In summary the most relevant output of the WasP engineering model for the present purposes is then the wind speed, the turbulence intensity and the wind direction at a particular height.

\section{Atmospheric models: Platform}

- CDM: PC or UNIX

- WAsP: PC

- WAsP-eng: PC Windows 98, Windows NT 4.0 and Windows 2000. Needs Word for the reporting tool.

\section{Atmospheric models: Compiler \\ - CDM: Fortran 77- or LF95 \\ - WAsP: Not relevant}


- WAsP-eng: Not relevant

\section{Atmospheric models: Calculational time}

- CDM: Depends on the input and model version. Can be fast (minutes) or slow (hours) depending how many iterations are needed. Thus this depends on the number of grids and the type input data available.

- WAsP: Minutes

WAsP-eng:

Minutes, but under all the windows there is some computationally demanding code which really stretches the limits of what most of today's desktop computers can support. For a normal size project with a full 12 sector extreme wind climate analysis, then the program may well need about $300 \mathrm{MB}$ of memory, and could keep the machine very busy for about five minutes. A machine with at least $128 \mathrm{MB}$ physical RAM and a processor of at least $500 \mathrm{MHz}$ is recommended.

\section{Atmospheric models: Convergence}

- CDM: Not always. Sometimes no solution is found for the stability part although it could probably be forced to a reasonable value.

- WAsP: Always.

- WAsP-eng: No definite conclusion on this subject yet, but it seems stable.

\section{INTERFACING, SOME IDEAS}

An important aspect which has to reminded is that all wake models assume a constant outer atmosphere over the farm, when calculating the wake effects itself (although some participants superimpose the wake deficit on the varying outer atmospheric flow). As such, the variations predicted by the atmospheric models on a scale, which is smaller than the size of the farm are ignored in the modelling of the wake itself.

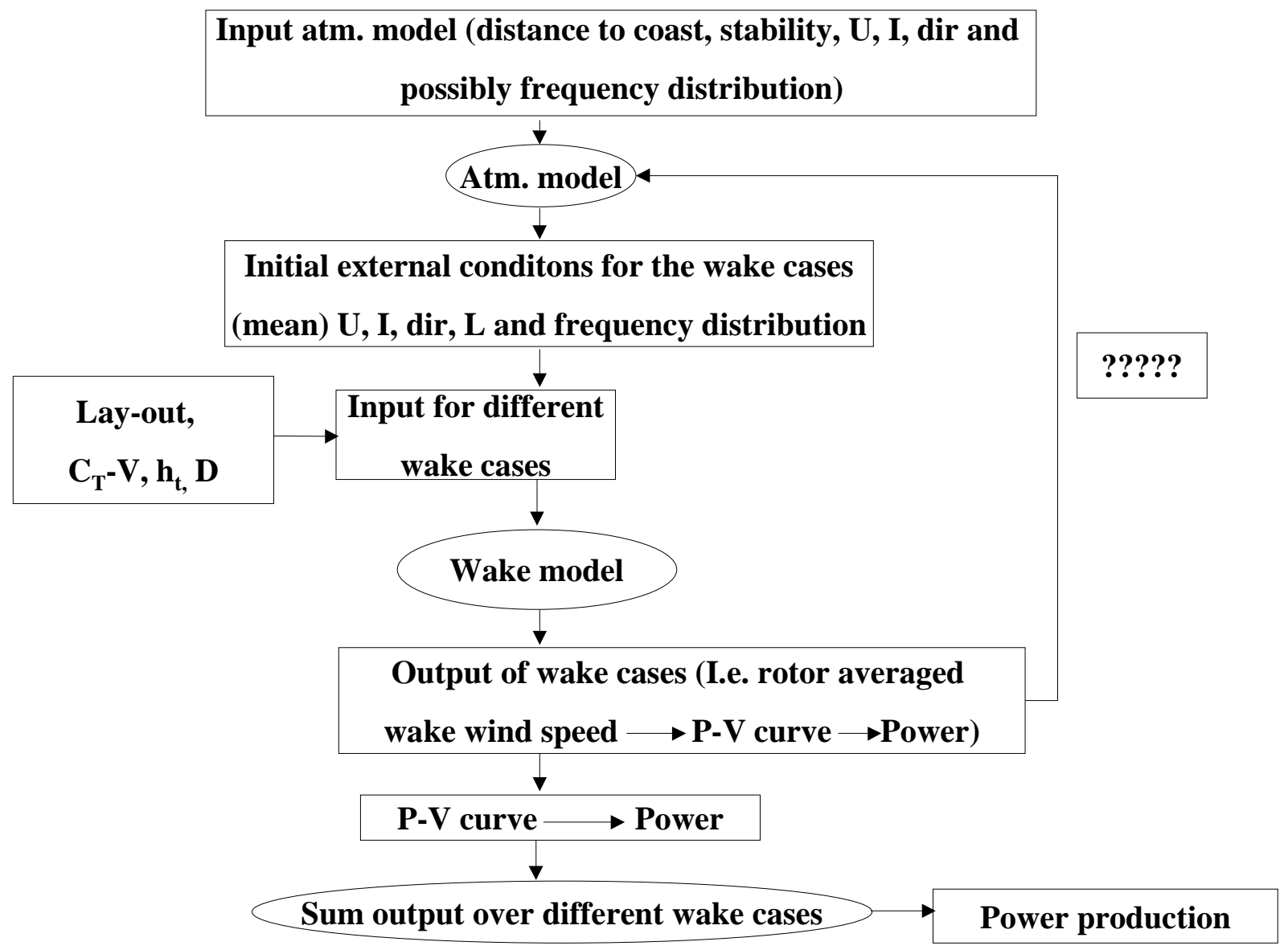


It is proposed to make a modular set-up for the design tool. The coupling between the atmospheric model and the wake model is established by means of input/output files with a prescribed format

The modular approach makes it possible to 'plug-in' different atmospheric and wake models, where only compatibility of the input/output files should be assured.

The most simple coupling is then given by a ' 1 way route': The output from an atmospheric model is used as input for a wake model. Hence it is only the output from the atmospheric models which should be made compatible to the input of the wake models, i.e. the initial external conditions for the different wake cases to be calculated by the wake models, should be provided by the atmospheric models. Basically the following atmospheric input is needed by the wake models (See section 3.5):

- (Mean) Wind speed at a particular height (or wind profile);

- (Mean) Turbulence intensity at a particular height (or profile);

- (Mean) Monin-Obukhov length scale (for most models);

- (Mean) Wind direction

Note that the frequency distributions of the above given quantities are also required. These frequency distributions should either be provided by the atmospheric models, or the atmospheric models are ran for particular cases which are summed over their frequency distribution. Additional input for the wake models should be provided by a wind farm tool, which translates the lay-out of the farm to the appropriate input data for the different wake cases.

Hence the design tool is merely a script which subsequently calls the atmospheric model and the wake model. It is anticipated that executables of the atmospheric and wake models will be used, in order to overcome, at least partly, the problem of property rights. After the wake cases have been calculated, the power production of the wind farm can easily be calculated by summation over the above mentioned frequency distributions. However, when the required input data for the wake models are compared with the output data of the atmospheric models (compare in the previous sections) some incompatibilities become apparent. Most wake models require the Monin-Obukhov length scale as input parameter, which is not provided by WAsP and WAsP Engineering. Furthermore, WAsP does not produce a turbulence intensity which is needed by the wake models. The output from the CDM program seems to be most compatible to the required input of the wake models. On the other hand this model may suffer from convergence problems, and it is considered to be much less sophisticated compared to the other atmospheric models. The compatibility between wake and atmospheric models is at present being further investigated, but most likely the atmospheric model will be a combination of the WAsP and the CDM model.

Apart from the one-way route coupling, a more elaborate coupling could be formed by an iteration, where information from the wake models is fed into a revised atmospheric run. The appropriateness of this option is at present still investigated. Among others, the possible influence from the wake model results on the atmospheric models needs to be investigated. It is anyhow clear that such coupling will increase complexity and computational effort of the design tool considerably, where on the other hand it is expected that the gain in accuracy is only limited. Therefore such iteration is not the most likely option to be chosen. Nevertheless a sensitivity study on the importance of this feedback will be conducted, using the CDM model and/or the mesoscale MIUU model from the University of Uppsala.

A third option would be to integrate wind turbine effects directly into an atmospheric model. Thereto the windfarm can be considered as a surface roughness [5] or as a "momentum sink". Another solution would be to include the turbines as pressure drops (where the pressure drop is known from momentum considerations). This is by far the most elegant option but also an option which is most time consuming and for which the resources in the present project are not sufficient. This is among others caused by the fact that a multi-nest meshing is needed with a higher resolution near the turbines.

\section{CONCLUSIONS}

- An inventory has been made of various wake models and atmospheric models, 
which are used in the ENDOW project. The inventory is based on a questionnaire, which has been distributed between the modelling partners;

- On the basis of the inventory some preliminary suggestions are made about the coupling between the atmospheric and wake models which is needed to develop the design tool;

- The most suitable interfacing is probably a ' 1 -way coupling' in which output from the atmospheric models is used as input for the wake models. Thereto the format of the output/input files should be prescribed. A modular approach is suggested in which different wake models and atmospheric models can be plugged in as executables. Alternatives may be an iterative coupling or the full integration of wind turbines into an atmospheric model. Most likely these options cannot be established within the scope of the project, but a sensitivity study on the importance of the feedback loop will be performed within the project;

- Some of the remaining questions are:

- How compatible is the output of the atmospheric models to the input of the wake models?

- Which atmospheric and wake models will be included in the design tool. This will among others depend on the Operating System, under which the design tool will be developed.

- Property rights of the atmospheric and wake models.

\section{ACKNOWLEDGEMENTS}

Financial support for this research was given in part by the European Commission's Fifth Framework Programme under the Energy, Environment and Sustainable Development Programme. Project Reference: ERK6-199900001 ENDOW (Efficient Development of Offshore Windfarms). Additonal funding was supplied by the Dutch Organisation for Energy and the Environment, NOVEM, reference 224.321-9961.

\section{REFERENCES}

[1] Crespo A. et. al. Numerical Analysis of wind turbine wakes, Proceedings of Delphi Workshop on Wind turbine applications, 1985

[2] Ainslie, J, Calculating the flow field in the wake of wind turbines, Journal of Wind Engineering VOLUME 27, 1988, pp213-224 [3] Barthelmie, R. Hojstrup, J and Courtney,M.1995 Assessment of the wind power resource in the coastal zone using results from the Vindeby project British Wind Energy Association Conference 1995, 231

[4] Bulder, B.H. FyndFarm - a wind farm design support tool, Proceedings of the ECWEC conference held at Dublin 1997", pp 246 -- 248,October, 1997

[5] Hegberg, T The effect of large windfarms on the atmospheric boundary layer, ECNWind-memo-01-045

[6] Magnusson, M., Rados, K.G., and Voutsinas, S.G., A Study of the Flow Downstream a Wind Turbine Using Measurements and Simulations, Wind Engineering 20 (1996) 389. 


\title{
STATUS OF THE HORNS REV OFFSHORE PROJECT
}

\author{
J. W. Bonefeld ${ }^{1}$
}

Tech-wise A/S, Kraftværksvej 53, DK-7000 Fredericia,

Phone: +45 7923 3080, fax: +45 7556 4477, e-mail: jw@@techwise.dk

\section{S. Neckelmann ${ }^{2}$}

Tech-wise A/S, Kraftværksvej 53, DK-7000 Fredericia,

Phone: +457923 3338, fax: +45 7556 4477, e-mail: sne@,techwise.dk

\begin{abstract}
As a major element in the Danish energy policy $750 \mathrm{MW}$ offshore wind power facilities are to be erected between 2002 and 2008. The 160 MW Horns Rev Offshore Project in the North Sea is the first of these facilities to come past the drawing board and be given the final erection permit. The project is now so far that all contracts have been concluded in the multi-contract project, which comprises a wind farm with 80 turbines and an interconnection to the grid (offshore substation and a cable leading to the shore and the main high voltage grid). Data have been collected for an evaluation of the feasibility of the project and for EIA purposes and according to the recorded data the mean wind speed is assessed to be $9.7 \mathrm{~m} / \mathrm{s}$. By now the authorities and the owners (Elsam and Eltra) have reached a common ground for the question of settlement and proper legislation has been adopted. The project's construction costs total about DKK 2.0 billion (Euro 268 mio.).
\end{abstract}

Keywords: Energy Policies, North Sea, Demonstration Projects, Off-Shore

\section{Introduction}

A major element in the Danish energy policy in the new millennium is the $750 \mathrm{MW}$ offshore wind power facilities to be erected between 2002 and 2008. The 160 MW Horns Rev offshore project is the first of these facilities.

The project is one of five large-scale demonstration facilities. The establisment of this wind farm should contribute to answering if and if so how the Government's ambitious targets set out in its energy plan "Energy 21" are to be met. According to the energy plan the
Danish waters are to harbour a total of 4000 MW by 2030.

The project is now so far that all contracts have been concluded and the manufacturing is going ahead at full speed to be ready for the erection and commissioning. So now is an appropriate occasion for Transmission System Operator Eltra and the Power Utility Elsam to publish details of the work that has been realised until now and of the planning of future activities.

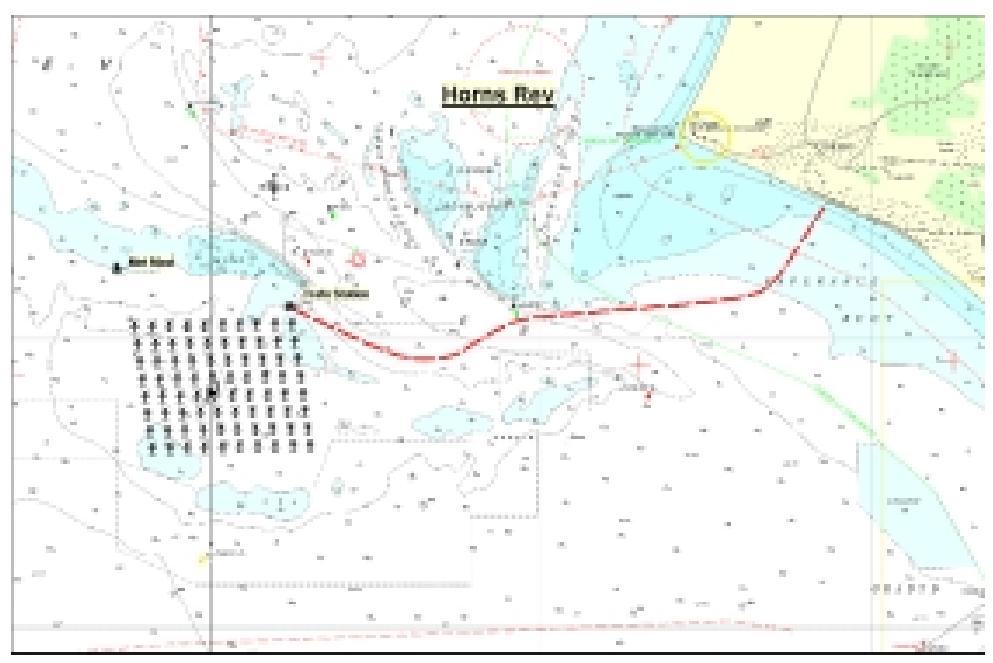

Figure 1. Layout of the Horns Rev Wind Farm.

\footnotetext{
${ }_{, 2}^{12}$ All correspondence
} 


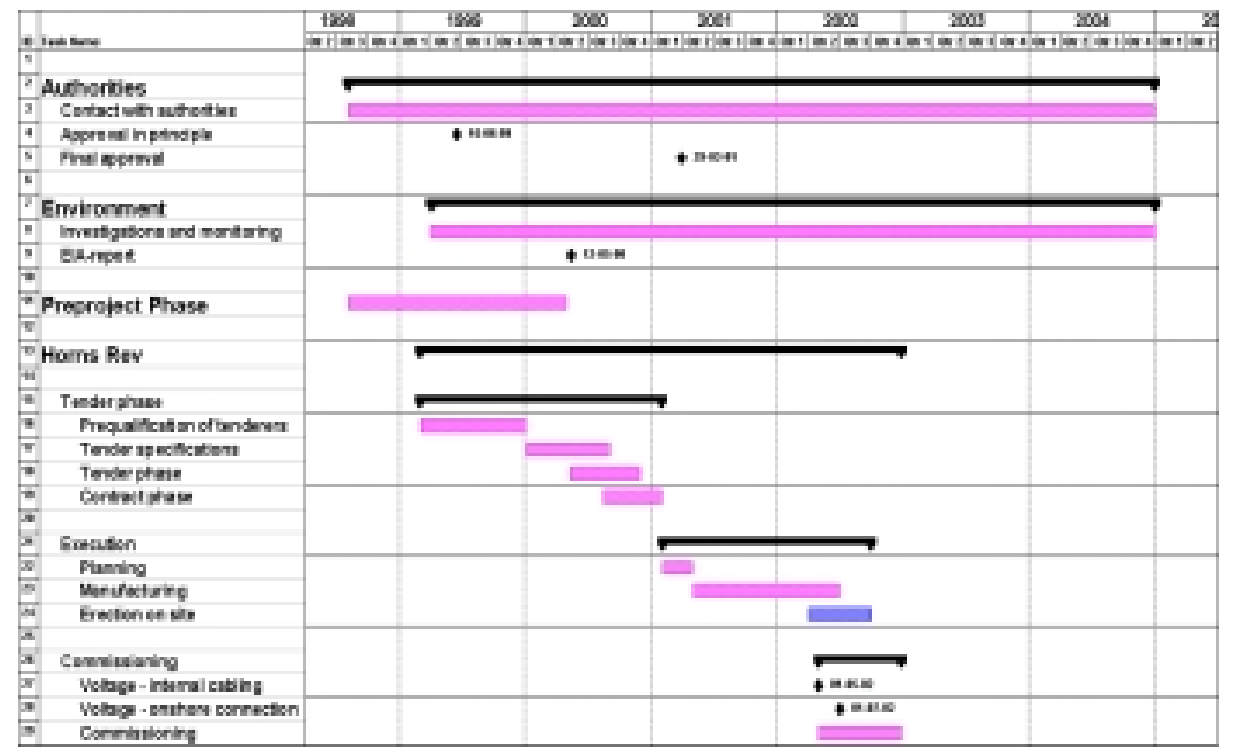

Figure 2. Time Schedule for the Horns Rev Project.

\section{Outline}

As can be seen from Figure 1, the facility is located at Horns Rev off the Danish coast of the North Sea just north-west of Esbjerg and comprises a wind farm with 80 turbines and an interconnection to the shore (transformer substation and a cable leading to the main high voltage grid). The turbines will be placed 560 $\mathrm{m}$ apart at water depths between 6.5 and 13.5 $\mathrm{m}$. The seabed is made up of firm sand and gravel going deep down.

During the past two years the local environment has been scrutinised through among other things a permanent meteorological mast recording data on the wind regime, wave action and currents. On the basis of the acquired data the mean wind speed at a height of $62 \mathrm{~m}$ has been assessed to be 9.7 $\mathrm{m} / \mathrm{s}$. The data have been collected with a number of purposes in mind. For instance the recorded wave data have been used to deduce weather windows from the statistics computed and hence the accessibility to be expected according to the mode of transport.

\section{Regulatory Aspects}

The background for establishing the wind power facility was the joint ministerial order issued to Eltra and Elsam as part of the Danish Government's overall energy targets detailed in its energy plan "Energy 21" covering the offshore part of the project. The technical preproject studies and the EIA review were launched based on an in-principle approval granted in 1999. Having treated the relative modest number of objections to the EIA review, the authorities were in a position to award the final erection permit in the

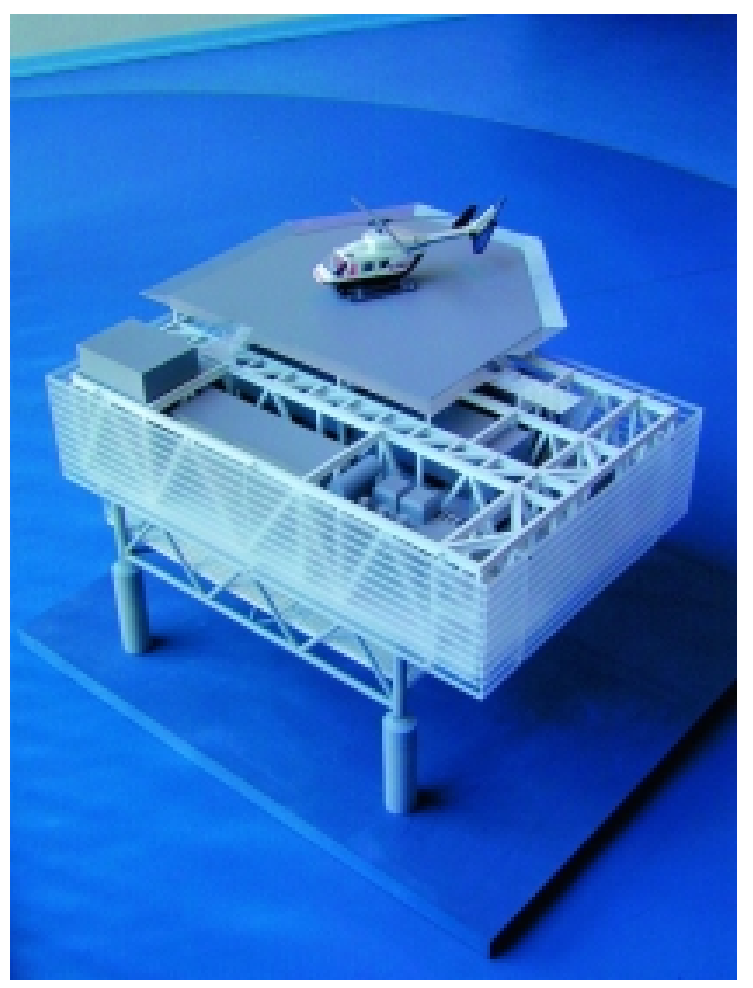

Figure 3. Offshore Transformer Substation Module. 
beginning of 2001. Also the land cable has been approved following due regulatory treatment.

In parallel with the regulatory procedures, the authorities and the owners have been negotiating the question of settlement, and the negotiations have now been translated into statutory specifications of the settlement of the produced energy.

\section{Ownership}

The wind farm facility is being erected by Eltra and Elsam. Eltra is the owner of the interconnection to the shore and Elsam is the owner of the actual wind farm.

Being the independent Transmission System Operator of the western part of Denmark, Eltra has the overall responsibility for ensuring a reliable and effective electricity supply in its own catchment area. As a consequence, there is an essential task for Eltra in implementing the necessary development efforts to be able to introduce the increasing volumes of renewable energy in the electricity system. In this connection Eltra has developed a set of conditions governing the connection to the grid applicable to wind farms supplying power to the transmission grid.

Elsam is Denmark's largest producer of heat and electricity. In addition to its business activities concerned with the production and sale of heat and electricity, Elsam dedicates other business resources to developing projects relative to the environment and energy - both nationally and internationally.

\section{Time Schedule}

As can be seen from the time schedule shown in Figure 2 the project has now put the phases comprising the authorities, pre-project investigations, tendering and contracting behind, and contractors have been found for all major supplies and contracts. These contractors are now in the process of manufacturing to be ready for the erection and commissioning. The plan is to finish the installation of the last foundation piles for Eltra's offshore transformer module in the spring 2002. The land cable has been laid in the winter of 2001/2002. The driving of the foundation piles for the turbines, turbine erection, laying of farm-internal cables and laying the cable to the shore will start in early spring 2002. After having commissioned the interconnection system to the shore around July 1, 2002, the turbine test period will start and commercial production will be allowed in steps. It is expected that the commissioning will find its final conclusion by the end of 2002.

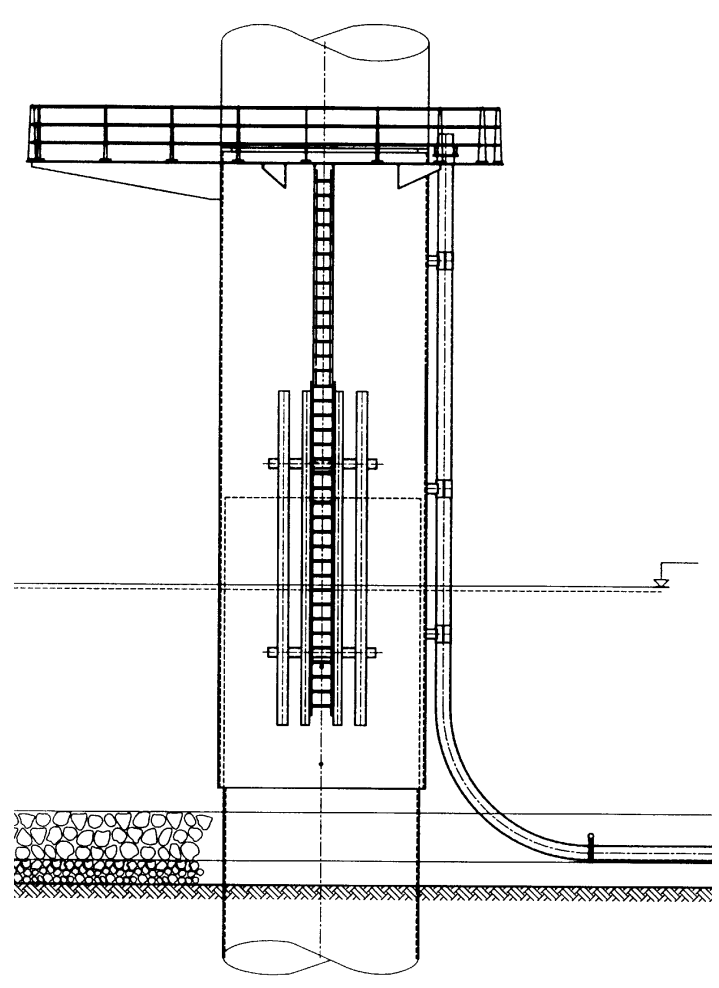

Figure 4. Offshore Monopile Wind Turbine Foundation 


\section{Project Status}

Eltra has now placed orders for the submarine cable with Nexans, for the land cable with $\mathrm{ABB}$, for the $34 / 150 \mathrm{kV}$ transformer with Alstom, for the switchgear with $\mathrm{ABB}$ and for the transformer platform (Figure 3) with HBG. Elsam has placed orders for the turbines, the turbine erection and the remote control system with Vestas. The turbines are Vestas V80, and A2SEA is the sub-contractor for the erection of the turbines. An order for the foundations (see Figure 4) has been placed with MTHS and the farm internal cables with Nexans. Orders for the $34 \mathrm{kV}$ switchgear at the platform and the spare diesel generator have been placed with Siemens and Enmaco, respectively.

\section{Economy}

The project's construction costs total about DKK 2.0 billion (Euro 268 mio.) with about DKK 300 mio. (Euro 40 mio.) for the interconnection to the grid and DKK 1700 mio. (Euro 228 mio.) for the wind farm. The production is expected to exceed 600 GWh/year.

Figure 5 illustrates the settlement scheme specified in the legislation. Ie. after 42,000 full load hours, the revenue is based on the market price plus the value of the "generated" RE certificates (Renewable Energy certificates).

\section{Conclusion}

When planning an offshore wind farm it is paramount to have reliable information on the physical conditions of the site, especially detailed information on the energy potential. In addition, it is essential to know the degree of accessibility and reliability to be achieved. Depending on the owner's interests the contracting strategy should be given careful attention.

During the project phase, capital expenditure should always be compared to operating costs when technical and operational issues are discussed.

So far, the Horns Rev project has had to handle several challenges. The reason for this is that even though the technology used is proven it is also scaled, in addition, the site conditions are new, and not least the liberalisation of the power sector entails new commercial conditions. Furthermore, operating a main high voltage grid with wind farms of this size constitutes a major challenge.

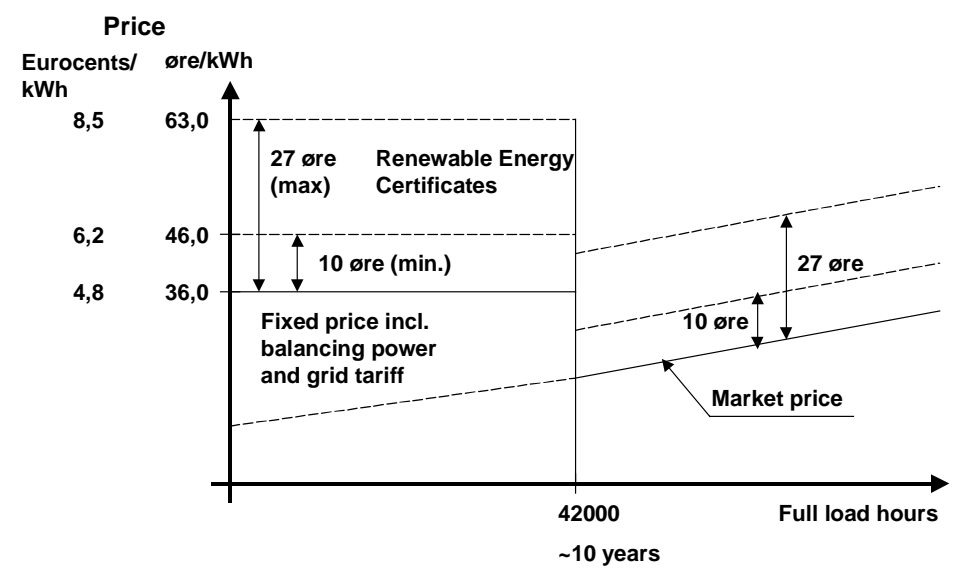

Figure 5. Economy of the Horns Rev project 


\author{
Demian Khan \\ Entec UK Ltd \\ Doherty Innovation Centre, Pentlands Science Park, Bush Loan, Penicuik, EH26 0PZ, U.K. \\ Tel: +44 (0)131 445 6014, Email: khand@entecuk.co.uk
}

David Infield

Centre for Renewable Energy Systems Technology

Loughborough University, Loughborough, UK

Tel. +44 (0)1509 223466, www.crestuk.org

\begin{abstract}
The rise and fall of the sea surface due to tides effectively moves an offshore wind turbine hub through the wind shear profile. This effect is quantified using measured data from 3 offshore UK sites. Statistical evidence of the influence of tide on mean wind speed and turbulence is presented. The implications of this effect for predicting offshore wind resource are outlined.
\end{abstract}

Keywords: tidal, tide, offshore, wind, resource, $\mathrm{MCP}$

\section{INTRODUCTION}

As wind developers move offshore, new issues arise in estimating the long term wind resource at prospective sites. One such issue is the influence of a fluctuating hub height above sea level, due to the rise and fall of the tides. The North Sea and Atlantic have considerably higher tidal ranges than the Baltic [1] and the UK coastline experiences higher tidal ranges than Germany, Holland and Denmark, as illustrated in Fig. 1. This issue may therefore have most pertinence for developers around the UK coastline.

As the tide rises and falls, the offshore wind turbine effectively moves through the wind shear profile. Although shear profiles are commonly assumed to be less pronounced offshore, the mean wind speed nevertheless increases significantly with height above the surface, as shown by data from Rodsand, for example [5]. Thus we can expect on average to find higher wind speeds at low tide and lower wind speeds at high tide, shown in Fig. 2.

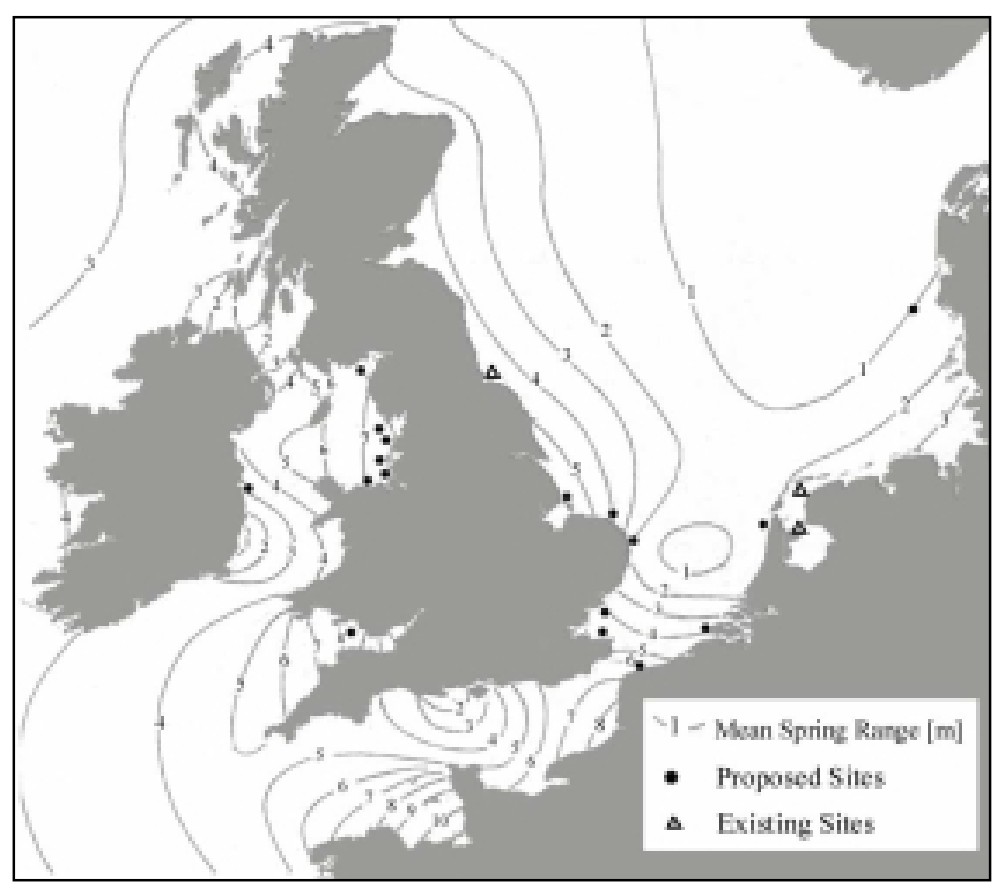

Figure 1: Map of mean spring tidal range with offshore wind locations refs. [2-4]. The average tidal range is about $75 \%$ of the spring range, or halfway between mean neap and mean spring tide.

Tide is measured in metres above chart datum.

Two scenarios are considered for their implications on offshore wind resource predictions: Firstly, where wind records are available from both the

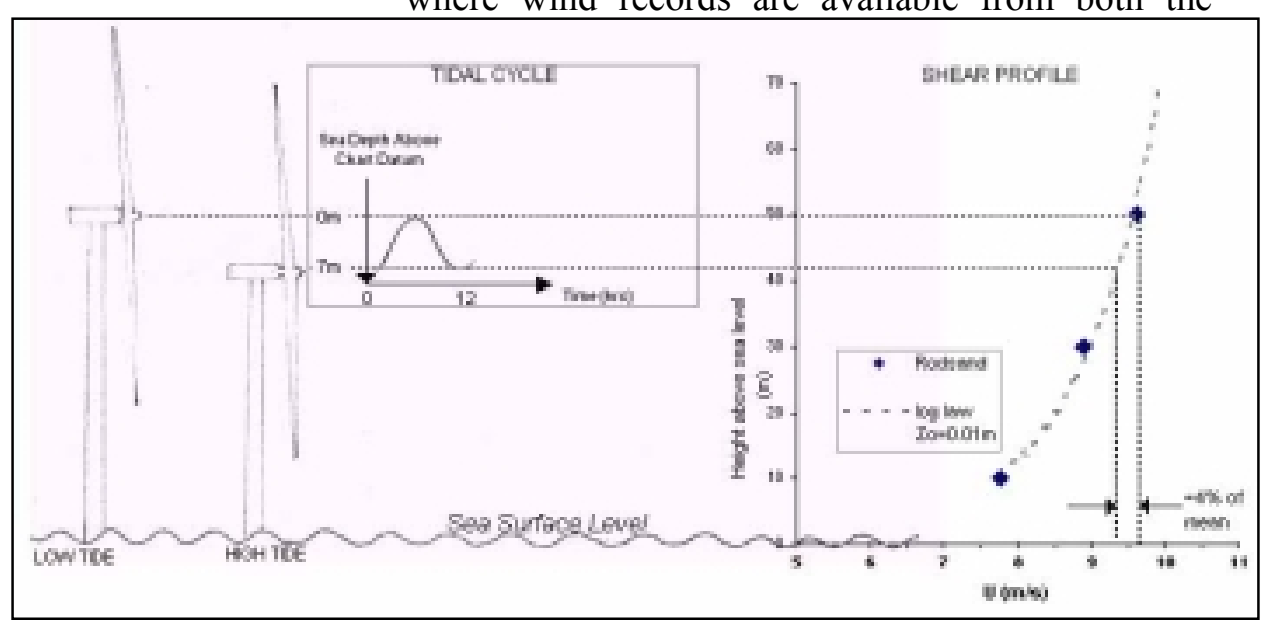

Figure 2: Offshore wind turbine moving through the shear profile during a tidal cycle. Representative values are used, with a measured offshore shear profile from Rodsand, 
offshore development site plus an onshore reference site and, secondly, where only wind records from an onshore reference site are available, i.e. no suitable offshore data exists.

The aims of this study are to identify any tideinduced fluctuation in wind speed, to quantify this fluctuation, and to assess how this knowledge may influence offshore wind resource predictions.

\section{ANALYSIS OF OFFSHORE DATA}

\subsection{Wind data}

Wind data for this study have been available from Powergen's offshore mast located at Scroby Sands, near Great Yarmouth [6], the RES mast located off Skegness and the Powergen/Saorgus site at Kish Bank lighthouse, Dublin Bay, Fig. 3. Anemometry is performed at various heights above mean sea level (AMSL): $33 \mathrm{~m} / 51 \mathrm{~m}$ at Scroby Sands, $17 \mathrm{~m} / 29 \mathrm{~m} / 43 \mathrm{~m}$ at Skegness and $31 \mathrm{~m}$ at Kish Bank.

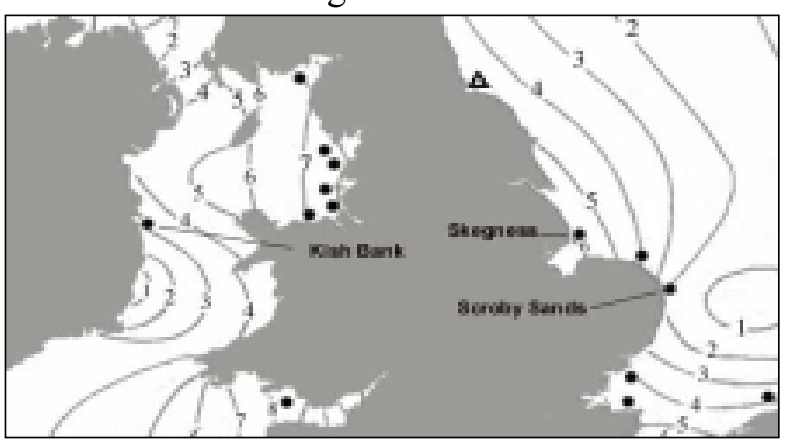

Figure 3. Location of offshore wind measurement sites used in this study

\subsection{Tidal data}

Measured sea-state data was not available at the offshore mast locations considered in this study. Shore line tidal data are available at a series of Ports and other coastal locations where measurements have historically been made. Measured tidal time series (at least $\sim 3$ months) are used to determine 'harmonic constants' which can be used to form a deterministic model of the tide at that location. These models are available in software packages, generally used for predicting the tide for navigational purposes. Historical time series of tide can be hindcasted using such packages, which has advantages over measured time series, including coverage of a greater number of ports, and $100 \%$ availability. Errors are in the range of centimeters compared to measured data.

For this study, tidal time series have been taken from the nearest available Port, see Table 1. At Lowestoft, measured tidal data have been obtained from the British Oceanographic Data Centre. At Skegness and Kish Bank, Proudman Oceanographic Laboratory's software 'POLTIPS' has been used to produce a tidal time history.
To transform the tide from the port to the site, Admiralty chart [7] was used. This indicates lines of co-tide (equal time) and co-range (equal range). Differences in range and tidal profile between the port and the site were assumed to be negligible while time differences were estimated to the nearest 5 minutes, and applied to the time series.

\begin{tabular}{|l|c|c|}
\hline Site Name & Scroby Sands & Skegness \\
\hline Distance offshore & $4.1 \mathrm{~km}$ & $5.3 \mathrm{~km}$ \\
\hline $\begin{array}{l}\text { Height of wind } \\
\text { measurements AMSL }\end{array}$ & $33 \mathrm{~m}, 51 \mathrm{~m}$ & $\begin{array}{c}17 \mathrm{~m}, 29 \mathrm{~m}, \\
42 \mathrm{~m}\end{array}$ \\
\hline $\begin{array}{l}\text { Nearest Port with available } \\
\text { tidal time series }\end{array}$ & Lowestoft & Skegness \\
\hline Mean Spring Range at Port & $1.9 \mathrm{~m}$ & $6.0 \mathrm{~m}$ \\
\hline Mean Neap Range at Port & $1.1 \mathrm{~m}$ & $2.8 \mathrm{~m}$ \\
\hline Distance from Port to site & $21.3 \mathrm{~km}$ & $9 \mathrm{~km}$ \\
\hline $\begin{array}{l}\text { Approx. tide time shift from } \\
\text { Port to site }\end{array}$ & $\begin{array}{c}90 \text { mins earlier } \\
\text { at site }\end{array}$ & $\begin{array}{c}5 \mathrm{mins} \\
\text { earlier at site }\end{array}$ \\
\hline $\begin{array}{l}\text { Period of data used } \\
\text { (complete years) }\end{array}$ & $1996-1998$ & $1999-2000$ \\
\hline
\end{tabular}

Table 1. Details of tide data sources for 2 offshore sites

\subsection{Wind speed vs. sea depth.}

Once concurrent time series of wind speed data and sea depth were obtained, the data were binned by sea depth. Fig. 4 shows the result of 2 years of 10 minute data at Skegness. A general trend of decreasing wind speed with increasing sea depth can be seen, which is most pronounced and consistent at the lowest elevation $(17 \mathrm{~m})$. The wind speeds are normalised by their long term mean to preserve confidentiality, hence the mean wind speed is unity.

At Scroby Sands and Kish Bank, the results do not demonstrate the same trend conclusively. Peaks of wind speed are noted at either end of the tidal spectrum, though the reasons for this are not yet clear.

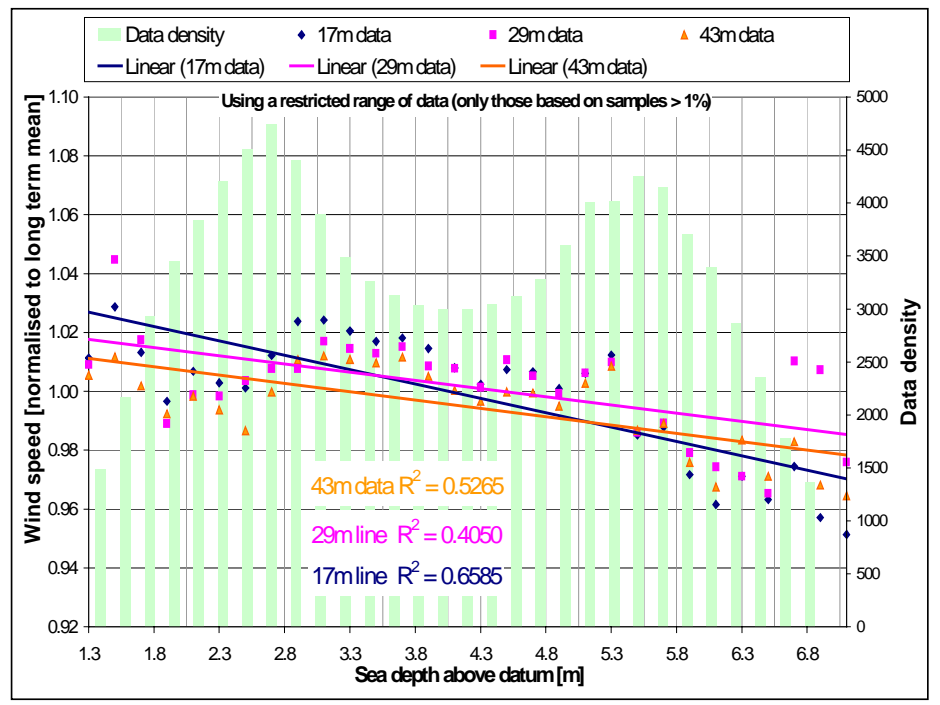

Figure 4: Variation of wind speed with absolute sea depth at Skegness. Only bins containing at least $1 \%$ of data are shown. $\mathrm{R}^{2}$ is a measure of goodness of fit ( $1=$ perfect, $0=$ no fit $)$ 


\subsection{Systematic variation in wind speed in a tidal cycle.}

The above analysis uses absolute sea depth values. The results show considerable scatter and variation in sample size, especially during extreme tides. The results from all 3 sites were not entirely coherent. To focus on the effect of the tide on the wind speed in each tidal cycle, a systematic analysis was performed as follows:

The time series was divided into $\mathrm{N}$ tidal cycles: 1942 cycles at Scroby, 1384 at Skegness, each of approx. 12 hours. The wind speed within each cycle,

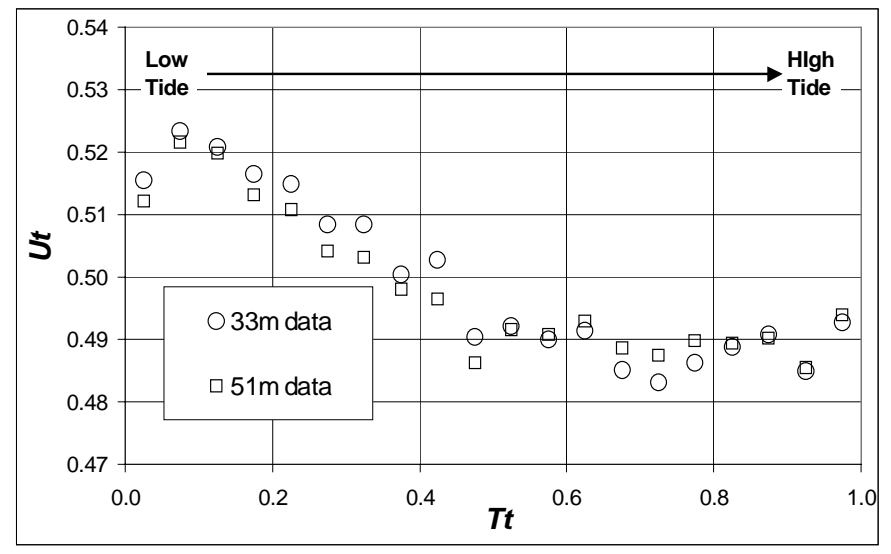

Figure 5: Systematic variation of wind speed in tidal cycles at Scroby Sands.

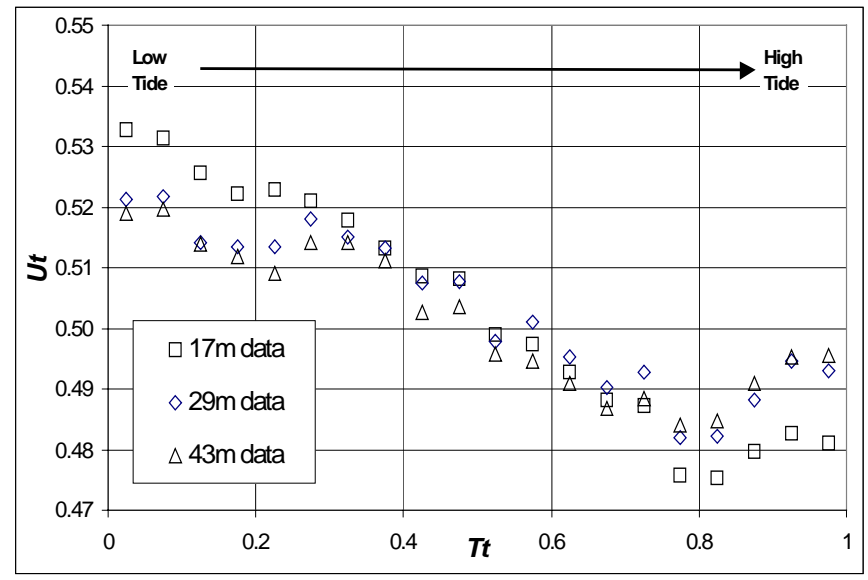

Figure 6: Systematic variation of wind speed in tidal cycles at Skegness

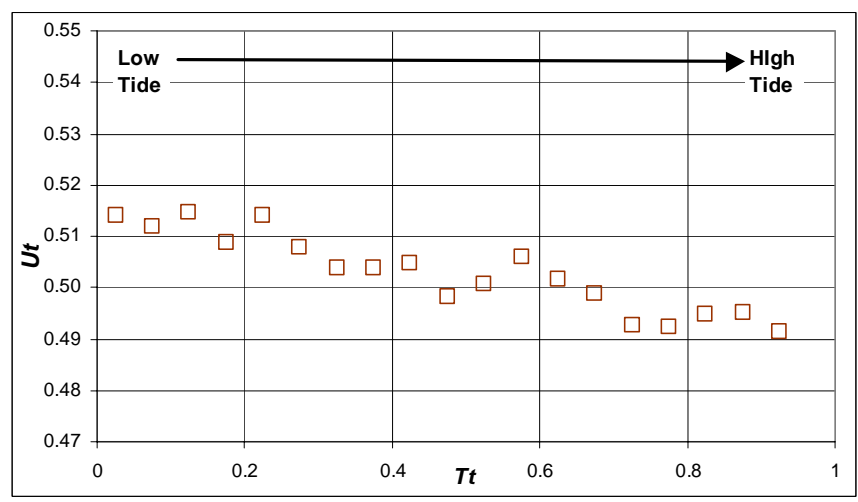

Figure 7: Systematic variation of wind speed in tidal cycles at Kish Bank, $31 \mathrm{~m}$ height.
$U$, was scaled to the range of wind speeds in that cycle to produce a new measure of wind speed, $U t$, which varies between 0 and 1 :

$U t=\frac{U-U \min _{n}}{U \max _{n}-U \min _{n}} \mathrm{n}=1$ to $\mathrm{N}$

where

$U=\quad 10$ minute mean wind speed

$U \min /=$ minimum and maximum 10 min. speeds

Umax within the $\mathrm{n}^{\text {th }}$ tidal cycle.

The tidal depth $T$, was similarly scaled in each cycle:

$T t=\frac{T-T \min _{n}}{T \max _{n}-T \min _{n}} \mathrm{n}=1$ to $\mathrm{N}$

where

$T=\quad$ sea depth above chart datum $(10 \mathrm{~min}$ intervals)

$T \mathrm{~min} /=$ minimum (low tide) and maximum Tmax (high tide) sea depths within the $\mathrm{n}^{\text {th }}$ tidal cycle.

Thus the effect of variations in wind speed at nontidal time scales was effectively removed, and the effect of all tidal cycles averaged. New time series, $U t$ and $T t$ were produced, varying between 1 (max. in tidal cycle) and 0 (min. in tidal cycle). When the results from all tidal cycles were combined and binned by $T t$, a clearer trend emerges: Figs 5-7. It can be seen that the effect of $T t$ on $U t$ is stronger at lower elevations, as expected from the shear profile (Fig.2).

The effect is also greater during periods of larger tidal range, as shown in Figure 8. Here, the Skegness data were divided into large and small tidal cycles, and the systematic analysis performed on each set. The impact on wind speed of larger tidal cycles can be clearly seen.

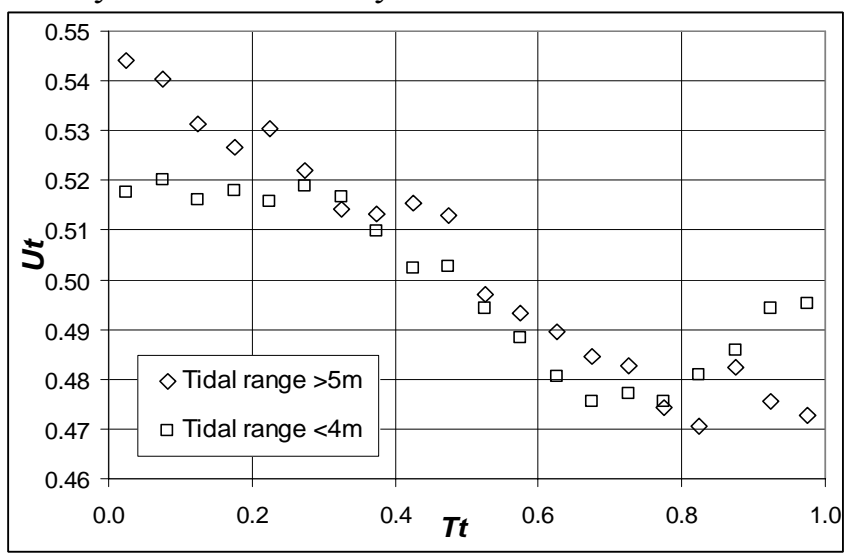

Figure 8 . The effect of tidal range on systematic variation in wind speed during a tidal cycle at Skegness. This example uses wind data measured at $17 \mathrm{~m}$ elevation. 


\subsection{Systematic variation of turbulence in a tidal} cycle

Turbulence levels are largest close to the sea surface, reducing with increasing height.

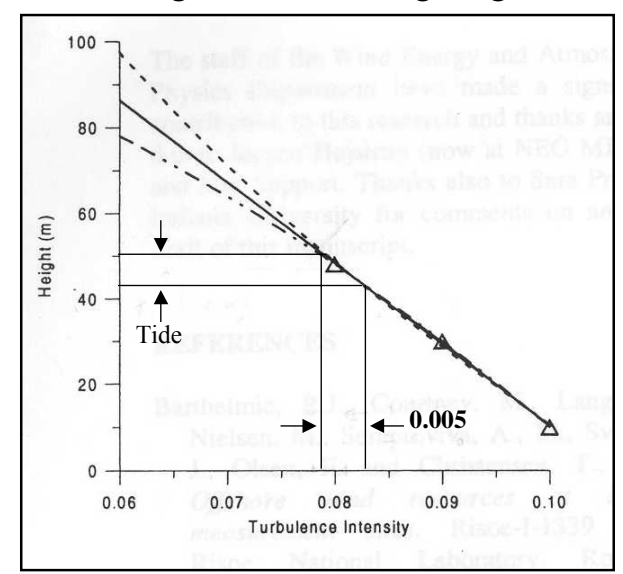

Figure 9. Vertical turbulence profile measured at Vindeby offshore mast, Barthelmie [5]

Thus turbulence levels are expected to show a similar tidal influence when analysed systematically, as described in Section 2.4. The results are shown in Figure 10.

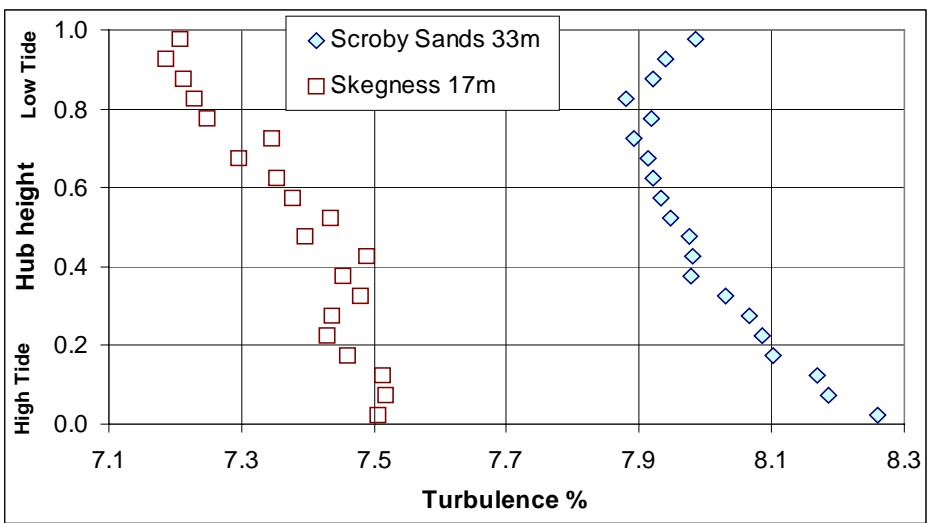

Figure 10. Results of systematic analysis of turbulence at Scroby Sands and Skegness. The axes have been inverted to shown tide on the vertical and turbulence on the horizontal. Thus the shape of the results can be compared to that expected from Figure 9.

Since turbulence levels are not confidential, the mean absolute value, in percent, has been superimposed on the horizontal axis. The systematic variation has also been converted to an absolute value by a process of averaging. Thus the scales shown on Figure 10 give the reader a representative measure of how much the tidal cycle influences turbulence. The result appears to be consistent with the scale of variation expected from Figure 9. Since wake recovery is influenced by turbulence levels, the tidal influence may be relevant for current wake models, especially when applied to seas of large tidal ranges for the first time.
The lack of linearity seen in the above trends may be due in part to errors in the placement of the high/low tide times. The adjustment of tide times from the Port to the sites used above is based on estimates from low resolution charts [2],[7] rather than site measurements. Measured sea-state data from the sites is required for verification of these graphs.

\subsection{Statistical evidence}

An apparent effect of sea depth on wind speed has been identified above. Confirmation should be available from statistical calculations. Multi linear regression has been applied to identify a model of the form:

$y=b_{1} x_{1}+b_{2} x_{2}+\ldots \ldots . .+b_{n} x_{n}$

This can be used to estimate the improvement in predicting offshore wind speeds, $y$, from onshore wind speeds, $\mathrm{X}_{1}$, by including a tidal parameter, $\mathrm{X}_{2}$. The model was implemented by the Matlab function stepwise.m [8] which uses the regression technique by [9], giving regression coefficients $b_{1}, b_{2} \ldots b_{n}$ with confidence intervals and the $\mathrm{R}^{2}$ statistic of the multilinear fit. Onshore wind data was available at Hemsby Met station [10] for Scroby Sands, and an onshore mast at Skegness. The latter provided considerably more detailed measurement $(10 \mathrm{~min}$ average data, 3 heights, compared to hourly average at 1 height at Hemsby).

A factor was applied to the onshore wind speeds in order to avoid revealing the mean offshore wind speeds, which are commercially confidential. This did not effect the graphs and statistics relating to the tidal influence.

This analysis was not applied at Kish Bank, since the tidal effect identified there is smaller, and a smaller quantity of reliable wind data is available than at the other two sites. 


\begin{tabular}{|c|c|c|c|c|c|c|c|}
\hline$y$ & \multicolumn{2}{|r|}{$X$} & \multicolumn{4}{|c|}{ B } & $\mathrm{R}^{2}$ \\
\hline & $\mathrm{X}_{1}$ & $\mathrm{X}_{2}$ & $\mathrm{~b}_{1}$ & $\begin{array}{c}\text { std } \\
\text { error }_{1}\end{array}$ & $b_{2}$ & $\begin{array}{c}\text { std } \\
\text { error }_{2}\end{array}$ & \\
\hline U33 & Uhem & - & 1.00 & $1.56 \%$ & - & - & 0.848512 \\
\hline U33 & Uhem & Tmes & 1.00 & $1.56 \%$ & -0.02710 & $336 \%$ & 0.848529 \\
\hline U33 & Uhem & Tpol & 1.00 & $1.56 \%$ & -0.03450 & $274 \%$ & 0.848538 \\
\hline U33 & Uhem & $\log ($ Tpol $)$ & 1.00 & $1.56 \%$ & -0.04778 & $270 \%$ & 0.848541 \\
\hline U33 & Uhem & $(\mathrm{Tpol})^{2}$ & 1.00 & $1.56 \%$ & -0.00961 & $326 \%$ & 0.848532 \\
\hline U51 & Uhem & - & 1.02 & $1.61 \%$ & - & - & 0.832867 \\
\hline U51 & Uhem & Tmes & 1.02 & $1.61 \%$ & -0.01190 & $829 \%$ & 0.832870 \\
\hline U51 & Uhem & Tpol & 1.02 & $1.61 \%$ & -0.02640 & $389 \%$ & 0.832881 \\
\hline U51 & Uhem & $\log ($ Tpol $)$ & 1.02 & $1.70 \%$ & -0.03996 & $350 \%$ & 0.832886 \\
\hline U51 & Uhem & $(\mathrm{Tpol})^{2}$ & 1.02 & $1.70 \%$ & -0.00687 & $494 \%$ & 0.832876 \\
\hline
\end{tabular}

Table 2: Results of multi-linear regression at Scroby Sands

Key:

Std error ${ }_{n}=\left(95 \%\right.$ confidence interval of $\left.b_{n}\right) / b_{n}$

$\mathrm{R}^{2}=$ The proportion of variation in observations

explained by the model ( 1 is a perfect fit).

$U 33=$ wind speed at scroby sands, $33 \mathrm{~m}$ height AMSL

$U 51=$ wind speed at scroby sands $51 \mathrm{~m}$ height AMSL

Uhem $=$ wind speed at Hemsby Met station (factored)

Tmes $=$ measured tide at Lowestoft

Tnol $=$ calculated tide at Lowestoft .

\begin{tabular}{|c|c|c|c|c|c|c|c|}
\hline $\mathrm{y}$ & \multicolumn{2}{|r|}{$\bar{X}$} & \multicolumn{4}{|c|}{ B } & $\mathrm{R}^{2}$ \\
\hline & $\mathrm{X}_{1}$ & $\mathrm{X}_{2}$ & $b_{1}$ & std error ${ }_{1}$ & $\mathrm{~b}_{2}$ & std error ${ }_{2}$ & \\
\hline$\overline{\text { U17off }}$ & U10on & - & 0.8690 & $1.2 \%$ & - & - & 0.767304 \\
\hline U17off & U10on & Tpol & 8689 & $1.2 \%$ & 0.02427 & $109 \%$ & 0.767401 \\
\hline U17off & U10on & $\log ($ Tpol $)$ & 0.8689 & $1.2 \%$ & -0.06073 & $155 \%$ & 0.767352 \\
\hline U17off & U10on & $(\mathrm{Tpol})^{2}$ & 0.8689 & $1.2 \%$ & -0.00311 & $100 \%$ & 0.767417 \\
\hline U29off & U28on & - & 0.9096 & $1.0 \%$ & - & - & 0.822671 \\
\hline U29off & U28on & Tpol & 0.9096 & $1.0 \%$ & -0.01159 & $200 \%$ & 0.822691 \\
\hline U29off & U28on & $\log ($ Tpol $)$ & 0.9096 & $1.0 \%$ & -0.02268 & $378 \%$ & 0.822677 \\
\hline U29off & U28on & $(\mathrm{Tpol})^{2}$ & 0.9096 & $1.0 \%$ & -0.00148 & $193 \%$ & 0.822695 \\
\hline U43off & U46on & - & 0.9199 & $0.9 \%$ & - & - & 0.842268 \\
\hline U43off & U46on & Tpol & 0.9200 & $0.9 \%$ & 0.0152 & $146 \%$ & 0.842302 \\
\hline U43off & U46on & $\log ($ Tpol $)$ & 0.9200 & $0.9 \%$ & 0.06377 & $123 \%$ & 0.842315 \\
\hline U43off & U46on & $(\text { Tpol })^{2}$ & 0.9200 & $0.9 \%$ & 0.001826 & $144 \%$ & 0.842303 \\
\hline
\end{tabular}

Table 3: Results of multi-linear regression at Skegness

Key:

U[H] off $=$ offshore wind speed,$[\mathrm{H}] \mathrm{m}$ height AMSL

$U[H]$ on $=$ onshore wind speed,$[\mathrm{H}] \mathrm{m}$ height

Tpol $=$ calculated tide at Skegness 
It can be seen from Table 2 that a negative coefficient is automatically assigned to the tidal data, and the $\mathrm{R}^{2}$ statistic is improved compared to using only onshore wind data. Where $b_{1}$ is 1 , this is because the onshore data was factored to force the mean to be equal to the mean of the offshore $33 \mathrm{~m}$ data. This did not affect the other parameters.

At Skegness, the response of the regression to a tidal parameter is slightly better, Table 3 (2). The improvement in $\mathrm{R}^{2}$ is greater at lower elevations, where the wind shear has greatest effect. These encouraging results support both the presence of an appreciable tidal effect on wind speeds and the validity of including tidal data in an offshore/onshore wind correlation.

The form of the tidal parameter may need optimisation. At Scroby Sands, a log term appears to work best (lowest standard error, greatest improvement in $\mathrm{R}^{2}$ ), whereas at Skegness, the square term fares better.

\section{USE OF TIDAL PARAMETERS IN RESOURCE PREDICTIONS}

Two scenarios of data availability are considered. Firstly, where wind records are available from both the offshore development site and an onshore reference site and, secondly, where only wind records from an onshore reference site are available i.e. no offshore data. In both instances, knowledge of tidal behavior may prove valuable, and has hitherto generally been ignored by offshore wind resource analysts.

\subsection{Offshore-onshore MCP}

Most offshore wind developers will seek to correlate offshore wind speed measurements to onshore measurement to provide an estimate of the long term mean. In this first scenario, the two data sets will be correlated in a Measure-Correlate-Predict (MCP) process. The presence of tidal fluctuations in the offshore wind records may degrade the correlation as it is absent in the onshore wind. The scope for improving the correlation by removing the tidal fluctuations from offshore records is now considered.

\subsubsection{Choice of tidal parameter}

In order to improve the correlation between onshore and offshore data, the influence of tide has to be either added to the onshore data

\footnotetext{
${ }^{2}$ The positive coefficient of $b_{2}$ at Skegness $43 m$ data - an exception - is not fully understood.
}

or removed from the offshore data. For this, a parameter proportional to the tide must be chosen. A possible test for a sensible tidal parameter is removal of the systematic trend discussed in Section 2.4. The result in Fig. 10

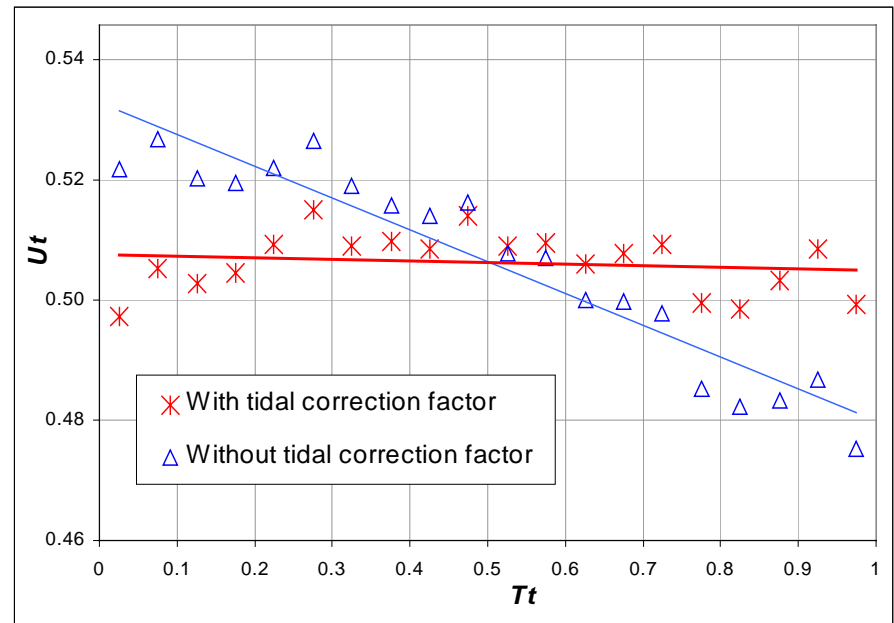

Figure 11. Removal of Systematic tidal variation in wind speed by use of a linear tidal parameter $b_{2}$. Data used was the $17 \mathrm{~m}$ elevation offshore wind speed at Skegness.

shows the outcome using a linear parameter, optimised by trial and error. Here, the onshore wind speed was adjusted:

$$
U^{\prime}=U+b_{2} T
$$

Then $U$ ' was input into equation (1) as before. The coefficient $b_{2}$ used was 0.06 , about twice the value suggested by multi-linear regression (Table 3). Note the tidal coefficient is positive here as we need to remove the effect of the tide from the offshore wind speed, rather than add it to the onshore wind speed as in the regression analysis in the previous section. The results in Fig. 11 show that the tidal trend was effectively removed by using this parameter.

\subsubsection{Adjusted Measure-Correlate-Predict Process}

For MCP, in-house codes are commonly used. An example used here is WCORR, developed by wind engineers at PowerGen, (Power Technology Centre). This uses 3 straight line fits to each directional bin of data (below cutin, up to rated and above rated), and calculates correlation coefficients for each directional bin.

To represent real conditions, the Scroby Sands site was chosen because the onshore data, from Hemsby Met. Station, was in the form of hourly means, rounded to the nearest knot. This is typical of what will be available for 
most offshore developers. The 10 minute data available at the Skegness onshore mast may give a more accurate correlation, but is not a historical record.

For the current study, the onshore wind speed at Hemsby was adjusted (though the offshore wind could have been chosen), by a linear tidal parameter, $\mathrm{b}_{2}$ :

$\mathrm{U}_{\text {hem }}{ }^{\prime}=\mathrm{U}_{\text {hem }}+\mathrm{b}_{2} \mathrm{~T}_{\mathrm{pol}}$

The original and adjusted data were passed through the correlation routine and the correlation coefficients noted (closer to unity the better the correlation). As a further test, they were plotted in Excel and a least squares linear fit produced. The results are given in Table 4.

\begin{tabular}{|c|c|c|c|}
\hline $\mathrm{X}$ & $\mathrm{Y}$ & $\begin{array}{c}\text { Correlation } \\
\text { coefficient } \\
\text { ii }\end{array}$ & Excel R $^{2}$ \\
\hline Uhem & $\begin{array}{c}\mathrm{U} 3 \\
3\end{array}$ & 0.9005 & 0.8109 \\
\hline Uhem' & $\begin{array}{c}\mathrm{U} 3 \\
3\end{array}$ & 0.9006 & 0.8110 \\
\hline
\end{tabular}

Table 4. Results of correlation with and without tidal parameter at Scroby Sands

From Table 4, it appears that removal of the

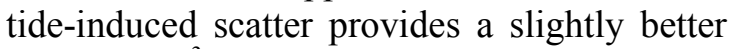
correlation.

This could then be used to provide a prediction of mean offshore wind speed free of tide-bias. Finally, the long term tidal influence could be applied using the long term tidal distribution, rather than the short term measurements during the correlation period. In other words, the effect of the tide would be removed during the concurrent MCP period to reduce scatter, then put back to represent the long term mean.

The forgoing assumes that the frequency distribution of sea depths in a small sample (e.g. a correlation bin of wind speed and direction) is not representative of the long term mean. Fig. 12 shows an example based on 2 years of tidal data at Skegness, illustrating that the small amount of data included in each bin, or cell of a wind frequency distribution table, departs considerably from the long term mean. If each of the distributions on the plot were

\footnotetext{
${ }^{3}$ Note: this improvement may be more evident at sites with a larger tidal range, or with 10 minute, unrounded onshore data, or where shorter periods of concurrent data are available.
}

more or less equal, we could say that indeed tide and any effect it produces, does average out over a short time. However, since the distributions are different, we cannot make this assumption.

If the technique were repeated for different periods of data, a clearer picture could be established of the benefits of a tidal-MCP. One might expect the improvement, $i$, in resource prediction accuracy to be a function of the following variables:

$$
i=f\left\{\text { tidal range }, \frac{1}{\text { data period }}, \frac{1}{\text { hub height }}\right\}
$$

\subsection{Offshore Resource predictions using only onshore reference data.}

Some exceptions, such as the Blyth Offshore project in the UK are sites which are close to shore and have good coastal/harbour wind data available, hence no offshore wind data was used in resource predictions.

This second scenario, where no offshore wind data is available, is more common in the early stages of an offshore development. Generally, the reference wind speed will be derived from the nearest onshore measurement site. This, combined with terrain information will be input into a wind flow modelling package, such as WaSP, to produce the expected offshore wind regime. The hub height and shear profile will be assumed as if the sea level were static. But in the light of the present study, it may be questioned whether this is reasonable.

The tidal fluctuations in wind speed may not significantly affect the long term average wind speed, as the fluctuations are symmetrical about the mean sea level. More significantly, the energy available in the wind may be

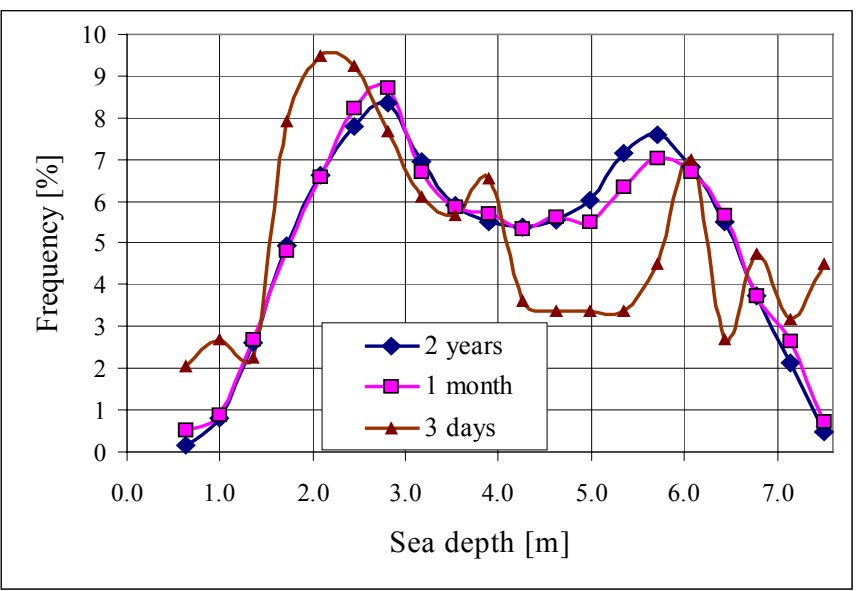

Figure 12. Example of tidal depth frequency distributions: Long term (all data 2 years), in 1 wind speed bin ( 1 month of data), and in a wind 
effected, as the mean cube of the wind speed will be increased by such variations. The following equation quantifies how normal turbulence, $I$ (a measure of variation about a mean) contributes to the mean cube, and hence the energy available in the wind:

$\overline{U^{3}}=\bar{U}^{2}\left(\bar{U}+3 I^{2}\right)$

Where $I=\frac{\sigma}{\bar{U}}$

And $\bar{U}=$ mean wind speed in a sampling period

$$
\begin{aligned}
& \sigma=\text { standard deviation of wind speed } \\
& \overline{U^{3}}=\text { mean cube of the wind speed }
\end{aligned}
$$

We see that the "extra energy" available from the turbulence is given by $3 \mathrm{I}^{2}$. This applies over a single sampling period, say 1 hour, but the same should apply to a longer time period such as is the case with tidal cycles. If we now define the tidal fluctuations as $\mathrm{Ti}$, a proportion of the mean wind speed in a tidal cycle ${ }^{4}$, we can say an increase in energy of $3 \mathrm{Ti}^{2}$ occurs. At a Ti fluctuation level of $4-5 \%$, such as that found at Skegness, this would equate to an increase in power of $0.5-0.75 \%$. This would not be identified by a WaSP \& mean sea level approach.

An initial simulation was performed with and without the tidal influence, by using the correction factor identified in section 3.1 and measured offshore data from Skegness. This found the increase in mean cube due to the tide was considerably smaller than suggested above. Further work is required, though empirical evidence of this 'extra energy' will be difficult to obtain, as any given site has fixed tidal characteristics.

The potential improvement in resource prediction accuracy suggested here, less than $1 \%$, is small compared to known error levels due to wind speed records and wind flow models. However, in the process of making the best possible assessments, it may be prudent to include some representation of it.

\section{CONCLUSIONS}

The presence of a tidal influence on wind speeds at 3 offshore sites has been demonstrated. This effect varies with location and height above sea level. A tidal parameter can be chosen to remove the influence of tides and improve the correlation of offshore to

\footnotetext{
${ }^{4}$ The systematic analysis was done using wind speeds averaged over $1 / 2$ a tidal cycle which is around 6 hours
}

onshore wind speeds. Furthermore, the tidal influence on hub height effects turbulence intensity. A thorough treatment of this effect within an offshore/onshore MCP may pay dividends of improved resource predictions, especially at high tidal range sites, or those where short periods of wind data are available. The tidal-induced fluctuations in wind speed should produce slightly higher energy yields than are expected by assuming a static sea level.

\section{FURTHER WORK}

CREST, Loughborough University, are engaging on a programme of research to further investigate the influence of tide on offshore wind fields, as well as surface roughness changes onshore to offshore, and stability effects.

\section{ACKNOWEDGEMENTS}

This research was performed as part of an $\mathrm{MSc}$ in Renewable Energy Systems Technology at CREST. It was supported by Powergen Renewables. In particular we would like to thank: Dr Dave Pearce and Dr Chris Ziesler of Power Technology Centre at Ratcliffe, for their valued assistance and support. Thanks are also due to Matt Rebbeck of Renewable Energy Systems Ltd for providing the Skegness data, and also to those at CREST who gave useful input.

Tidal range information was derived from Admiralty Charts 5058/9 by permission of the Controller of Her Majesty's Stationery Office and the UK Hydrographic Office. Hemsby Meteorological data was supplied by British Atmospheric Data Centre, though their excellent academic web service $w w w . b a d c . r l . a c . u k$. Lowestoft tidal data was provided by the British Oceanographic Data Centre. Tidal hindcasting was performed using POLTIPS software (Leisure version) made available by the Proudman Oceanographic Laboratory,.

\section{REFERENCES}

[1] "Threats and Opportunities in the Coastal Areas of the European Union", Ministry for Housing, Spatial Planning and Environment, the Netherlands, 1997.

Also reproduced at http://www.coastalguide.org/lands/landrcol.ht $\mathrm{ml}$ 
[2] Admiralty Chart 5058, ed.5, United Kingdom Hydrographic Office, 1996

[3] British Wind Energy Association website: www.offshorewindfarms.co.uk

[4] "Offshore Wind Energy - Building a new industry for Britain", Border Wind, Greenpeace, 1998

[5] Barthelmie, R.J. 'Monitoring offshore wind and turbulence characteristics in Denmark', proc. BWEA21, 1999, pp311-316

[6] Pearce,D. Ziesler,C. "The Estimation of Offshore Wind Resource" proc. BWEA21, 1999, pp289-300

[7] Admiralty Chart 5059, Southern North Sea, United Kingdom Hydrographic Office, 1996

[8] Stepwise Regression, Matlab Statistics Toolbox Version 2.2 (R11) 24-Jul-1998

[9] Draper, Norman and Smith, Harry, Applied Regression Analysis, Second Edition, John Wiley \& Sons, Inc. 1981 pp. 307-312.

[10] British Atmospheric Data Centre website, with kind permission. 
Registered Workshop Participants

Name

\author{
Rebecca Barthelmie \\ Gunner Larsen \\ Jørgen Høstrup \\ Hans Bergstrom \\ Mikael Magnusson \\ Wolfgang Schlez \\ Kostas Rados \\ Bernhard Lange \\ Per Vølund \\ Søren Neckelmann \\ Soren Mogensen \\ Gerard Schepers \\ Luuk Folkerts \\ Mike Anderson \\ Demian Khan
}

Peter Eecen

Jakob Wedel-Heinen

Stephan Joeckel

Christian Hülsmann

Frank Flottemesch

Henk den Boon

Sara Pryor

Hans Jørgensen

Sten Frandsen

Lars Landberg

Ole Rathmann

Paul Hannah

Igor Waldl

Thomas Pahlke

Thorben G. Nielsen

Kurt Hansen

Neil Douglas

Brian Hurley

Anabel Gammidge

Tetsuya.Kogaki

Makoto Iida

Ole Bech Pedersen

Thomas Dalgaard

Davide Medici

George Grills

Staffan Niklassan

Dirk Steudel
Affiliation

Country

DK

$\begin{array}{ll}\text { Risø } & \text { DK } \\ \text { Ris } \varnothing & \text { DK }\end{array}$

Uppsala University $\quad$ SE

SMHI SE

Garrad Hassan UK

Robert Gordon University UK

University of Oldenberg DE

SEAS DK

TECHWISE DK

NEG MICON DK

ECN NL

Ecofys NL

Renewable Energy UK

Systems Ltd.

ENTEC

$$
\text { ECN }
$$

DNV

Enron Wind

Enron Wind

Enron Wind

E-Connection

Risø/Indiana University

Risø

Risø

Risø

Ris $\varnothing$

National Wind Power

Overspeed

Overspeed

Vestas Wind Systems

DTU

The Natural Power

Consultants Ltd

eirtricity/airtricity

AMEC Wind

National Institute of

Advanced Industrial \&

Science

University of Tokyo JP

Vestas a/s DK

DNV DK

Department of Mechanics, SE

$\mathrm{KTH}$

Amherst Renewable Energy USA

Research Lab

Vindkompaniet Oland SE

Repower Systems AG DE
Email

R.Barthelmie@risoe.dk

Gunner.Larsen@risoe.dk

jorgen.hojstrup@risoe.dk

Hans.Bergstrom@met.uu.se

Mikael.Magnusson@smhi.se

wolfgang.schlez@gmxpro.de

kgrados@nps.navy.mil

Bernhard.Lange@uni-oldenburg.de per.volund@seas.dk sne@techwise.dk

1cc@neg-micon.dk

schepers@ecn.nl

1.folkerts@ecofys.nl

mike.anderson@res-ltd.com

KHAND@entecuk.co.uk

eecen@ecn.nl

jakob.wedel-heinen@dnv.com roland.weitkamp@enron.com christian.huelsmann@enron.com frank.flottemesch@enron.com den.boon@e-connection.nl sara.pryor@risoe.dk hans.e.joergensen@risoe.dk sten.frandsen@risoe.dk lars.landberg@risoe.dk ole.rathmann@risoe.dk paulhannah@natwindpower.co.uk h.p.waldl@overspeed.de t.pahlke@planungsgemeinschaft.de tgn@vestas.dk ksh@mek.dtu.dk Neil@naturalpower.com

bhurley@eirtricity.ie anabel.gammidge@amec.com kogaki.t@aist.go.jp

iida@cfdl.t.u-tokyo.ac.jp obp@vestas.dk

Thomas.Dalgaard@dnv.com davide@mech.kth.se

ggrills@ecs.umass.edu

sn@vindkompaniet.se

d.steudel@repower.de 
Bibliographic Data Sheet

Risø-R-1326(EN)

Title and authors

Proceedings of the ENDOW Workshop 'Offshore Wakes: Measurements and Modelling'

Barthelmie, R.J. (ed.)

ISBN ISSN

87-550-3018-1(Internet)

0106-2840

Department or group Date

VEA

March 2002

Groups own reg. number(s)

Project/contract No(s)

ERK6-CT1999-00001

\begin{tabular}{llll}
\hline Pages & Tables & Illustrations & References \\
68 & 10 & 54 & 70 \\
\hline
\end{tabular}

Abstract (max. 2000 characters)

The papers presented in these Proceedings are the result of a workshop held at Risø National Laboratory on March 7 and 82002 entitled 'Offshore Wakes: Measurements and Modelling'. The Workshop was arranged to showcase results of the European Community supported project 'Efficient Development of Offshore Windfarms (ENDOW)' and featured a series of eight presentations discussing modelling of wakes and boundary layers, existing and new measurements from offshore wind farms and how these will be linked in a new design tool and applied at planned offshore wind farms.

In addition seven invited presentations covered a range of relevant topics from analytical approaches to fatigue and extreme loads in wind turbine clusters, current wake modelling in WAsP, optimising power production at Arklow Bank, Particle Image Velocimetry study of a wind turbine wake in a yaw, offshore wind measurements in Massachusetts, accuracy of SODAR measurements for wind energy and tidal influence of offshore wind speeds and turbulence.

\section{Descriptors INIS/EDB}

BOUNDARY LAYERS; MATHEMATICAL MODELS; MEETINGS; OFFSHORE SITES; POWER GENERATION; TURBULENCE; WIND; WIND TURBINE ARRAYS

Information Service Department, Risø National Laboratory,

(Afdelingen for Informationsservice, Forskningscenter Risø), P.O.Box 49, DK-4000 Roskilde, Denmark.

Telephone +4546774004 , Telefax +4546774013 